\title{
IV. »JE NE SUIS NI DE DROITE NI DE GAUCHE«: VIÉNOTS GEISTIGE UND POLITISCHE STANDORTSUCHE (1918-1931)
}

Während Pierre Viénot in außenpolitischer Hinsicht frühzeitig relativ klare Vorstellungen und Standpunkte entwickelt hatte, stand hinsichtlich der Frage nach der inneren Ausgestaltung von Staat und Gesellschaft das gesamte Nachkriegsjahrzehnt für ihn im Zeichen der Suche und der Orientierung. Dabei zeigt sich, daß diese Suche als zeittypisches Phänomen der jungen Nachkriegsintellektuellen anzusehen ist, für die die Erlebnisse oder Auswirkungen des Weltkriegs die Ursache einer tiefgreifenden geistig-moralischen Krise waren. Vor dem Hintergrund der von diesen Intellektuellen angestoßenen gesellschaftlichen Erneuerungsdebatten soll im folgenden die geistige und politische Entwicklung Viénots während der zwanziger Jahre untersucht werden. Zunächst erfolgt dabei eine intellektuelle Standortbestimmung Viénots innerhalb jener Bewegungen der krisenbewußten Jugend, welche sich dem Ziel einer politisch-gesellschaftlichen Erneuerung verschrieben hatte. Zum zweiten schließt sich daran eine Analyse der politischen Evolution Viénots an, die ihn weg von seinem Herkunftsmilieu zur politischen Linken führte.

\section{1. Überlegungen im Zeichen der Krise: Viénots Verbindungen zu den Emeuerungsbewegungen seiner Zeit}

\subsection{Das Krisen- und Generationsbewußtsein der französischen Nachkriegsintellektuellen}

»Nous sommes une génération très infortunée«, stellte Paul Valéry 1922 fest, »à laquelle est échu de voir coïncider le moment de son passage dans la vie avec l'arrivée de ces grands et effrayants événements dont la résonance emplira toute notre vie ${ }^{1}$. Diese pessimistische Aussage mag verwundern, denn schließlich lag das Kriegsende zu diesem Zeitpunkt bereits vier Jahre zurück. War nicht Frankreich als Sieger aus der Grande Guerre hervorgegangen, und war die deutsche Gefahr nicht durch den Versailler Vertrag auf lange Zeit gebannt? Die Freude über den militärischen Sieg währte in Frankreich in

Paul Valéry, Note (ou L'Européen), in: DERS., Euvres, Bd. 1, hg. von Jean HYTIER, Paris ${ }^{2} 1957$, S. 1000-1014, hier S. 1000. Die "Notiz«, aus der die zitierte Passage stammt, war Teil eines am 15.11.1922 in Zürich von Valéry gehaltenen Vortrags. Inhaltlich bezieht sie sich auf die "Crise de l'espritu, der die Notiz hier angehăngt ist. Der Text erschien auch in deutscher Sprache: DERS., Europa, in: Europdische Revre 2 (1926/27) S. 341-353. 
der Tat nur kurz. Viel länger dauerte der Schock an, den die Einsicht in die Fragilität westlicher Kultur- und Zivilisationsvorstellungen mit sich brachte. Valéry hatte bereits 1919 eine "Krise des Geistes« diagnostiziert, resultierend aus dem Bewußtsein der Sterblichkeit der europäischen Kulturvölker ${ }^{2}$. Er thematisierte die Verunsicherung des Menschen angesichts einer von technischem Fortschritt und kapitalistischem Kräftespiel dominierten Welt:

L'orage vient de finir, et cependant nous sommes inquiets, anxieux, comme si l'orage allait éclater. Presque toutes les choses humaines demeurent dans une terrible incertitude. Nous considérons ce qui est détruit; nous ne savons pas ce qui va nâtre, et nous pouvons raisonnablement le craindre. Nous espérons vaguement, nous redoutons précisément; nos craintes sont infiniment plus précises que nos espérances; nous confessons que la douceur de vivre est derrière nous, que l'abondance est derrière nous, mais le désarroi et le doute sont en nous et avec nous ${ }^{3}$.

Die Diagnose Valérys kann als symptomatisch für die jungen Intellektuellen in den zwanziger Jahren betrachtet werden. So stellte Francis Delaisi 1926 fest, die Welt habe noch immer nicht zu ihrem Gleichgewicht zurückgefunden, weder in materieller, noch in moralischer Hinsicht. Noch immer sei der Geist nicht auf der Höhe der Zeit: »[...] les idées sont en retard sur les faits«. Delaisi forderte daher eine wrévision générale de nos idées«". Die Kluft »entre l'homme qui pense et son époque ${ }^{5}$ stellte den Ausgangspunkt vielfältiger Überlegungen zur künftigen Gestaltung von Politik und Gesellschaft dar. Dabei dominierten vor allem Pessimismus und Krisenbewußtsein das Denken. »Alles ist hin«, konstatierte Drieu la Rochelle und meinte damit »eine ganze Welt und alle alten Zivilisationen ${ }^{6}$. Die Werte, die bisher als weithin akzeptiert galten, seien nicht nur in ihrer gegenwärtigen Form abgestorben, sondern in ihrem tiefsten Wesen verletzt. Drieu la Rochelle, für den die »décadence« zum Leitmotiv seines Denkens und literarischen Schaffens wurde ${ }^{7}$, beschrieb die geistige und politische Heimatlosigkeit der Nachkriegszeit nicht ohne Pathos folgendermaßen:

Vgl. DERS., La crise de l'esprit, in: DERS., Cuvres, Bd. 1, S. 988-1000.

DERS., Note, S. 1000.

4 Francis DELAISI, Les contradictions du monde moderne, in: L'Europe nouvelle, 30.1.1926, S. 139-142, hier S. 139.

5 Pierre de LANUX, Intelligence et démocratie, in: NRF 22 (1924) S. 261-274.

6 Pierre DRIEU LA ROCHELlE, Kapitalismus, Kommunismus und europäischer Geist, in: Europäische Revue 3,1 (1927/28) S. 61-65, hier S. 61.

7 Zur Bedeutung der »décadence» im Denken Drieu la Rochelles vgl. Jean-Louis LoUBET DEL BAYLE, Politique et civilisation. Essai sur la réflexion politique de: Jules Romain, Drieu la Rochelle, Bernanos, Camus, Malraux, Toulouse 1981, S. 66-85; Solange LEIBOVICI, Le sang et l'encre. Pierre Drieu la Rochelle. Une psychobiographie, Amsterdam, Atlanta 1994, S. $215-227$ 
Es gibt keinen Gott mehr, keine Aristokratie, keine Bourgeoisie, keinen Besitz, kein Vaterland; aber es ist uns auch kein Proletariat geboren worden. Jeder, auf der Rechten wie auf der Linken, trägt dieses Geständnis im Herzen. Es gibt nur noch Menschen, die gezwungen sind, etwas neues zu schaffen, um nicht zu sterben ${ }^{8}$.

Die aus einer pessimistischen Zeitdiagnose heraus geborene Überzeugung von einer notwendigen inneren Erneuerung wurde zum einigenden Band der krisenbewußten Intellektuellen. Dabei traten die Modernisierungstendenzen vor allem als ein generationstypisches Phänomen in Erscheinung. Die "génération de la crise «" also jene jungen Männer, die zu jung waren, um selbst am Krieg teilzunehmen, wohl aber alt genug, um dessen Konsequenzen zu spüren, wurden zum Träger des sogenannten »esprit des années trente ${ }^{10}$. Die Ideen, die diesen Geist der dreißiger Jahre ausmachten und die sich um das Problem einer tiefgreifenden kulturellen und spirituellen Krise drehten, manifestierten sich allerdings bereits in den zwanziger Jahren und hatten ihren Ausgangspunkt im Ersten Weltkrieg. Ihren Kulminationspunkt erreichten sie zu Beginn der dreiBiger Jahre in der Bewegung der »nonconformistes«. Aber auch in den bestehenden Parteien machte die Jugend sich lautstark, zum Teil mit eigenen Gruppierungen, bemerkbar.

Pierre Viénots geistige Entwicklung und Gedankenbildung in den zwanziger Jahren waren eng mit diesen Überlegungen zu Kulturkrise und politischer Erneuerung verbunden. Seine politische Evolution vollzog sich vor dem Hintergrund einer intellektuellen Jugend, die neue Wege beschreiten wollte, die anstehenden Probleme zu lösen und zum Teil auch die politischen Parteigrenzen zu überwinden suchte. Dabei kam es, wie im folgenden noch gezeigt werden wird, zur wechselseitigen Rezeption von Gedanken und Ideen. In der Forschung wird Viénot sogar den nonkonformistischen Intellektuellen zugerechnet ${ }^{11}$. Gleichzeitig gehörte er, wie an anderer Stelle bereits gezeigt ${ }^{12}$, eindeutig zur "génération du feu«. Da die Nonkonformisten jedoch eine Bewegung der "génération de la crise « darstellten, erscheint diese Zuordnung Viénots auf den ersten Blick erstaunlich, da gerade die Krisengeneration sich von jener der Kriegsteilnehmer abzusetzen versuchte. Gegenüber den Frontkämpfern, die ihr Leben aufs Spiel gesetzt oder gar verloren hatten, empfand die Nachkriegsgeneration ein Unterlegenheitsgefühl, welches sie nur durch Abgrenzung in Verbindung mit gesteigerter intellektueller Aktivität überwinden konnte. "Wir Jüngeren«, gestand Jean Prévost, »haben uns während des ganzen Krieges den

8 Pierte DRIEU LA ROCHELlE, Kapitalismus, Kommunismus und europäischer Geist, in: Europdische Revue 3,1 (1927/28) S. 61-65, hier S. 62.

9 Vgl. WINOCK, Générations intellectuelles, S. 26. Siehe zur Klassifikation Kap. I.2.2.

10 Jean TOUCHARD, L'esprit des années 1930: Une tentative de renouvellement de la pensée politique française, in: Tendances politiques dans la vie française depuis 1789, Paris 1960, S. 89-118.

1 Vgl. Bock, Der Weg Pierre Viénots, S. 105.

12 Vgl. Kap. I.2.2. 
Älteren gegenüber geringer an Wert gefühlt, beinahe hielten wir uns unserer Jugend wegen für schuldig [...]. Von dem Moment an, da wir sicher waren, die Gefahren nie zu teilen, schien uns unsere Minderwertigkeit für immer besie-

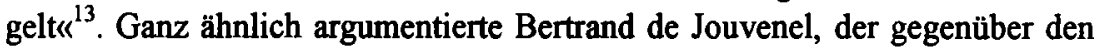
Kriegsteilnehmem »une infériorité fortement ressentie ${ }^{14}$ verspürte. Da das Bewußtsein einer tiefen Kulturkrise jedoch innerhalb aller Intellektuellengenerationen spürbar war, stellt sich die Frage, ob in der Realität nicht doch ein generationenübergreifendes Zusammengehörigkeitsgefühl im Zeichen der Krise möglich war.

Folgt man den Äußerungen der jungen Nachkriegsintellektuellen, so erscheint dies kaum denkbar, denn von ihnen wurden die generationellen Trennlinien besonders hervorgehoben. Dies zeigte sich exemplarisch in der 1927 durch Jean Luchaire und Émile Roche erfolgten Gründung der Zeitschrift Notre Temps, die dem Briandismus nahestand und die als eine Tribüne »exclusivement réservée à la génération nouvelle ${ }^{15}{ }^{15}$ konzipiert war. Notre Temps versammelte junge Autoren wie Alfred Fabre-Luce, Bertrand de Jouvenel, Jacques Kayser, Pierre Mendès France oder Henri Daniel-Rops und griff jene Themen auf, die die Nachkriegsjugend bewegte. Pierre Brossolette, der bis 1934 zu den regelmäßigen Mitarbeitern zählte, formulierte den Bedarf an neuen Idealen, die dem Leben nach der Zerstörung alter Glaubensinhalte wieder einen Sinn geben könnten. Den Pessimismus, der hinter dieser Forderung stand, sah er als charakteristisch für die Epoche $\mathbf{a n}^{16}$. Das Feindbild von Notre Temps stellte besonders die Vorkriegsgeneration dar, die als verantwortlich angesehen wurde für die sincapacité dans laquelle se trouvent nos institutions, nos organisations, nos mentalités politiques d'opérer la réadaption de l'État aux conditions nouvelles de la vie ${ }^{17}$. Die Anpassung des Staates und seiner Institutionen an die moderne Welt sollte nun von den propagierten »jeunes équipes « geleistet werden.

Das Bedürfnis nach intellektueller Identitätsfindung und Selbstdefinition führte die jungen Autoren um Notre Temps immer wieder zur Beschwörung der Generationsgrenzen, was in Titeln wie »Frontières et générations $\aleph^{18}$ und Sonderheften zur »Querelle des générations et crise des démocraties ${ }^{19}{ }^{19}$ ihren Ausdruck fand. Ihre Vorgängergeneration bezeichnete sie als wverlorene Ge-

13 Jean PRÉVOST, Jahrgang 21, in: Europdische Revue 1 (1925/1926) S. 318-321, hier S. 318.

14 Bertrand de JOUVENEL, Un voyageur dans le siècle, 1903-1945, Paris 1979, S. 77.

15 Jean LuCHAIRE, Émile RoCHE, Présentation, in: Notre Temps, 20.6.1927, S. 1. Die Zeitschrift wurde vom Quai d'Orsay subventioniert. Vgl. BELLANGER, Histoire générale de la presse, S. 488.

16 Pierre BROSSOLETTE, Le pessimisme de notre temps, in: Notre Temps, 15.5.1930, Sondernummer »Deux générations d'après-guerre: 1830-1930« Sp. 450.

17 Jean LUCHAIRE, Émile ROCHE, Une discipline politique, in: Notre Temps, 20.6.1927, S. 8183, hier S. 82.

18 Jean LUCHAIRE, Frontières et générations, in: Notre Temps, 29.3.1931, Sp. 489-492.

19 Notre Temps, 2-9.7.1933. Ein anderes Sonderheft erschien zum Thema »Querelle des générations et crise des idées«: Notre Temps, 30.7-6.8.1933. 
neration «, die die Zeichen der Zeit nicht erkannt habe. Diese halte sich für modern, ohne die Kluft zwischen sich selbst und ihrer Epoche zu bemerken. Literarisch orientiere sie sich noch immer an Gide oder an den Surrealisten, aber, so das Urteil Marcelle Prats, sà nous, la génération d'après-guerre, ces jjeunes‘ paraissent bien démodés ${ }^{20}$. Die Politik der Emeuerung, die von den jungen Intellektuellen gefordert wurde, bezeichnete Jean Luchaire als Realismus, seine Altersgruppe als "génération réaliste ${ }^{421}$. Dieser Realismus, so Luchaire, drücke keine Opposition zum Begriff des Idealismus, sondern vielmehr zum Verbalismus aus. Reine Lippenbekenntnisse und Absichtserklärungen sollten der Realisierung von Zielen weichen: »[...] la ferme volonté de réorganiser les cadres de la vie sociale et de la vie internationale selon les exigences des réalités présentes et en vue des vraisemblables exigences du proche avenir ${ }^{22}$. Dabei erwies sich die "génération réaliste « auch als briandistische Generation, als Anhängerin des Völkerbundes und der Locarnopolitik ${ }^{23}$. Man mochte sich der Begriffswahl Luchaires anschließen oder nicht, er drückte das Streben und die Sehnsucht aus, die von den jungen Männern geteilt wurden. Die Solidarität mit der Generation, der man sich zugehörig fuihlte, wurde dabei als wichtiger erachtet als sonstige Loyalitäten, etwa zu Klassen oder Parteien.

Weniger radikal als Notre Temps deuteten die beiden Nonkonformisten René Dupuis und Alexandre Marc 1933 die Beziehung der Kriegs- und der Nachkriegsgeneration zueinander. In ihrem Werk »Jeune Europe« diagnostizierten sie die "entrée de la jeunesse sur la scène du monde ${ }^{24}$ in zwei Phasen. Die erste Generation sei 1918-1925 ins politische Leben eingetreten und habe hauptsächlich durch symbolische Akte der Rebellion versucht, ihrer inneren Beunruhigung zu entkommen. Doch Intellektuelle wie Aragon, Montherlant oder Breton seien in ihren Hoffnungen auf eine politische und sozio-ökonomische Erneuerung enttäuscht worden. Die alten Funktionsträger, die alten politischen Ideen und Methoden seien zurückgekehrt. Von dieser wrecherche fiévreuse et inquiète, $[. .$.$] négation stérile ou [...] violence verbale et inutile { }^{25}$ hebe sich die zweite Gruppe ab, die zu Beginn der dreißiger Jahre aufgetreten sei und sich der Tat verschrieben habe. Die Autoren stellten fest, daß es keinen Bruch zwischen den beiden Generationen gebe, die zweite sei vielmehr die gereifte Fortsetzung der ersten. Diese sei nicht wegen ihrer Unfähigkeit gescheitert,

Vgl. Michel TREBrTSCH, Le front commun de la jeunesse intellectuelle. Le "Cahier de revendications« de décembre 1932, in: Gilbert MERLIO (Hg.), Ni gauche ni droite: les chasséscroisés idéologiques des intellectuelles français et allemands dans l'entre-deux-guerres, Bordeaux-Talence 1995, S. 209-227, hier S. 215.

24 René DUPUIS, Alexandre MARC, Jeune Europe, Paris 1933, S. 195.

25 Ibid. S. 192. 
sondern "parce qu'ils ont été sollicités par les événements trop tôt, parce qu'ils se sont trouvés devant le désordre du monde avant d'avoir pu surmonter leur propre désordre intérieur $[\ldots] \ll^{26}$.

Anknüpfend an diese zeitgenössische Deutung werden auch in der heutigen Intellektuellenforschung verbindende Elemente zwischen der "génération du feu " und der "génération de la crise« ausgemacht. So sieht Michel Trebitsch Ähnlichkeiten zwischen der geforderten »révolte de l'esprit« der Avantgardisten und der "révolution spirituelle« der Nonkonformisten: "Même refus du politique, même tentative, par-delà les partis, de constituer un /front uni des avantgardes ou de la jeunesse ${ }^{27}$. Allerdings geht auch Trebitsch von einem etwa $1925 \mathrm{zu}$ situierenden Bruch mit den avantgardistischen Utopien aus, die zu einer Hinwendung zur Politik führte. Zwischen den beiden von Dupuis und Marc genannten Generationen fügt sich laut Trebitsch noch eine dritte ein: jene "génération réaliste«, die vom Notre Temps-Kreis um Jean Luchaire propagiert wurde. Ihr Auftreten habe im Zeichen einer Rückkehr zum Konkreten, zum politischen Engagement gestanden. Thre doppelte Ablehnung von amerikanischem Kapitalismus und sowjetischem Kollektivismus führte zur Suche nach einem Dritten Weg, dem sich eine Vielzahl von Zirkeln und Gruppierungen bereits in den zwanziger Jahren verschrieben hatten ${ }^{28}$.

Aus den vorausgegangenen Ausführungen lassen sich verschiedene Schlüsse ziehen. Zum ersten erscheint es offensichtlich, daß der Erste Weltkrieg als »accélérateur du découpage générationnel ${ }^{29}$ fungierte. So folgten, relativ rasch hintereinander, die von Marc Bloch so bezeichneten "générations courtes « ${ }^{30}$ der Zwischenkriegszeit. Die Übergänge zwischen den einzelnen Generationen waren jedoch fließender als der verbale Rigorismus in Notre Temps oder an anderer Stelle es vermuten läßt. »Il arrive enfin «, stellt Bloch fest, »que les générations s'interpénètrent. [...] La notion de génération est donc très souple, comme tout concept qui s'efforce d'exprimer, sans les déformer, les choses de l'homme ${ }^{31}$. Die gesteckten Grenzen waren also nicht nur eine Frage des Geburtsjahres, sondern in nicht zu unterschätzendem Maße eine Angelegenheit der geistigen Übereinstimmung. Diese konnte zwar bei Altersgenossen stärker ausgeprägt sein, aber gerade dort über diese Grenzen hinausreichen, wo der Erste Weltkrieg als Bezugshorizont der politischen Sozialisation noch gegeben war. Nur so ist es zu erklären, daß Intellektuelle wie Arnaud Dandieu (geb. 1897) und Robert Aron (geb. 1898) zu den repräsentativsten Vertretern des Nonkonformismus gezählt werden, der als eine Bewegung der Nachkriegsintel-

${ }^{26}$ Ibid. S. 193.

27 TREBISCH, Le front commun, S. 214.

28 Ibid. S. 215.

29 ORY, SIRINELLI, Les intellectuels, S. 72.

${ }^{30}$ Marc BLOCH, Apologie pour l'histoire ou métier d'historien, Paris 1993 [Erstausgabe 1949], S. 184.

31 lbid. 
lektuellen gilt. Ähnliches gilt für den Wortführer des Neo-Sozialismus, Marcel Déat (geb. 1894), sowie für den 1893 geborenen Pierre Drieu la Rochelle. Sie alle gehörten stricto sensu nicht der Generation der von Notre Temps proklamierten »jeunes équipes« an. Dennoch brachten sie genau die Themen zur Sprache, die als typisch für den Zeitgeist angesehen wurden. Drieus Gedanken kreisten unablässig um das Thema der »decadence«, Arons und Dandieus bekanntestes Werk hatte gar den Titel »Décadence de la nation française ${ }^{\text {(32. }}$. Niedergang und Erneuerung, das waren die Themen, die die jungen Intellektuellen in den zwanziger und dreißiger Jahren umtrieben. Es waren auch die Themen, die Pierre Viénot beschäftigten, und obwohl er nie aktiv bei Notre Temps mitarbeitete ${ }^{33}$, so erschien er doch 1932 auf einer Liste der parlamentarischen Mitarbeiter der Zeitschrift, zusammen unter anderem mit Pierre Mendès France, Pierre Cot, Gaston Bergery und Marcel Déat ${ }^{34}$. Auch dies kann als Beispiel für die fließenden Generationsgrenzen betrachtet werden, denn Viénot und erst recht Déat waren eigentlich zu alt für die »jeunes équipes«.

Offenbar wurde Viénot von seinen Zeitgenossen im Umkreis von Notre Temps als Vertreter jener Ideen gesehen, die dort proklamiert wurden. Viénots Zugehörigkeit zur »génération du feu« scheint also keinen grundsätzlichen Ausschlußgrund für eine engere Verbindung zu den Erneuerungsbewegungen der Nachkriegsjugend darzustellen. Angesichts der in der Literatur erhobenen Behauptung, Viénot sei ein nonkonformistischer Intellektueller ${ }^{35}$, gilt es zu klären, inwieweit Viénot tatsächlich inhaltlich mit jenen Ideen übereinstimmte, die dem intellektuellen Nonkonformismus angehören, der am nachdrücklichsten eine gesellschaftlich-politische Erneuerung forderte.

\subsection{Die französischen Nonkonformisten und ihre Suche nach dem Dritten Weg}

Der Befund einer tiefgehenden Krise war keine originäre Thematik der dreißiger Jahre und ihrer intellektuellen Jugend. Vielmehr ging die Diskussion über Krise und Niedergang der Weltwirtschaftskrise, mit der sie oft in Zusammenhang gebracht wird und die Frankreich erst ab Ende 1931 erreichte, voraus ${ }^{36}$. Dennoch ist zu Beginn der dreißiger Jahre ein tiefgreifender Wandel zu konstatieren, der die spezifischen Entstehungsbedingungen der nonkonformistischen Bewegung begünstigte ${ }^{37}$. Bereits die Zeitgenossen hatten das Gefühl, Zeugen von »années tournantes« $\mathrm{zu}^{\mathrm{sein}}{ }^{38}$. Unbeeindruckt von der intellektuellen Krisen-

32 Robert ARON, Arnaud DANDIEU, Décadence de la nation française, Paris 1931.

${ }^{33}$ Die Durchsicht aller Jahrgänge von Notre Temps förderte keinen Artikel von Viénot zutage

34 Notre Temps, 12.6.1932.

35 Vgl. BOCK, Der Weg Pierre Viénots, S. 105.

${ }^{36} \mathrm{Vgl}$. TREBIrSCH, Le front commun, S. 213.

37 Vgl. LOUBET DEL BAYLE, Les non-conformistes, S. 11-31.

$38 \mathrm{Vgl}$. Henri DANIEL-ROPS, Les années toumantes, Paris 1932. 
debatte konnten sich jedoch die Politiker und große Teile der Bevölkerung in den zwanziger Jahren noch weitgehend Illusionen über die innen- und außenpolitische Situation Frankreichs hingeben ${ }^{39}$. Vor allem in den Jahren von 1926 bis 1931 schien Frankreichs Bilanz - oberflächlich betrachtet - glänzender denn je: Mit dem Regierungsantritt Poincarés 1926 begann eine Phase innenpolitischer Stabilität, wie sie seit Kriegsende nicht mehr dagewesen war, und mit der Stabilisierung des Francs setzte auch ein wirtschaftlicher und finanzieller Aufschwung ein, der 1930 seinen Höhepunkt erreichte. Auf außenpolitischem Gebiet schien das Ende der Nachkriegszeit endgültig erreicht. Die Locarnopolitik Briands und der Abschluß des Briand-Kellogg-Paktes bestärkten den Glauben an eine friedliche Zukunft Europas, und mit dem Young-Plan schien auch das leidige Thema der Reparationen erledigt zu sein. Zudem konnte die Grande Nation das Ansehen auskosten, welches sie weithin genoB. Thre Armee galt als die stärkste der Welt, doch gleichzeitig trat Frankreich als nachdrücklichster Befürworter der Genfer Völkerbundspolitik auf, verkörpert in der allseits geachteten Person Aristide Briands. Frankreich konnte als Prototyp der parlamentarischen und liberalen Demokratie angesehen werden und hatte nach dem Ersten Weltkrieg einen wichtigen Beitrag zum Export dieses Modells nach Mittel- und Osteuropa geleistet. All diese Illusionen von Frieden, Stabilität und Sicherheit zerbrachen zu Beginn der dreißiger Jahre und entpuppten sich als pure Luftschlösser. Die Weltwirtschaftskrise traf das überwiegend agrarisch geprägte und weit weniger als Deutschland in die internationalen Handels- und Finanzströme eingebundene Frankreich mit zwei Jahren Verspätung. Neben einem eklatanten Export- und Produktionsrückgang und der Massenarbeitslosigkeit brachte dies auch ein chronisches Staatsdefizit mit sich, dessen Bekämpfung in der Folgezeit zur vordringlichsten politischen Aufgabe erklärt wurde $^{40}$. Frankreichs Bedürfnis nach Sicherheit war noch immer nicht befriedigt und stellte Anfang der dreißiger Jahre das Problem Nummer eins in seinen Beziehungen zu Deutschland dar. Auf internationalem Feld erlebte das System kollektiver Sicherheit mit dem Überfall Japans auf die Mandschurei im September $1931^{41}$, der die Machtlosigkeit des Völkerbundes angesichts internationaler Aggression verdeutlichte, seinen langsamen Niedergang. Mit der Weigerung Frankreichs, nach dem Deutschland zugestandenen Hoover-Moratorium in der Reparationsfrage seine Kriegsschuldzahlungen an die USA weiterhin zu be-

39 Vgl. Jacques CHASTENET, Histoire de la Troisième République, Bd. 5, Les années d'illusion, 1918-1931, Paris 1962.

40 Zur Wirtschaftskrise in Frankreich vgl. Dominique BORNE, Henri DUBIEF, La crise des années trente, 1928-1938, Paris ${ }^{2} 1989$ (Nouvelle histoire de la France contemporaine, 13), S. 20-43; Serge BERSTEIN, La France des années 30, Paris ${ }^{2} 1993$, S. 25-46.

41 Vgl. dazu Jasper WIECK, Weg in die "Décadence«: Frankreich und die mandschurische Krise 1931-1933, Bonn 1995 (Pariser Historische Studien, 40); Jean-Baptiste DuROSELLE, Histoire diplomatique de 1919 à nos jours, Paris ${ }^{3} 1962$, S. 157-163; GIRAULT, FRANK, Turbulente Europe, S. 177-180. 
gleichen, begab es sich zudem in die politische Isolation und geriet gegenüber einem immer offensiver auftretenden Deutschen Reich zunehmend in die Defensive. Kurzum: innerhalb kürzester Zeit war das Ansehen Frankreichs im Niedergang begriffen, und das Land stand großen politischen, wirtschaftlichen und sozialen Problemen gegenüber. Der Umbruch der dreißiger Jahre zeigte sich am sinnfälligsten durch das Abtreten jener Männer, die die Nachkriegszeit am deutlichsten geprägt und die Stabilität des Systems verkörpert hatten. 1929 zog sich Poincaré aus dem politischen Leben zurück, im selben Jahr starben Marschall Foch und Clemenceau. 1931 folgten ihnen General Joffre und 1932 Briand ins Grab. Von den großen Heerfuihrern des Ersten Weltkriegs war somit nur noch Marschall Pétain übrig geblieben, dessen Glanz um so strahlender erschien. Mit der Stabilität der Regierungen war es 1932 ebenfalls zu Ende. Nachdem das Kabinett Herriot im Dezember über die Frage der interalliierten Schulden gestürzt war, folgten fünf Regierungen innerhalb von 13 Monaten. Die politische, wirtschaftliche und internationale Problematik läßt die Entwicklung Frankreichs in den dreißiger Jahren im Urteil der Historiographie als große krisenhafte Evolution, als Niedergang, als Weg in die Dekadenz erscheinen $^{42}$. Die politische und ökonomische Instabilität zog indessen eine regelrechte Woge von Antiparlamentarismus und Antiliberalismus nach sich. Es handelte sich nicht mehr nur um eine Regierungskrise nach der anderen, das politische System selbst stand nun zur Diskussion.

In dieser Umbruchsphase zu Beginn der dreißiger Jahre manifestierte sich die offensive Revolte einer Gruppe junger Intellektueller, die zumeist im ersten Jahrzehnt des Jahrhunderts geboren worden waren, und die sich zur Formulierung ihrer Ziele eines bis dahin ungewohnten revolutionären Vokabulars bedienten ${ }^{43}$. Diese sogenannten Nonkonformisten gehörten dabei weder einer gemeinschaftlichen Organisation an, noch veröffentlichten sie ein gemeinsames Manifest, noch gab es eine einheitliche Führungsfigur. Auch die politische Orientierung dieser Intellektuellen variierte sehr stark. Dennoch läßt sich eine gemeinsame ideologische Ausrichtung erkennen, und trotz der Vielzahl ihrer Publikationsorgane wurden die nonkonformistischen Intellektuellen als eine Bewegung wahrgenommen. Dies lag vor allem daran, daß sie immer wieder die gleichen Themen aufgriffen und in einem charakteristischen Vokabular erörterten. Jean Touchard, der sich als erster mit diesem Phänomen beschäftigte, stellte fest, daß »dans les années 1930 , de jeunes gens intellectuels se retrouvent

Vgl. z.B. BORNE, DUBIEF, La crise des années trente; Jean-Baptiste DUROSELLE, Politique étrangère de la France. La décadence 1932-1939, Paris 1979; Jacques CHASTENET, Histoire de la Troisième République, Bd. 6, Déclin de la Troisième, 1932-1938, Paris 1962.

${ }^{43}$ Vgl. LOUBET DEL BAYLE, Les non-conformistes, S. 28. 
autour des mêmes revues, parlent le même langage, utilisent le même vocabulaire; [...] tous se déclarent animés par une même volonté révolutionnaire « ${ }^{44}$.

Die nonkonformistischen Zeitdiagnosen und Erneuerungsideen wurden in Zeitschriften wie Ordre nouveau, Plans, Combat, Esprit, Cahiers oder Réaction erörtert. Die verschiedenen Strömungen und Zeitschriften lassen sich in drei große Zweige unterteilen ${ }^{45}$ : Zum ersten gab es eine Reihe von Publikationen, die sich unter dem Begriff Jeune Droite versammelten. Zum zweiten entwickelte sich eine Gruppe unter dem programmatischen Namen Ordre nouveau, und zum dritten schließlich entstand die Esprit-Bewegung.

Die Jeune Droite, deren charakteristischste Publikationen die Cahiers von Jean-Pierre Maxence und Réaction von Jean de Fabrègues darstellten ${ }^{46}$, wurzelte ideologisch im Gedankengut der Action française. In ihrem Gründungsmanifest stellte Réaction die Unterdrückung des Menschen durch den »despotischen demokratischen Staat" und die industrialisierte Gesellschaft fest, die das Leben normiere. Die Lösung sollte eine Reaktion im doppelten Sinne sein: "Réaction en politique contre la décadence démocratique, fille du nombre et de la quantité. [...] Réaction sociale: contre l'individualisme, l'étatisme et la lutte des classes, pour permettre le développement de la personne humaine libre dans ses cadres sociaux naturels $\aleph^{47}$. Réaction gab sich also betont antidemokratisch und antikapitalistisch, und zur Überwindung der konstatierten Mißstände empfahl sie die Rückkehr zur Monarchie, die Unterordnung der Wirtschaft unter das Gemeinwohl und die Besinnung auf eine als christlich titulierte Ordnung. Die hier beschriebenen Befunde sind charakteristisch für die Nonkonformisten, die Rezepte muten allerdings eher traditionell-konservativ an. Die Entstehung der Jeune Droite war ursächlich verknüpft mit der Krise der Action française seit ihrer Verurteilung durch Papst Pius XI. im Jahr 1926. Die zunehmende ideologische Verengung der Action française und die Abkehr vom Katholizismus, wie sie Charles Maurras ${ }^{48}$ praktizierte, hatte eine Gegenbewegung jener Jugendlichen hervorgerufen, die im Umkreis der Bewegung sozialisiert worden waren. Diese forderten in erster Linie die Einlösung jener Prinzipien, die sich die Action française früher selbst auf die Fahnen geschrieben hatte ${ }^{49}$.

44 Jean TOUCHARD, L'esprit des années 1930, S. 89. Vgl. auch Pierre ANDREU, Les idées politiques de la jeunesse intellectuelle de 1927 à la guerre, in: La Revue des Travaux de l'Académie des Sciences morales et politiques 101 (1957) S. 17-30.

45 Zur genauen Entstehungsgeschichte der einzelnen Guppen vgl. die detaillierte Darstellung bei LOUBET DEL BAYLE, Les non-conformistes, S. 37-157.

46 Die Cahiers erschienen erstmals 1928, Réaction 1930. Vgl. ibid. S. 48 und S. 62.

47 Manifeste de Réaction (avril 1930), abgedruckt in: ibid. S. 439-441, hier S. 440.

$48 \mathrm{Zu}$ Charles Maurras vgl. DigEON, La crise allemande, S. 435-448.

49 Vgl. Hans-Wilhelm ECKERT, Konservative Revolution in Frankreich? Die Nonkonformisten der Jeune Droite und des Ordre Nouveau in der Krise der 30er Jahre, München 2000 (Studien zur Zeitgeschichte, 58), S. 55. 
Die zweite große Gruppierung, Ordre nouveau, entstand Anfang 1931 aus dem Zusammentreffen eines ursprünglich religiös orientierten Studienkreises um Alexandre Marc, zu dem der Philosoph Gabriel Marcel und der Karl BarthSchüler Denis de Rougement gehörten, mit Robert Aron und Arnaud Dandieu. Sie speiste ihre ideologischen Wurzeln im Gegensatz zur Jeune Droite nicht aus einem einheitlichen Reservoir, ihre Protagonisten kamen vielmehr aus den verschiedensten Lagern, von der Action française bis hin zu den Surrealisten. So hatten sich zwei der bedeutendsten Mitglieder des Ordre nouveau, Robert Aron und Arnaud Dandieu, in den zwanziger Jahren in den Kreisen des Surrealismus respektive des Sozialismus bewegt. Die beiden waren Ende des 19. Jahrhunderts geboren und somit älter als die meisten ihrer Mitstreiter.

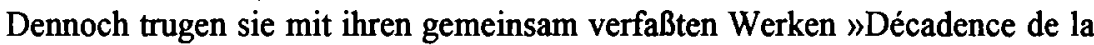
nation française « (1931), "Le cancer américain« (1931) und »La révolution nécessaire « (1933) am deutlichsten zur Ausformung der ideologischen Grundlage von Ordre nouveau bei. In ihrem Selbstverständnis sah sich die Bewegung als wun groupe d'esprits non conformistes et révolutionnaires « ${ }^{50}$. Da Ordre nouveau nicht auf ein verbindliches politisches Koordinatensystem seiner Mitglieder rekurrieren konnte, kam der Entwicklung einer revolutionären Doktrin zur Überwindung der Krise eine besondere Bedeutung $\mathrm{zu}^{51}$. Die Ausgangsüberlegung - jene Frage, die sich auch Viénot in den zwanziger Jahren unablässig stellte ${ }^{52}$ - drehte sich um das Verhältnis von Mensch und Maschine oder, anders formuliert, die Rolle des Individuums in der modernen, technisierten Gesellschaft. Ziel der geforderten "psychologischen Revolution« war es, eine Wertehierarchie zu schaffen, "qui rende à la personne humaine le rang qui lui revient: le premier. La machine économique et sociale doit exister pour la personne et non la personne pour la machine économique ${ }^{53}$. Ausgehend von dieser als Personalismus bezeichneten Philosophie forderte Ordre nouveau den Bruch mit dem abstrakten Individuum des Liberalismus, in dem ein Mensch ohne soziale Bindungen gesehen wurde. $\mathrm{Da}$ auf diesem falschen, weil rein abstrakten Individuum das demokratische und parlamentarische System basiere, müsse dieses bekämpft werden. Als weiteren Auswuchs des Liberalismus bezeichnete die Gruppe ein zur Anarchie neigendes und inhumanes Wirtschafts-

Manifeste de $L$ 'Ordre nouveau, abgedruckt in: LOUBET DEL BAYLE, Les non-conformistes, S. 442-444, hier S. 442.

51 So betonte die Gruppe wla primauté de la doctrine avec tout ce que cela comporte, en apparence, de sécheresse technique«. Positions d'attaque pour L'Ordre nouveau (1933), abgedruckt in: ibid. S. 444-447, hier S. 446.

52 Vgl. z.B. Pierre VIÉNOT, Antwort auf drei Fragen II.; Elemente der modernen Zivilisation. Der Verband für kulturelle Zusammenarbeit in Prag, in: Europatische Revue 4,2 (1928/29) S. 716-721, hier S. 719. Siehe dazu auch Kap. IV.2.2.

53 Manifeste de L'Ordre nouveau, in: LOUBET DEL, BAYLE, Les non-conformistes, S. 443. 
system $^{54}$. Ziel der revolutionären Emeuerung war die Schaffung eines Ordre nouveau, der Ordnung eines »homme concret«, die auf drei Säulen ruhen sollte: zum ersten auf der philosophischen Basis des Personalismus, der die Vorherrschaft des Menschen über die Gesellschaft sichert, zum zweiten auf einem "communisme antiproductivister, der die Produktion am Verbrauch orientiert, und zum dritten auf dezentralisierten regionalen Einheiten, die den Rahmen der Nation ersetzen und die Verbindung des Menschen »à la terre, à la race, à la tradition affective et culturelle« gewährleisten ${ }^{55}$. Die Zivilisation, die es zu erschaffen galt, sollte um die "Person« herum gestaltet werden, sie sollte antietatistisch und dezentralisiert $\operatorname{sein}^{56}$.

Die philosophische Kategorie des Personalismus wurde zunächst in der Gruppe Ordre nouveau verwendet, bevor sie vom Esprit-Kreis um Emmanuel Mounier in ihrer katholischen Variante erfolgreich für sich in Anspruch genommen wurde ${ }^{57}$. Eingeführt in Frankreich wurde der Personalismus von Alexandre Marc $^{58}$. Der 1904 in Odessa als Aleksandr Markowitsch Lipiansky geborene Sohn einer jüdischen Großbürgerfamilie mußte nach der Oktoberrevolution nach Frankreich fliehen. Marc studierte 1922/23 in Jena Philosophie, vor allem beschäftigte er sich mit den Schriften Martin Heideggers, Max Schelers und Edmund Husserls. Dabei kam er mit der von Scheler und William Stern entwickelten Kategorie der "Person« in Berührung, die er nach Frankreich importierte $^{59}$. Der Personalismus stellt den Versuch dar, aus der gleichzeitigen Ablehnung von liberalem Individualismus auf der einen und kommunistischem Kollektivismus auf der anderen Seite eine dritte Alternative der Beziehung zwischen Mensch und umgebender Gesellschaft zu realisieren. Die Person nimmt dabei ihren Platz in einer sozialen Hierarchie ein und orientiert ihr Handeln an der Gemeinschaft. Erreicht werden konnte dieses Ziel einer neuen, in Einklang der Bedürfnisse von Person und Gesellschaft geschaffenen Ordnung

Vgl. Positions d'attaque pour L'Ordre nouveau, in: ibid. S. 445. Dahinter steckte die Annahme von der zunehmenden sdéshumanisation de l'individu, réduit à n'être qu'un élément de calcul ou un facteur de prix de revient«. ARON, DANDIEU, Décadence, S. 134.

s5 Vgl. Manifeste de L'Ordre nouveau, in: LOUBET DEL BAYLES, Les non-conformistes, S. 443

56 Vgl. auch Alexandre MARC, Vers un ordre nouveau, in: DFR 6 (1933) S. 354-361.

$57 \mathrm{Zu}$ den verschiedenen Spielarten des Personalismus und dessen Bedeutung in den Intellektuellendebatten der Zwischenkriegszeit vgl. Thomas KELLER, Deutsch-französische DritteWeg-Diskurse. Personalistische Intellektuellendebatten der Zwischenkriegszeit, München 2001 (Übergänge, 39).

58 Vgl. zu dessen Vita Christian RoY, Alexandre Marc et la Jeune Europe (1904-1934). L'Ordre nouveau aux origines du personnalisme, Nice 1998 (Recherches européennes et internationales, 3), v.a. S. 53-152.

59 Vgl. John HELlMaN, Christian ROY, Le personnalisme et les contacts entre non-conformistes de France et d'Allemagne autour de l'Ordre Nouveau et de Gegner, 1930-1942, in BOCK, MEYER-KALKUS, TREBITSCH, Entre Locarno et Vichy, Bd. 1, S. 203-215, hier S. 203f;; ECKERT, Konservative Revolution, S. $63 \mathrm{ff}$. 
nur durch die Überwindung der seit der Französischen Revolution etablierten Parteigrenzen. Daß personalistische Ideen auf Viénot einen nachhaltigen Einfluß ausübten, zeigt eine Äußerung von ihm aus dem Jahr 1943. Als er sich während des Zweiten Weltkrieges Gedanken über die Nachkriegsordnung machte, griff Viénot auf Ideen zurück, die als personalistisch angesehen werden können, wenngleich er statt von der »Person« vom »Menschen« spricht. Dieser stellte für ihn das Gegenbild zum liberalen Individuum dar. $\mathrm{Imm}$ ging es zu diesem Zeitpunkt darum, eine Moral zu finden, sayant l'homme - je ne dis pas l'individu - pour centre«. Weiterhin ließ er wissen: "La grande réforme nécessaire à la France, ce sera de se guérir de cette caricature de l'homme que constitue l'individu. [...] La France devrait pouvoir être le pays de cette révolution là... $\ll^{60}$.

Auch in einem anderen Punkt teilte Viénot die Anschauungen der Nonkonformisten. Die Revolutionäre des Ordre nouveau betrachteten sich als jenseits des Parteienspektrums stehend: "Nous ne sommes ni droite, ni gauche, mais s'il faut absolument nous situer en termes parlementaires, nous répéterons que nous sommes à mi-chemin entre l'extrême droite et l'extrême gauche, par derrière le président, tournant le dos à l'assemblée « ${ }^{61}$. Bereits fünf Jahre zuvor hatte Viénot eine analoge Formulierung gebraucht, um seinen Unwillen auszudrücken, sich in das bestehende politische Spektrum einzufügen. Er selbst sei, ließ er Lyautey wissen, weder rechts noch links ${ }^{62}$.

Die dritte Säule der nonkonformistischen Bewegung stellte die im Oktober 1932 gegründete Zeitschrift Esprit dar $^{63}$, an deren Entstehung Emmanuel Mounier $^{64}$, Georges Izard, André Déléange und Louis-Émile Galey beteiligt waren und die vom katholischen Philosophen Jacques Maritain unterstützt wurde. Die ideologischen Ursprünge waren wie bei Ordre nouveau divers, allerdings bekannte sich die Mehrheit der Mitarbeiter zum Christentum, die meisten waren katholisch. In stärkerem Maße als die anderen Gruppierungen war Esprit vom universitären Milieu geprägt, was sich in der Beteiligung einer großen Anzahl von Professoren manifestierte. Darüber hinaus gehörten zu den ersten Mitarbeitern von Esprit die wichtigsten Autoren des Ordre nouveau, wie Robert Aron, Arnaud Dandieu, Henri Daniel-Rops, René Dupuis, Denis de Rougement und Alexandre Marc, die Esprit vermutlich als Tribüne für ihre

60 Viénot an Schlumberger, 11.2.1943: BLJD, Fonds Schlumberger, Ms 18359.

61 Robert ARON, Questions posées, in: $N R F 39$ (1932) S. 834-837, hier S. 837.

62 Viènot an Lyautey, 15.11.1927: AN, 474 AP 311.

${ }^{63}$ Vgl. hierzu die ausführliche Studie von Michel WINOCK, "Esprit«. Des intellectuels dans la cité 1930-1950, Paris ${ }^{2}$ 1996. (Die Erstauflage erschien unter dem Titel: Histoire politique de la revue »Esprit « 1930-1950, Paris 1975.)

${ }^{64} \mathrm{Zu}$ Mounier vgl. John Hellman, Emmanuel Mounier and the New Catholic Left 1930 1950, Toronto u.a. 1981. 
eigenen Ideen nutzen wollten ${ }^{65}$. Marc dachte sogar daran, aus Esprit die Literaturzeitschrift des Ordre nouveau zu machen ${ }^{66}$. Dies gelang ihm zwar nicht, wohl ist aber davon auszugehen, daß der Personalismus, der in der Folgezeit vom Esprit-Kreis als ihm originäre Philosophie ausgegeben wurde, über Marc seinen Einzug in diese Gruppe hielt ${ }^{67}$. Esprit sagte dem »désordre établi« den Kampf an, es ging ihm darum, »à liquider la faillite du monde moderne et à réaliser un ordre nouveau sur la primauté des valeurs spirituelles ${ }^{68}$. Als Gegner wurden auch hier Individualismus und Kollektivismus betrachtet. Während ersterer eine »liberté sans but à des hommes sans âme ${ }^{69}{ }^{6 u g e s t e h e, ~ e r s t i c k e ~}$ letzterer die soziale Gemeinschaft und den Menschen in der mechanisierten Knechtschaft der Masse. Als drittes Feindbild wurde "le faux spiritualisme fasciste ${ }^{70}$ angeführt, der den Menschen zu einer Idolatrie falscher Werte verführe: Rassismus, Nationalismus, Verehrung des Staates oder eines Führers. Als Lösung dieser Problematik müsse »une communauté de personnalités « ${ }^{71}$ geschaffen werden, eine solidarische und humane Gemeinschaft, in der der Mensch im Mittelpunkt steht. An die Stelle der als mörderisch betrachteten kapitalistischen Ordnung sollten dezentralisierte, kollektive Organismen treten, innerhalb derer die Entfaltung und Weiterentwicklung der Persönlichkeit zu Recht und Pflicht des einzelnen wird.

Über die rein politischen Forderungen hinaus bezog sich das Programm von Esprit auch auf das Privatleben, die Wissenschaft, die Literatur und die Kunst, die alle zur spirituellen Erweiterung des Menschen beitragen sollten. Eine »vision complète de l'homme ${ }^{72}$ wurde vorgestellt, die Jean Touchard zu dem Schluß führt, Mounier habe wune revue totale ${ }^{73}$ gründen wollen, die sich für alle menschlichen Bereiche interessiere. Mehr als den anderen Zeitschriften ging es Esprit tatsächlich um die spirituelle Komponente der geplanten Revolution, die im Personalismus umgesetzt werden sollte ${ }^{74}$. In der ständigen Auseinandersetzung des Menschen mit der ihn umgebenden politischen, wirtschaftlichen, sozialen und technischen Umwelt, sollte die Gesellschaft weiterentwickelt werden. Die geplante Revolution war somit ein Prozeß hin zum Perfekten. Für

65 Die erste Ausgabe der Zeitschrift Ordre nouveau erschien erst im Mai 1933. Vorher kollaborierten die Mitglieder dieser Bewegung mit den Zeitschriften Plans und Mouvements.

${ }^{66} \mathrm{Vgl}$. LOUBET DEL BAYLE, Les non-conformistes, S. 140f.

67 Vgl. ROY, Alexandre Marc, S. 385-422; ECKERT, Konservative Revolution, S. $77 f$.

68 Prospectus de présentation d'Esprit (fin 1933), abgedruckt in: LOUBET DEL BAYLE, Les nonconformistes, S. $450-452$, hier S. 450.

69 Ibid. S. 451 .

70 Ibid.

${ }^{71}$ Ibid.

72 Prospectus annonçant la fondation d'Esprit (février 1932), abgedruckt in: ibid. S. 448-450, hier S. 450.

7 TOUCHARD, L'esprit des années 1930, S. 93.

74 Serge Berstein faßt die Ideen von Ordre nouveau und Esprit deshalb als »le courant spiritualiste« zusammen. Vgl. BERSTEIN, La France des années 30, S. 95. 
Viénot genügte die geplante »révolution spirituelle« jedoch nicht, um eine umfassende politische und gesellschaftliche Erneuerung zu verwirklichen. Wichtiger war für ihn die Integrität und Selbstlosigkeit der politischen Elite, die er jedoch nicht durch eine wie auch immer geartete geistige Revolution erreichen zu können glaubte ${ }^{75}$.

„Est-il possible de définir une cause commune de la jeunesse française, une communauté d'attitude essentielle?«, fragte Denis de Rougement im Dezember 1932, als die Nouvelle Revue française ein "Cahier de revendications« veröffentlichte, in dem Autoren der diversen nonkonformistischen Zeitschriften ihre Forderungen und Vorschläge vortrugen. Die Anlehnung des Titels an die "Cahiers de doléances" der französischen Generalstände von 1789 war nicht zufällig gewählt, und Rougement sah in den nonkonformistischen Forderungen »les premières lignes de force d'une nouvelle révolution française ${ }^{76}$. Das "Cahier de revendications" stellte den ersten Versuch dar, eine Einheitsfront der nonkonformistischen Bewegungen zu schaffen. Weitgehender Konsens herrschte hinsichtlich der Einschätzung, sich in einer umfassenden Zivilisationskrise zu befinden, die alle bisherigen Maßstäbe übertraf. Ihren Ursprung fand diese Krise nach Meinung der Autoren in der gefährdeten Stellung des Menschen angesichts einer technisierten, inhuman gewordenen Welt ${ }^{77}$. Der Mensch schien nur noch als Werkzeug wirtschaftlicher Interessen zu existieren. Eine Bedrohung »dans le plus précieux de nous-mêmes ${ }^{78}$ wurde wahrgenommen, eine wachsende Kluft »entre la personnalité et son ambiance, entre l'homme tel qu'il est et l'homme tel qu'il se veut ${ }^{79}$. In einer $» W e l t$ ohne Geist ${ }^{80}$ stellten nach Meinung der Nonkonformisten Kapitalismus und Kollektivismus dasselbe Übel dar. Der Konflikt zwischen beiden Wirtschaftssystemen wurde als nur oberflächlich angesehen, da sie als zwei Seiten derselben Medaille galten. Beide basierten auf dem philosophischen Materialismus und beraubten den Menschen seiner spirituellen Seite ${ }^{81}$. Da die Schlußfolgerung daraus lautete:

75 Vgl. Pierre VIENoT, Enquête sur le rajeunissement de la France, in: La Grande Revre 38 (1934) S. 559-562, hier S. 560f.

76 Denis de ROUGEMENT, Cahier de revendications, in: NRF 39 (1932) S. 801

77 Aus diesem Konsens fielen nur die beiden Beiträge der kommunistischen Autoren Paul Nizan und Henri Lefebvre heraus, die vor allem den Kapitalismus für die Krise verantwortlich machten und auf klassische kommunistische Revolutionsstrategien zu dessen Überwindung verweisen. Vgl. Henri LEFEBVRE, Du culte de "L'esprit« au matérialisme dialectique, in: ibid. S. 802-805; Paul NIZAN, Les conséquences du refus, in: ibid. S. 800-811.

Thierry MAULNER, Révolution totale, in: ibid. S. 817-820, hier S. 817.

79 Arnaud DANDIEU, Claude CHEVALLEY, L'intelligence épée, in: ibid. S. 821-823.

${ }^{80} \mathrm{Vgl}$. Henry DANIEL-ROPS, Le monde sans âme, Paris 1932. Vgl. auch Emmanuel MOUNIER, Ce ne sont pas ceux qui disent: Esprit, esprit.., in: $N R F 39$ (1932) S. 824-826, hier S. 824: "Nous sommes pas seulement ces esclaves d'un monde sans âme, nés à l'humanité du jour où ils ont pris conscience de leur esclavage, et qui marchent au pas, dans une révolte technique, vers une nouvelle inhumanité».

81 Vgl. Thierry MAULNIER, Révolution totale, in: $N R F 39$ (1932) S. 817-820, hier S. $818 f$. 
"collectivisme et capitalisme sont identiques $\aleph^{82}$, konnte die Lösung nur in einem totalen Bruch mit den bestehenden politischen, wirtschaftlichen und sozialen Vorstellungen liegen, die von Esprit als »désordre établi« bezeichnet wurden ${ }^{83}$. Der Weg, dem es zu folgen galt, konnte also nicht einer der bereits bestehenden Alternativen sein, es galt vielmehr, einen Dritten Weg zu beschreiten. Die geforderte Revolution sollte demnach nicht den Weg für eine der etablierten Alternativen frei machen, sondern darüber hinausgehen. "Audelà» wurde zum Schlüssel- und Modebegriff der politischen Essayistik ${ }^{84}$. In dem Anspruch, eine neue Ordnung zu schaffen, die nicht etwa an jene der vortechnisierten Zeit anknüpfen, sondern schöpferisch nach vorne gerichtet sein sollte, sah Denis de Rougement Traditionslinien der Französischen Revolution: "L'Ordre nouveau, Combat, Esprit, travaillent dans la ligne des forces révolutionnaires profondes de la France. Cette révolte de la personne, c'est la révolte jacobine, c'est la révolte de 89 , dans ce qu'elle garde de valable et de dynamique; c'est dès à présent le ressort de la nouvelle Révolution Française « ${ }^{85}$. Obwohl die nonkonformistische Bewegung eine Anti-Bewegung war (antietatistisch, antidemokratisch, antiparlamentarisch, antiamerikanisch, antibürgerlich, antimaterialistisch, antirationalistisch, antikapitalistisch, antikommunistisch), war sie durchaus nicht antimodernistisch. Es ging ihr nicht darum, den technischen Fortschritt zu stoppen oder gar rückgängig zu machen. Es war ihr ein Anliegen, dessen als Bedrohung empfundene Begleiterscheinungen mit der geistigen Entwicklung des Menschen in Einklang zu bringen. Dabei sollte die geforderte Ordnung nicht wiederhergestellt, sondern erst geschaffen werden.

So einig sich die Nonkonformisten in der Ablehnung des bestehenden Systems waren, so schwierig war es für sie, eine gemeinsame Linie zu finden. Während beispielsweise der Begriff der Revolution vom Ordre nouveau und der Jeune Droite durchaus im politischen Sinn gebraucht wurde, sah Mounier in ihr vor allem eine spirituell-religiöse Erneuerung ${ }^{86}$. Die Jeune Droite favorisierte eine autoritäre und korporative Staatsverfassung mit wirtschaftsliberalen Zügen, wohingegen Ordre nouveau eine nationale Leitungsfunktion des Staates nur in wirtschaftlicher Hinsicht zulassen wollte. Auf politischer Ebene sollten kommunale

${ }^{82}$ Ibid. S. 819. An anderer Stelle wurde die Zielrichtung der geistigen Revolution vorgegeben gegen die "deux formes complémentaires du matérialisme contemporain: optimisme capitaliste d'une part, pessimisme marxiste de l'autre«. ARON, DANDIEU, La révolution nécessaire, S. 271.

83 Vgl. z.B. Philippe LAMOUR, La révolution et la jeunesse, in: ibid. S.812-814, der wla nécessité d'une rupture brutale« betont, hier S. 813. Zum Bruch mit dem »désordre établi« vgl. ausfuhrlich LOUBET DEL BAYLE, Les non-conformistes, S. 183-267.

84 Vgl. Henri de MAN, Au-delà du marxisme, Bruxelles 1927 (Die Originalversion erschien unter dem Titel: Zur Psychologie des Sozialismus, Jena 1926); Arturo LABRIOLA, Audelà du capitalisme et du socialisme, Paris 1932; Thierry MAULNIER, Au-delà du nationalisme, Paris 1938.

85 Denis de ROUGEMENT, A prendre ou à tuer, in: NRF 39 (1932) S. 838-845, hier S. 843.

${ }^{86} \mathrm{Vgl}$. ECKERT, Konservative Revolution, S. 87ff. 
und regionale Einheiten den Staat ersetzen ${ }^{87}$. Aufgrund ihrer Ablehnung von parteipolitischer Organisation blieben die Nonkonformisten eine nur locker zusammengeschlossene Gruppe mit heterogenen Ansichten. Wie unter diesen Umständen die geforderte Revolution und die Durchsetzung eines Dritten Wegs konkret realisiert werden sollte, bleibt offen, zumal das letztlich zu erreichende Ziel nicht verbindlich definiert wurde ${ }^{88}$. ,Die ¿ nonkonformistische Alternative zum bestehenden System konnten die jungen Revolutionäre nicht bieten.

Die Ausgangsfrage, ob Viénot den Nonkonformisten zuzurechnen ist, ist in formeller Hinsicht mit einem klaren Nein zu beantworten: Er gehörte niemals einem ihrer Zirkel an. Schwieriger ist die Frage jedoch inhaltlich zu klären. Gab es ausreichende Gemeinsamkeiten und Übereinstimmungen der Ansichten, um Viénot dennoch dieser intellektuellen Strömung zuzurechnen? Wie bei den Nonkonformisten taucht bei Viénot der Begriff der Ordnung als Schlüsselbegriff seines politischen Denkens immer wieder auf. In den zwanziger Jahren kreisten alle seine Gedanken um das Problem eines angemessenen politischen Systems für Frankreich, das die aus dem Modernisierungsschub in der Folge des Ersten Weltkriegs entstandenen Probleme zu lösen in der Lage wäre. Er forderte wie die Nonkonformisten die Überwindung der bestehenden politischen Ordnung, wobei er sich schwertat im Aufzeigen konkreter Altemativen ${ }^{89}$. Wie bereits erwähnt teilte Viénot die Meinung der Nonkonformisten, daß die Beziehung des modernen Menschen zu seiner technisierten und industrialisierten Umwelt eine der drängendsten Zeitfragen darstellte. Dabei stimmte er auch in ihre Kritik am parlamentarischen und demokratischen System ein. Nach dem Ersten Weltkrieg hoffte er auf die Überwindung der Demokratie und der in seinen Augen ausgeuferten Parlamentsherrschaft, die das politische System als ineffizient für die Lösung der anstehenden Aufgaben erscheinen ließen ${ }^{90}$. Auch dem Antikommunismus der Nonkonformisten konnte Viénot zustimmen. Die wenigen direkten Äußerungen zu diesem Thema lassen darauf schließen, daß Viénot persönlich nichts mit »Bolschewisten« gemeinsam haben wollte ${ }^{91}$ und

Eckert, ibid. S. 154ff., geht davon aus, daß die Ereignisse des 6. Februar 1934 furr die Nonkonformisten das Signal für den Staatsstreich darstellten. In der Folgezeit hätten sie Allianzen und taktische Bündnisse mit anderen politischen Bewegungen zur Erringung ihrer Ziele einzugehen versucht, darunter auch mit faschistischen Strömungen. Dagegen sieht Michel Trebitsch mit der Machtibernahme Hitlers das Ende der nonkonformistischen Sammlungsbewegungen, da das Prinzip des sni droite ni gauche « von nun an nicht mehr zu verwirklichen gewesen sei. Jean Touchard sieht im 6. Februar 1934 die Zäsur, die die Nonkonformisten vor die Wahl der politischen Lager gestellt habe. Auch fur Loubet del Bayle zerbrach die fragile Übereinstimmung der diversen nonkonformistischen Strömungen 1934. Vgl. TREBITSCH, Le front commun, S. 217f;; TOUCHARD, L'Esprit des années 1930, S. 107; LOUBET DEL BAYLE, Les non-conformistes, S. $399 \mathrm{f}$.

${ }^{89}$ Vgl. dazu Kap. IV.2.1

90 Vgl. auch hierzu näher ibid.

91 Vgl. Viénot an Lyautey, 7.4.1924: AN, 475 AP 311. 
dem sowjetischen System skeptisch, wenn auch nicht feindlich gegenüber$\operatorname{stand}^{92}$. Antiamerikanismus läßt sich hingegen im Denken Viénots nicht nachweisen. In seinen ganz auf das deutsch-französische Verhältnis ausgerichteten Gedanken spielte der Faktor Amerika keine Rolle, auch nicht als negatives $\mathrm{Mu}-$ sterbeispiel für Massenproduktion und Industrialisierung, deren inhumane Folgen von den Nonkonformisten kritisiert wurden. Auch als antikapitalistisch kann man Viénot nicht wirklich bezeichnen. Zwar sprach er sich für eine stärker vom Staat gelenkte Wirtschaft aus, doch ging es ihm vor allem darum, die sozialen Folgen des freien ökonomischen Kräftespiels dadurch zu milderm ${ }^{93}$. Eine fundamentale Kapitalismuskritik ist hinter seinen Anschauungen jedoch nicht zu finden. Dennoch sind seine Gedanken über eine teilweise Verstaatlichung von Unternehmen mit Monopolstellung ${ }^{94}$ als Versuch anzusehen, einen Dritten Weg im wirtschaftlichen Bereich zu beschreiten. Mehr als mit dem Nonkonformismus standen diese Ideen aber in Zusammenhang mit reformsozialistischen Ansätzen zur Lösung der Krise, von denen an anderer Stelle noch die Rede sein wird ${ }^{95}$. Andere Kritikpunkte der Nonkonformisten konnte Viénot gar nicht teilen. Antirationalistisch war er nie, vielmehr sah er sich als Franzose in der Tradition der Aufklärung mit ihrer Vernunftgläubigkeit und ihrem auf einem Vertrag gegründeten Staatsverständnis ${ }^{96}$. Daran schließt sich die Feststellung an, daß Viénot dem Anti-Etatismus der Nonkonformisten nichts abgewinnen konnte. Der Abschaffung des Staates und dessen Aufteilung in kleinere föderative Einheiten hätte er wohl kaum zugestimmt. Viénot besaß vielmehr »au plus haut point le sens de l'État ${ }^{97}$, und sein ausgeprägtes Verantwortungsbewußtsein zielte darauf ab, dem französischen Staat zu dienen. Die Reformen, die er seit den zwanziger Jahren forderte, zielten niemals auf die Abschaffung des Staates, sondern vielmehr auf dessen Stärkung und Steigerung seiner Effizienz ${ }^{98}$. So wenig wie Viénot als antietatistisch angesehen werden kann, so wenig war er auch antibürgerlich. Im Gegenteil: Trotz aller Versuche, sich von seinem traditionell-bürgerlichen Herkunftsmilieu zu lösen blieb er im Auftreten doch immer ein "grand bourgeois à allure aristocratique $"$ ". Als Ergebnis dieses Vergleichs der Hauptkritikpunkte der Nonkonformisten mit den Anschauungen Viénots kann festgehalten werden, daß es eine teilweise inhaltliche Übereinstimmung gab. Viénots Denken zielte - zumindest in den zwanziger Jahren JULIEN, L'Afrique du Nord, S. 78.

Vgl. ibid. S. 561.

Vgl. Kap. IV.1.3. souveraineté française, Paris ${ }^{3} 1972$, S. 78.

Vgl. DERS., 1912-1935: deux alliances russes, in: L'Europe nouvelle, 9.2.1935, S. 131- 135.

Vgl. DERS., Enquête sur le rajeunissement de la France.

Vgl. Pierre VIÉNOT, La sécurité par la compréhension d'autrui, S. 66.

Vgl. Charles-André JULIEN, L'Afrique du Nord en marche. Nationalismes musulmans et

Vgl. z.B. Viénot an Lyautey, 29.3.1924: AN, 475 AP 311; Pierre VIÉNOT, La République et ceux qui la soutiennent, in: Le Narrateur, 11.5.1935. 
- auf dasselbe Ziel wie die Nonkonformisten, nämlich die Überwindung der bestehenden demokratisch-parlamentarischen Ordnung. Doch der Themenkatalog war nur partiell identisch. Viele Forderungen der Nonkonformisten sind, wie gezeigt, bei Viénot nicht zu finden. Es gab also durchaus starke Berührungspunkte mit dem nonkonformistischen Gedankengut, ein Nonkonformist im eigentlichen Sinne des Wortes war Viénot jedoch nicht. Der Nonkonformismus war nur eine Erneuerungsbewegung von mehreren, der er nahestand und mit der es gedankliche Überschneidungen gab.

Dennoch kann zur Situierung Viénots in den intellektuellen Kontext seiner Zeit die Bedeutung dieser Krisen- und Emeuerungsdiskussionen, wie sie in den nonkonformistischen Zirkeln stattfanden, kaum überschätzt werden. Es ist davon auszugehen, daß Viénot sehr genau die intellektuellen Debatten im Umkreis des Nonkonformismus verfolgte, und diese auch Einfluß auf sein Denken ausübten. Neben den skizzierten inhaltlichen Übereinstimmungen gab es auch persönliche Kontakte zwischen Viénot und nonkonformistischen Intellektuellen sowie eine gegenseitige Rezeption der Ideen. So kannte er nachweislich die Artikel von Daniel-Rops und hatte gemeinsame Freunde mit diesem ${ }^{100}$. Die Nähe Viénots zum Gedankengut nonkonformistischer Intellektueller in Frankreich, aus dem sich seine ordnungspolitischen Vorstellungen nicht zuletzt gespeist haben, zeigt sich beispielhaft an seinen "Incertitudes allemandes«. Der Blickwinkel, unter dem Viénot Deutschland analysierte, spiegelt seine geistige Verankerung innerhalb der krisenbewußten jungen Intellektuellen wider. Anders als die Autoren der populären Länderstudien seiner Zeit war er gar nicht daran interessiert, sdie Deutschene in ihrem Wesen ergründen zu wollen, sondern er nahm das Land unter dem Signum der Krise und der Suche nach Erneuerung wahr. Die beiden Begriffe bezeichnen zwei Konstanten im Denken Viénots: seine Überzeugung einer umfassenden Kultur- und Zivilisationskrise angesichts des unbewältigten Modernisierungsschubs nach dem Ersten Weltkrieg und sein unablässiges Streben nach der Schaffung einer neuen, den Erfordernissen der Zeit angepaßten Ordnung. Die politische Entwicklung, die Viénot während der zwanziger Jahre durchlebte und die ihn von seinem konservativen Herkunftsmilieu weg bis hin in die Sozialistische Partei führte, wird nur vor diesem Hintergrund erklärbar und nachvollziehbar.

Die Ähnlichkeit von Viénots Überlegungen mit denen der Nonkonformisten führten auch zu einer Rezeption seiner Ideen in deren Zirkeln. So tauchen in einem der Schlüsseltexte des Nonkonformismus, "La révolution nécessaire« von Robert Aron und Arnaud Dandieu, Viénots »Incertitudes allemandes« in der Bibliographie auf ${ }^{10 !}$. Christian Roy weist in seiner Studie über Alexandre Marc darüber hinaus Verbindungen zwischen Ordre nouveau und Viénot nach. Offenbar erweckten die »Incertitudes allemandes« in dieser Gruppe ein derar-

100 Viénot an Lyautey, 27.7.1932: AN, 475 AP 311.

${ }^{101} \mathrm{Vgl}$. ARON, DANDIEU, La révolution nécessaire, S. 291. 
tiges Interesse, daß der Kontakt mit dem Autor gesucht wurde ${ }^{102}$. Die Ablösung des Individuums durch die Klasse, die Viénot als grundlegendes Symptom des Zerfalls der bürgerlichen Kultur in Deutschland beschrieben hatte, reflektierte die Hoffnungen der Nonkonformisten:

La civilisation bourgeoise ne connaît que l'individu. Celui-ci a cessé d'être, en Allemagne, le sujet de la vie collective. Le groupe, et avant tout, la classe, se sont substitués à lui. [...] L'ouvrier [...] refuse l'idéal individualiste de la morale sociale bourgeoise, et lui substitue une moralité nouvelle, à base de solidarité, qui n'est pas sans parenté, d'ailleurs, avec celle du mouvement nationaliste, au moins dans sa forme italienne ou allemande ${ }^{103}$.

Auch beim bevorzugten deutschen Ansprechpartner des Ordre nouveau, der Gruppe um die Zeitschrift Gegner, fielen die "Incertitudes allemandes" auf fruchtbaren Boden ${ }^{104}$. Der Nationalrevolutionär Harro Schulze-Boysen ${ }^{105}$, ab 1932 Schriftleiter und Herausgeber von Gegner und »der einzige wirkliche Gesprächspartner und Bündnisgenosse von O[rdre] N[ouveau] $\aleph^{106}$, zeigte sich begeistert über das Buch und wollte es selbst ins Deutsche übersetzen ${ }^{107}$. Dies übernahm dann zwar die Sekretärin von Emst Robert Curtius, Eva Mertens, doch Schulze-Boysen veröffentlichte eine Rezension in Gegner, aus der seine uneingeschränkte Zustimmung zu Viénots Befund sprach. In den Augen Schulze-Boysens beschrieb Viénot »das philosophische Wagnis Deutschland, [...] eine Angelegenheit, die ganz Europa angeht. Ein dramatischer Kampf um

${ }^{102} \mathrm{Vgl}$. ROY, Alexandre Marc, S. $280 \mathrm{f}$.

${ }^{103}$ VIÉNOT, Incertitudes allemandes, S. 58ff.

${ }^{104} \mathrm{Zu}$ den Verbindungen zwischen französischen Nonkonformisten und einzelnen Strömungen der deutschen Konservativen Revolution vgl. RoY, Alexandre Marc, S. 263-340; Jacques DROZ, Les non-conformistes des années 1930 et leurs relations avec l'Allemagne, in: Helmut BERDING u.a. (Hg.), Vom Staat des Ancien Régime zum modernen Parteienstaat. Festschrift für Theodor Schieder zu seinem 70. Geburtstag, München, Wien 1978, S. 440449, hier S. 445ff;; Hans Manfred BOCK, La crise des idéologies et l'idéologie de la crise. Les chassés-croisés idéologiques et la recherche de la »troisième voie« en France et en Allemagne, in: MERLIO, Ni gauche ni droite, S. 299-311. Zur vergleichenden Perspektive der europäischen »lost generation « vgl. Robert WOHL, The Generation of 1914, Cambridge, Massachusetts 1979.

${ }^{105}$ Harro Schulze-Boysen (1909-1942) stammte aus einem national-konservativen großbürgerlichen Elternhaus, studierte Jura und schloß sich dem Jungdeutschen Orden an. Zu Beginn der dreißiger Jahre versuchte er, nationales Bewußtsein und sozialrevolutionäre Gesinnung zusammenzubringen und setzte sich für eine "Querfront« der jungen Generation jenseits bestehender Partei-, Ideologie- und Klassengrenzen ein. Zu den Nonkonformisten unterhielt er auch nach 1933 Kontakte, v.a. zum Ordre nouveau und zu Plans. Zusammen mit Arvid Harnack wurde Schulze-Boysen zum führenden Kopf der Widerstandsgruppe Rote Kapelle. Am 22.12.1942 wurde er in Berlin-Plötzensee hingerichtet. Vgl. Alexander BAHAR, Sozialrevolutionärer Nationalismus zwischen Konservativer Revolution und Sozialismus. Harro Schulze-Boysen und der »Gegner ( - Kreis, Koblenz 1992; Hans COPPI, Harro SchulzeBoysen - Wege in den Widerstand. Eine biographische Studie, Koblenz ${ }^{2} 1995$

${ }^{106}$ KELLER, Dritte-Weg-Diskurse, S. $184 f$.

107 Vgl. RoY, Alexandre Marc, S. 280. 
neue Lebensformen! ${ }^{108} \mathrm{Daß}$ Viénot über Ordre nouveau gut unterrichtet war, ist umso wahrscheinlicher, als sein Freund Wladimir d'Ormesson im Patronagekomitee dieser Gruppe mitwirkte. Dieses existierte jedoch nur bis 1933, als d'Ormesson sich zunehmend über den revolutionären Ton von Ordre nouveau beunruhigte $^{109}$. Im selben Jahr 1933 gehörte Viénot zu den Unterzeichnern einer Protestschrift, die sich gegen die Ausweisung des exilierten Russen Alexandre Marc aus Frankreich wandte ${ }^{110}$.

Den Radikalismus der Nonkonformisten teilte Viénot zwar hinsichtlich des Ziels einer umfassenden kulturellen und politischen Erneuenung, nicht aber hinsichtlich der von ihnen propagierten revolutionären Mittel. Als die "Incertitudes allemandes" erschienen, hatte sich Viénot bereits entschlossen, den Weg des Parlamentarismus zu gehen. Da die Nonkonformisten etwa zeitgleich, zwischen 1930 und 1934, den Höhepunkt ihrer Gruppenbildung erlebten, kam es nie zu einer direkten Mitarbeit Viénots in einem ihrer Zirkel. Eine Emeuerung des Systems sollte aus seiner Sicht von innen heraus versucht werden. Mit Viénots zunehmender Akzeptanz der parlamentarischen Demokratie schwanden auch die Berührungspunkte mit dem Nonkonformismus. Er teilte zwar auch zu späterer Zeit noch die Hoffnung der Nonkonformisten auf eine neue politische Ordnung, doch war diese Übereinstimmung nunmehr so oberflächlich, daß zu den Hochzeiten der nonkonformistischen Aktivitäten Viénot sich von dem teilweisen inhaltlichen Konsens der zwanziger Jahre schon wieder entfernt hatte. Die Thematik von Kulturkrise und Erneuerung wurde nämlich - wie in den Eingangsüberlegungen zu diesem Kapitel gezeigt ${ }^{111}$ - innerhalb eines breiteren Spektrums von Intellektuellen diskutiert als in den begrenzten Zirkeln der Nonkonformisten.

\subsection{Die Krise der linken Parteien und Reformansätze der Jugend}

Auch innerhalb der bestehenden Parteien gab es ab Ende der zwanziger Jahre Bestrebungen, auf den Modernisierungsschub und die damit einhergehenden Probleme zu reagieren ${ }^{112}$. Seit $1927 / 28$ traten innerhalb der Radikalsozialisti-

${ }^{108}$ Harro SCHULZE-BOYSEN, Ungewisses Deutschland, von Pierre Viénot, in: Gegner, 15.1.1932, S. 29.

${ }^{109}$ Vgl. RoY, Alexandre Marc, S. 196.

${ }^{110}$ Vgl. ibid. S. 136.

111 Vgl. Kap. IV.1.1

${ }^{112}$ In seiner Untersuchung grenzt Loubet del Bayle die Bewegung der Nonkonformisten von jenen Erneuerungstendenzen der Jugend ab, die sich innerhalb der existierenden Parteien oder bereits bestehender ideologischer Strömungen vollzog. Bewegungen wie die Jeunes-Turcs, die Jeunes Communistes oder die Néo-Socialistes trugen in seinen Augen zwar zum »Geist der dreißiger Jahre" bei, waren aber nicht dem Nonkonformismus zuzurechnen. Dagegen stellt Jean-François Sirinelli die Frage, ob nicht sowohl Touchard als auch Loubet del Bayle in ihren Studien einen verengten Blickwinkel an den Tag gelegt hätten. Im Gegensatz zu ihnen zählt Sirinelli sowohl die Jeunes-Tures als auch Révolution constructive, eine Gruppe innerhalb der SFIO, zu derselben Tendenz politischer Emeuerung wie die Nonkonformisten 
schen Partei eine Gruppe junger Pariser Intellektueller auf, die sich Jeunes Radicaux oder Jeunes-Turcs nannten ${ }^{113}$. Die Jeunes-Turcs waren eine Gruppierung der Nachkriegsgeneration innerhalb des Parti radical, der es vor allem um eine doktrinäre Reformierung ihrer Partei ging, um eine Anpassung an die Nachkriegszeit. Die Radikalsozialistische Partei verkörperte wie keine andere das laizistisch-parlamentarische System der Dritten Republik. Da ihre Doktrin aber auf das agrarische, von sozialer Stabilität geprägte Frankreich des 19. Jahrhunderts rekurrierte, erschien sie der Jugend nicht mehr adäquat angesichts der Herausforderungen der Nachkriegszeit. Zudem hatte eine langjährige Regierungsbeteiligung zu einem ideologischen Verschleiß geführt, so daß die Partei zunehmend konzeptionslos und opportunistisch erschien. »En révolte contre la gérontocratie $"{ }^{114}$ forderten die Jeunes-Turcs daher eine personelle und ideelle Erneuerung. Sie sammelten sich um die Zeitschriften La Voix und La République $^{115}$, und zu ihren Wortführern zählten Bertrand de Jouvenel, Jean Mistler, Pierre Cot, Jean Zay und der Journalist Jacques Kayser, mit dem Viénot seit Beginn der dreißiger Jahre befreundet war $^{16}$. Zay, der wie Pierre Cot später zusammen mit Viénot der Volksfrontregierung angehören sollte, betonte an erster Stelle »la lutte des générations«, eine Auseinandersetzung, die er als bedeutender ansah als den Klassenkampf ${ }^{417}$. Bei allen Nuancierungen ihrer Ansichten stimmten die Jeunes-Turcs in einer Reform des Staates überein, der eine Stärkung der Exekutive sowie eine Einbeziehung sozio-ökonomischer Kräfte in die Repräsentativorgane vorsah. Darüber hinaus befürworteten sie die Leitung oder zumindest die Kontrolle des Staates über die Wirtschaft und, in internationaler Hinsicht, eine föderative Organisation Europas um die Achse Deutschland-Frankreich. Auch bei diesen Überlegungen zeigen sich Überschnei-

im engeren Sinne. Auch sie haben in seinen Augen einen konstitutiven Beitrag zum "Geist der dreißiger Jahre» geleistet. Vgl. LOUBET DEL BAYLE, Les non-conformistes, S. 31; SRINELLI, Génération intellectuelle, S. 394-396; DERS., Note sur Révolution constructive: des »non conformistes « des années vingt?, in: Bulletin du Centre d'Histoire de la France contemporaine 6 (1985) S. 69-73.

${ }^{113}$ Vgl. Serge BERSTEIN, Histoire du Parti radical, Bd. 2, Crise du radicalisme, 1926-1939, Paris 1982, S. 94-125.

${ }^{114}$ P.-E. DECHARME, Les jeunes radicaux ont précisé hier soir leur position, in: L'Appel, 15.12 .1933

115 Diese wurden von Émile Roche gegründet, der zusammen mit Jean Luchaire auch Notre Temps herausgab. Vgl. BELLANGER, Histoire générale de la presse, S. 563f.

${ }^{116}$ Das erste Treffen zwischen Kayser, dem »jeune radical en vue $\ll$, und den Viénots fand im Januar 1931 statt. Vgl. Andrée Mayrisch an ihre Mutter, 13.1.1931: NL Viénot. Der Diplomat Armand Bérard berichtet, daß Viénot in seiner Zeit als Unterstaatssekretär im Außenministerium nahezu täglich Besuch von zwei befreundeten Journalisten erhielt, nämlich von Jacques Kayser und Georges Boris, dem Direktor von La Lumière. Vgl. Armand BÉRARD, Un ambassadeur se souvient. Au temps du danger allemand, Paris 1976, S. 325. Zu Kayser siehe Aurélien BOUET, Jacques Kayser (1900-1963): Un radical de gauche, in: RHMC 43 (1996) Nr. 1, S. 119-136.

117 Alfred FABRE-LuCE, Ce que pensent les jeunes radicaux, in: Pamphlet, 22.12.1933. 
dungen mit den Gedanken Viénots. Dieser sprach sich von den zwanziger bis in die dreißiger Jahre für eine Reformierung des Staates aus, welche der Regierung mehr Autorität verschaffen sollte ${ }^{118}$. Auch staatlichen Eingriffen in die Wirtschaft stand er - wie bereits erwähnt - nicht ablehnend gegenüber, und die deutsch-französische Schlüsselstellung für Europa erkannte auch Viénot, wenngleich er sich zur künftigen Gestaltung des Kontinents nicht konkret äußerte. Anders als die Neo-Sozialisten um Marcel Déat wurden die Jungtürken nicht aus ihrer Mutterpartei ausgeschlossen. Im Gegenteil: Édouard Herriot versuchte, sie in die Leitungsgremien der Partei aufzunehmen, ohne ihre Ideen zum offiziellen Wahlprogramm zu erheben. Ein Teil der JeunesTurcs, darunter Kayser, Zay, Cot und Mendès France setzte sich seit dem Herbst 1934 zusammen mit Édouard Daladier für eine Sammlung der linken Kräfte in der Volksfront ein, die auch von Viénot leidenschaftlich unterstützt wurde ${ }^{119}$.

Auch in der Sozialistischen Partei machten sich in der Zwischenkriegszeit Krisensymptome bemerkbar. Seit ihrer Gründung 1905 bekannte sie sich zur marxistischen Revolutionstheorie, hatte aber unter Jean Jaurès zu einer reformatorischen parlamentarischen Praxis gefunden. 1924 und 1932 ging sie Wahlbündnisse mit den Radikalsozialisten ein, verweigerte sich dann jedoch einer Regierungsbeteiligung. Diese Widersprüche riefen eine Gegenbewegung junger Sozialisten hervor, die der diagnostizierten doktrinären Sklerose abhelfen wollten. In der Tat beschränkte sich die SFIO in dieser Zeit vor allem auf Neueditionen der Werke von Jules Guesde und Jean Jaurès, blieb aber die theoretische Auseinandersetzung mit neuen Phänomenen wie der Massenproduktion und dem Massenkonsum, dem italienischen Faschismus oder der sowjetischen Planwirtschaft schuldig ${ }^{120} .1930$ veröffentlichte Marcel Déat, der als möglicher `Thronfolger، Léon Blums galt ${ }^{121}$, sein Buch "Perspectives socialistes«, in dem er eine Revision der marxistischen Doktrin forderte. Déat verlangte unter anderem das Eintreten der SFIO nicht nur für das Proletariat, sondern auch für die von den Folgen des Kapitalismus ebenfalls betroffene Mittelklasse sowie die Trennung von Kapitalismus und Staat, um auf diese Weise die Kontrolle des Staates über die Wirtschaft sicherzustellen. Der staatliche Eingriff in die Wirtschaft war, so zeigt sich, eine Standardforderung der erneuerungswilligen intellektuellen Jugend. Er war populär nicht nur bei den Nonkonformisten, sondern auch in den reformorientierten Kreisen der etablierten linken Parteien. Daher ist es nicht verwunderlich daß Viénot, der mit Vertretern verschiedener reformorientierter Gruppierungen, mit Nonkonformisten, mit Jeunes-Turcs

${ }^{118}$ Vgl. Pierre VGínOT, Sont-ils fous?, in: Le Narrateur, 10.3.1934; DERS., La République et ceux qui la soutiennent, in: Le Narrateur, 11.5.1935.

${ }^{119}$ Vgl. DERS., Rassemblement républicain, in: Le Narrateur, 6.7.1935; DERS., Le 14 juillet, in: Le Narrateur, 20.7.1935; DERS., Pour une politique constructive, in: Le Narrateur, 7.9.1935.

${ }^{120} \mathrm{Vgl}$. BERSTEIN, La France des années 30, S. 83.

121 Vgl. Georges LEFRANC, Les gauches, S. 215. 
und mit Neosozialisten Kontakt hatte ${ }^{122}$, diese Forderung übernahm. Die Annahme der Reformfähigkeit des Kapitalismus und die Abkehr vom Klassenkampf bedeuteten mithin eine Abwendung vom historischen Materialismus ${ }^{123}$. Die Thesen Déats und seiner Anhänger wurden daher als unvereinbar mit den doktrinären Grundlagen der SFIO angesehen, so daß 1933 der Ausschluß der Neo-Sozialisten aus der Partei erfolgte.

Die Krise der SFIO war dennoch nicht beendet, denn eine andere Gruppe formierte sich in ihren Reihen, die sich Révolution constructive nannte und die Kritik der Ausgeschlossenen an der doktrinären Sklerose der Partei teilte ${ }^{124}$. 1932 erschien ein Buch mit dem programmatischen Titel »Révolution constructive«, welches das Manifest der gleichnamigen Gruppe junger Intellektueller darstellte ${ }^{125}$. Diese hatten sich bereits in den zwanziger Jahren während des Studiums an der École normale supérieure kennengelernt, so daß der Ursprung der Bewegung vor den dreißiger Jahren anzusetzen ist ${ }^{126}$. Stéphane Clouet bescheinigt den Mitgliedern von Révolution constructive ein mit den Nonkonformisten vergleichbares Generations- und Krisenbewußtsein sowie das Streben nach Erneuerung:

'Révolution constructiver ne se contente pas de raisonner négativement, contre la guerre, les partis, le Parlement, le fascisme, le national-socialisme, le bolchévisme, l'étatisme. Elle veut fonder une société et une culture - donc des valeurs sociales - nouvelles ${ }^{127}$.

$\mathrm{Zu}$ den zeitweiligen Mitgliedern der Révolution constructive zählten auch der Journalist Pierre Brossolette, der später als Widerstandskämpfer Berühmtheit erlangen sollte ${ }^{128}$, sowie der Parlamentarier André Philip ${ }^{129}$, der sich ebenfalls

${ }^{122} \mathrm{Vgl}$. d'Ormesson, Pierre Viènot, S. 109: NL d'Ormesson II.

${ }^{123}$ Déats Buch fand innerhalb der SFIO kaum Resonanz, fuihrte jedoch zum Bruch mit Léon Blum. Vgl. Marcel DÉAT, Perspectives socialistes, Paris 1930; BRENDER, Kollaboration in Frankreich, S. 23-55; BERGOUNIOUX, Le néo-socialisme.

${ }^{124}$ Stéphane Clouet, der die einzige Monographie zu Révolution constructive verfaßt hat, geht von »similitudes frappantes avec celle [la conception] de Marcel Déat« aus. Vgl. CLOUET, De la rénovation à l'utopie socialiste, S. 75. KELLER, Dritte-Weg-Diskurse, S. 126f., führt diese Ähnlichkeit auf die sowohl bei Déat wie bei Révolution constructive erfolgte de ManRezeption zurück.

${ }^{125} \mathrm{Zu}$ den elf Gründungsmitgliedern gehörten Pierre Boivin, Suzanne Boully, Maurice Deixonne, Jacques Godard, Max Grignon, Jean Itard, Ignace Cohen, Emilie Lamare, Georges Lefranc, Claude Lévi-Strauss und Robert Marjolin.

${ }^{126}$ Dies betont v.a. SIRNELLL, Génération intellectuelle, S. 394.

${ }^{127}$ CLOUET, De la rénovation à l'utopie socialiste, S. 17.

${ }^{128}$ Der Sozialist Pierre Brossolette (1903-1944) traf 1942 in London ein und schloß sich de Gaulle an. Er unternahm für das Bureau central de Renseignements et d'Action unter Colonel Passy mehrere Verbindungsmissionen zur inneren Résistance in Frankreich. Bei seiner letzten Mission wurde er von der Gestapo verhaftet und verübte am 22. Mărz 1944 Suizid, um keine Informationen preiszugeben. Vgl. Guillaume PIKETTY, Pierre Brossolette. Un héros de la Résistance, Paris 1998; Guy PERRIER, Pierre Brossolette. Le visionnaire de la Résistance, Paris 1997. 
nach 1940 an der Seite de Gaulles fand. Einen der bestimmenden ideologischen Einflüsse stellte dabei der »planisme« Hendrik de Mans dar, der 1933 im Auftrag der belgischen Arbeiterpartei den »Plan de travail« verfaßt hatte ${ }^{130}$. Der „Plan der Arbeit« sollte die Möglichkeiten sozialistischer Politik angesichts der Krise ausloten, und sein Hauptaugenmerk galt der Bekämpfung der Arbeitslosigkeit. De Man schlug eine »économie mixte ${ }^{131}$ zur Eindämmung der gegenwärtigen Wirtschaftskrise vor, in der die Wirtschaft in drei Sektoren unterteilt werden sollte: zum ersten einen nationalisierten öffentlichen Sektor, der jene Wirtschaftszweige umfaßte, die von öffentlichem Interesse waren, zum zweiten einen staatlich kontrollierten Sektor der großen, in Kartellen zusammengefaßten Unternehmen und zum dritten einen freien Sektor, der die kleinen Unternehmen einschloß. Der Planismus verstand sich dabei als soziale Doktrin, die als »intermédiaire entre l'économie capitaliste et l'économie socialiste ${ }^{132}$ den gesuchten Dritten Weg zwischen beiden Optionen darstellen sollte. Dabei verstand de Man den Planismus als eine revolutionäre Maßnahme:

Et c'est peut-être ce qu'il y a de plus révolutionnaire dans le planisme que cette idée d'un engagement immédiat visant à une réalisation immédiate; la volonté d'un ordre nouveau qui soit un ordre concret et saisissable, la volonté aussi d'orienter l'action politique non point sur ce que l'on veut conserver, c'est-à-dire sur ce que l'on voit derrière soi, mais sur ce que l'on veut conquérir, sur ce que l'on voit devant soi ${ }^{133}$.

Trotz ihrer Gemeinsamkeiten mit den Neosozialisten ${ }^{134}$ und ihrer Forderung nach einer Revision der sozialistischen Strategie, verblieben die Mitglieder der

${ }^{129}$ Im Juli 1942 verließ André Philip (1902-1970) Frankreich, um sich in London de Gaulle anzuschließen. Im Comité français de la Libération nationale wurde er zum Kommissar des Inneren ernannt. Vgl. YVERT, Dictionnaire des Ministres, S. 719f.

${ }^{130}$ Zu Henri de Man vgl. Peter DODGE, Beyond Marxism. The Faith and Works of Hendrik de Man, The Hague 1966; Michel BRÉLAZ, Henri de Man. Une autre idée du socialisme, Genève 1985; Kersten OsCHMANN, Über Hendrik de Man: Marxismus, Plansozialismus und Kollaboration. Ein Grenzgänger in der Zwischenkriegszeit, Diss. Freiburg 1987; Thomas KELLER, Der Planismus von Hendrik de Man. Ein deutsch-belgisch-französischer Austauschdiskurs, in: Michel GRUNEWALD (Hg.), Le milieu intellectuel de gauche en Allemagne, sa presse et ses réseaux (1890-1960), Bern 2002 (Convergences, 24), S. 391-421.

${ }^{131}$ Der Ruf nach einer "économie mixte« oder »économie dirigée« zur Linderung der Wirtschaftskrise war in den dreißiger Jahren recht populär und ging of mit der Forderung nach Stärkung der Exekutive einher. Notre Temps brachte 1932 ein Sonderheft zu diesem Thema heraus. Vgl. Économie dirigée 1932, in: Notre Temps, 7./14.8.1932. Siehe auch Bertrand de JOUVENEL, Économie dirigée, Paris 1927; André PHILIP, La crise et l'économie dirigée, Paris 1935.

${ }^{132}$ Henri de MAN, Le Socialisme devant la crise, Le Mans o. J. (Cahiers de Révolution constructive, 8), S. 11.

${ }^{133}$ Ibid. S. 19.

${ }^{134}$ So trat Révolution constructive auch für die Interessen der Mittelklasse ein, die wie die Arbeiter in Opposition zum Kapitalismus stünden. Auf der anderen Seite interessierten sich die Neosozialisten auch für den Planismus als möglichen Weg aus der Krise. Obwohl die Neosozialisten als erste den belgischen "Plan der Arbeit» in Frankreich bekannt machten, 
Révolution constructive innerhalb der SFIO; die programmatischen Grundlagen der Sozialistischen Partei wurden von ihnen nicht grundlegend abgelehnt ${ }^{135}$. Obwohl die Gruppe bis zum Ende der Zwischenkriegszeit existierte, brach laut Georges Lefranc der 6. Februar 1934 ihre Wirksamkeit innerhalb der SFIO ${ }^{136}$. Dennoch entfalteten ihre planwirtschaftlichen Überlegungen gerade seit Mitte der dreißiger Jahre einen großen Einfluß. Vor allem die Gewerkschaften CGT und CFTC machten sich diese Gedanken zu eigen und verfaßten 1934/35 selbst Pläne zur Wirtschaftslenkung. Gerade die CGT wollte den Planismus von der Volksfront übernommen sehen, was jedoch am vereinten Widerstand von Radikalsozialisten, Kommunisten und von Léon Blum scheiterte. Interessanterweise fanden planwirtschaftliche Elemente dann aber doch ihren Einzug in die zweite Regierung Blum im März 1938. Über Persönlichkeiten wie etwa Jules Moch, der vom Planismus ebenso geprägt war wie André Philip, beeinflußten sie die Sozialistische Partei auch darüber hinaus ${ }^{137}$.

Stärker als vom Nonkonformismus, von den Jungtürken oder den Neosozialisten waren Andrée und Pierre Viénot von den Ideen der Révolution constructive und insbesondere vom Planismus beeinflußt. Andrée Viénot war selbst Mitglied von Révolution constructive und galt als erklärte Anhängerin Hendrik de Mans ${ }^{138}$. Sie war bereits zu Beginn der dreißiger Jahre in die SFIO eingetreten und hatte sich dem Planismus angeschlossen. Etwa zur selben Zeit, als Viénot Andrée Mayrisch heiratete, schrieb er an Jean-Richard Bloch, er erwarte sich viel von der Anwesenheit de Mans bei den Dekaden von Pontigny ${ }^{139}$. Zweifellos übte die überzeugte Sozialistin Andrée Mayrisch auf Pierre Viénot

erschien er in Frankreich im Organ der Révolution constructive: Henri de MAN, Pour un plan d'action, Le Mans o. J. (Cahiers de Révolution constructive, 1).

${ }^{135}$ So erklärte Révolution constructive: "Du socialisme, nous acceptons tous les principes tels qu'il sont formulés dans la charte du parti. Mais nous ne prenons à notre compte, sans bénéfice d'examen, aucune des méthodes traditionnellement suivies«. Le groupe de Révolution constructive, Notre position. Après Toulouse, in: Revolution constructive. Organe mensuel du Groupe de Révolution constructive (Parti socialiste S.F.I.O.), Juillet 1934.

${ }^{136} \mathrm{Vgl}$. LEFRANC, Les gauches en France, S. 215.

${ }^{137} \mathrm{Vgl}$. zum Einfluß der Planismus-Ideen Jacques AMOYAL, Les origines socialistes et syndicalistes de la planification en France, in: Le Mouvement social 87 (1974) S. 137-169; JeanFrançois BIARD, Le débat sur le régime intermédiaire et le plan (juillet 1933-juillet 1934), in: Cahiers Léon Blum 15/16 (1984) S. 17-46; DERS., Le socialisme devant ses choix. La naissance de l'idée du plan, Paris 1985; BIIS, Socialistes, S. 116; BERGOUNIOUX, GRUNBERG, Le long remords du pouvoir, S. $122 \mathrm{ff}$.

${ }^{138}$ Die Mitgliedschaft Andrée Viénots bei Révolution constructive geht aus einem Mitgliederverzeichnis Georges Lefrancs hervor, abgedruckt bei CLOUET, De la rénovation à l'utopie socialiste, S. 142. Weitere Hinweise auf ihre Aktivität innerhalb der Gruppe konnten jedoch nicht ermittelt werden, zumal die Zeitschrift Révolution constructive nur sehr schwer und bruchstückhaft aufzufinden ist. 1934 berichtet Andrée Viénot von einem Artikel, den sie für Révolution constructive schreiben will. Vgl. Andrée Viénot an ihre Mutter, 30.11.1934: NL Viénot.

${ }^{139}$ Viénot an Jean-Richard Bloch, 26.9.1929: BN, Papiers Bloch, XLVII, Lettres adressées à Jean-Richard Bloch. 
im Hinblick auf seine politische Gedankenbildung einen bedeutenden Einfluß aus, und vermutlich war sie es, die Viénot auf die Ideen de Mans aufmerksam machte. Auch Viénot sah in der Folgezeit in den Vorschlägen de Mans einen konstruktiven Ansatz, die anstehenden wirtschaftlichen Probleme zu lösen. Seine Überlegungen zur staatlichen Lenkung der Wirtschaft beziehen sich explizit auf de Mans »Plan de travail«, dessen Ideen er in dieser Hinsicht übernahm: "Je crois qu'il faut chercher une solution voisine de celle indiquée par le plan de travail élaboré par Henri de Man pour le Parti Ouvrier Belge, une sconception pluraliste de la socialisation « $^{140}$. Viénot führte konkret de Mans Pläne zur Unterteilung der Wirtschaft in drei Sektoren mit unterschiedlichen Graden des staatlichen Eingriffs an. Zu Beginn der dreißiger Jahre, nachdem das Ehepaar Viénot Berlin verlassen und eine Wohnung in Paris bezogen hatte, stand es in engem Kontakt $\mathrm{zu}$ den Vertretern einer reformorientierten Linken. Wladimir d'Ormesson, der als einer der seltenen Vertreter der konservativen Rechten zu den regelmäßigen Gästen gehörte, beschreibt die Treffen im Hause Viénot als sehr interessant: „On y rencontrait la fleur des pois des Jeunes Turcs` de la gauche française [...]! Car je me rapelle avoir coudoyé simultanément Marcel Déat et Pierre Cot, Spinasse et Monnet, Bergery et Georges Boris « ${ }^{141}$. Der Kontakt Viénots mit den Vertretern dieser linken Reformgruppierungen und deren Wortführern war offenbar derartig eng, daß er in der Forschung fälschlicherweise selbst den "youthful and prodigiously talented Radicals $\aleph^{142}$ zugerechnet wurde. Der Radikalsozialistischen Partei gehörte er jedoch, trotz seiner engen Freundschaft zum Wortführer der Jeunes-Turcs, Jacques Kayser, niemals an. Die Tatsache, daß Viénot in der Literatur sowohl zu den Nonkonformisten als auch zu den Jungtürken gezählt wird, macht deutlich, daß er mit jeder der beiden Bewegungen Berührungspunkte hatte und mit Teilen von deren Forderungen übereinstimmte. Bei genauerem Hinsehen zeigt sich jedoch, daß Viénot keines der Programme der angesprochenen Erneuerungsbewegungen gänzlich übernahm. Vielmehr suchte er bei allen Bewegungen, die sich mit dem Thema von Krise und Erneuerung beschäftigten, Anregungen, um schließlich eine eigene Antwort auf die drängenden Fragen der Zeit zu finden wie etwa auf die der Stellung des Individuums in der modernen Gesellschaft. Nicht zuletzt diente die Auseinandersetzung mit den reformorientierten jungen Intellektuellen auch dazu, selbst Klarheit über den eigenen politischen Standpunkt zu erlangen, ein Prozeß, der erst zu Beginn der dreißiger Jahre abgeschlossen werden sollte. Im Laufe seiner Suche kam Viénot dabei

${ }^{140}$ Pierre VIÉNOT, Enquête sur le rajeunissement de la France, S. 561.

${ }^{141}$ D'Ormesson, Pierre Viénot, S. 109: NL d'Ormesson II.

${ }^{142}$ Martin S. ALEXANDER, A bas les marchands de canons! Efforts to control the private manufacture and trade in arms in France during the 1930s, in: VAlsse, Le pacifisme en Europe, S. 285-302, hier S. 292. 
auch mit einer anderen Bewegung in Berührung, die sich als revolutionäres Modell anbot, die bestehende Ordnung zu überwinden, dem Faschismus.

\subsection{Zwischen Nonkonformismus und Faschismus}

»Je suis peut-être un peu plus ,fasciste< que vous«, so gab Pierre Viénot 1925 seinem Freund Max Clauss zu verstehen, wmais pour mon pays en non in abstracto ${ }^{143}$. Während Viénots Heidelberg-Aufenthalt diskutierten die beiden unter anderem über Begriffe wie Demokratie, Führertum und Volksgemeinschaft sowie über die Neuerscheinungen »La victoire« von Alfred FabreLuce und Oswald Spenglers »Untergang des Abendlandes ${ }^{144}$. Bedeutete das Bekenntnis zum Faschismus im eigenen Land aber tatsächlich eine Zustimmung zu jener Ideologie, die kurze Zeit vorher in Italien an die Macht gelangt war? Im Sommer 1924 hatte sich Viénot mehrere Wochen in Florenz aufgehalten, um die italienische Sprache für die geplante diplomatische Eingangsprüfung zu erlernen. Dabei beobachtete er auch sehr genau die politischen Vorgänge in seinem Gastland, und zwar »attentivement et sans parti pris « ${ }^{145}$. In den Augen Viénots habe die kurz vor seiner Ankunft erfolgte Ermordung des sozialistischen Abgeordneten Giacomo Matteotti die essentiellen Fehler des Regimes enthüllt: "Un parti ne peut pas être national; il peut usurper l'usage de la force, se substituer à l'état: il reste un parti. Voilà ce que fait apparaître la crise actuelle « ${ }^{146}$. Für Viénot verwirklichte Italien im Augenblick die tyrannische Herrschaft von Machiavellis »Principe«, gestützt auf die $\mathrm{Zu}$ stimmung der Masse ${ }^{147}$. Das Recht des »Tyrannen« nahm also Bezug auf das demokratische Prinzip. Doch genau darin lag nach Meinung des französischen Beobachters der Widerspruch und die Schwäche des Regimes: „On exige de lui [du peuple] que, par son consentement, il donne à un parti la possibilité de garder un pouvoir fondé par ailleurs sur le mépris même de ce consente-

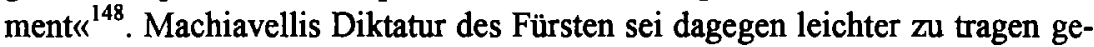
wesen, denn sie habe vom einzelnen nicht den aktiven Willensakt der politischen Verzichtleistung gefordert. Viénots Diagnose für die Zukunft des faschistischen Regimes in Italien war pessimistisch. Seiner Meinung nach habe es kein einziges Problem zu lösen vermocht. Italien befinde sich im latenten Bürgerkriegszustand; unter der vermeintlichen Ordnung, die repressiv aufrecht erhalten werde, herrsche ein fundamentales moralisches Chaos ${ }^{149}$. Das Prinzip

\footnotetext{
${ }^{143}$ Viénot an Clauss, 28.2.1925, zit. nach MULlER, Der Publizist Max Clauss, S. 380.

${ }^{144} \mathrm{Vgl}$. ibid.

${ }^{145}$ Viénot an Lyautey, 1.7.1924: AN, 475 AP 311.

${ }^{146}$ Ibid.

${ }^{147}$ Viénot bezeichnete dies als vtyrannie consentie $\ll$. Ibid.

148 Ibid.

${ }^{149}$ Ders. an dens., 1.8.1924: AN, 475 AP 311.
} 
des "consentement«, auf das Mussolini rekurriere, könnte sich eines Tages gegen ihn wenden. Der Faschismus, so Viénots Fazit, könne die Hoffnungen auf eine neue Ordnung nicht erfillen:

Le fascisme a prétendu créer un ordre nouveau; il a espéré faire sortir du désordre de son emploi de la violence, un ordre à lui et assurer l'état sur un nouveau fondement. Il n'y a pas réussi; il reste un désordre organisé, un désordre gouvernant ${ }^{150}$.

Bei der Argumentation Viénots fällt auf, daß er den Faschismus nicht etwa deswegen kritisierte, weil er antidemokratisch oder antiliberal war, sondern hauptsächlich wegen der von ihm angewandten Gewalt und der gleichzeitigen Unfähigkeit, eine effektive Ordnung herzustellen. Ordnung und Unordnung waren die Schlüsselwörter, nach denen das italienische Regime beurteilt wurde. Die Analyse der italienischen Verhältnisse stand also unter dem Eindruck der eigenen Suche nach einer »neuen Ordnung" für Frankreich. Der Faschismus, wie er sich in Italien darbot, konnte jedoch Viénots Meinung nach nicht als Vorbild dienen. Dessen Ablehnung machte ihn gleichwohl noch lange nicht zum Demokraten. Denn gerade in dem Rekurs Mussolinis auf die Massen, in dem Versuch der Massenmobilisierung und -beeinflussung sah Viénot das demokratische Prinzip am Walten, und dies war ihm im Grunde suspekt. Das bereits 1895 von Gustave le Bon diagnostizierte Zeitalter der Massen ${ }^{151}$ war in den Augen Viénots vor allem gekennzeichnet durch deren Unberechenbarkeit und mangelnde politische Reife. Er sah darin eine potentielle Gefahr für jene neue Ordnung, die den Staat stabil und effizient gestalten sollte. In gewisser Weise ging demnach die Skepsis gegenüber der Demokratie mit der Skepsis gegenüber dem Faschismus Hand in Hand.

Wenn Viénot sich nun mit Blick auf Frankreich als Faschist bezeichnete, so stellt dies kein Bekenntnis zur faschistischen Ideologie dar. Kurze Zeit vorher hatte er noch mit dem Gedanken einer monarchischen Restauration gespielt und einige Jahre später wollte er partout wweder rechts noch links« sein. Das italienische Experiment betrachtete er als gescheitert, da es das Chaos im Land nicht habe beseitigen können. Welche Bedeutung legt er also in das Wort Faschismus? Die Antwort darauf bleibt er schuldig, aber aus seinen Äußerungen läßt sich schließen, daß Viénot in erster Linie eine Stärkung der Exekutive, eine effiziente Staatsführung und die Eindămmung einer ausufernden Parlamentsherrschaft anstrebte. Es läßt sich darüber hinaus nicht leugnen, daß Viénot in den zwanziger Jahren antidemokratische und antiparlamentarische Züge an den Tag legte. Wenn er jedoch diese Ansichten als faschistisch bezeichnet, dann wird er dem neuartigen politischen Phänomen nicht gerecht und benutzt den Begriff nur als Worthulse. Viénot befürwortete weder ausgeprägt nationalistisches oder gar rassistisches Gedankengut, ein ausgesprochener Antimarxis-

${ }^{150}$ Ders. an dens., 1.7.1924: AN, 475 AP 311.

${ }^{151}$ Gustave le BON, La psychologie des foules, Paris 1895. Das Buch erschien unter dem deutschen Titel: Psychologie der Massen, Stuttgart 1908. 
mus ist bei ihm nicht festzustellen, die Massenmanipulation lehnte er aus tiefstem Herzen ab, eine Bejahung von Kollektivorganisationen verhinderte Viénots ausgeprägter Individualismus, die in Italien proklamierte Einheit von Staat und Partei vermochte ihn nicht zu überzeugen, und eine gewaltverherrlichende Neigung besaß er nie ${ }^{152}$. Da Viénot das Neue, modern Erscheinende begeisterte und er sich in den zwanziger Jahren auch in diversen Kreisen bewegte, die sich der politischen Erneuerung verschrieben hatten, liegt die Vermutung nahe, daß in diesem Zusammenhang der Faschismus für ihn eine Bewegung von mehreren darstellte, die eine revolutionäre Überwindung der bestehenden Ordnung postulierte und ein neues politisches und gesellschaftliches Modell, in gewisser Weise auch einen Dritten Weg anbot. Viénots antiparlamentarisches und antidemokratisches Gedankengut erscheint jedoch eher durch sein Herkunftsmilieu bestimmt, das heißt in traditionell konservativen Bahnen verlaufend, als daß es Ausdruck jener »revolutionären Rechten« wäre, deren Entstehung der israelische Historiker Zeev Sternhell Ende des 19. Jahrhunderts ansetzt und der er präfaschistischen Charakter bescheinigt ${ }^{153}$.

Doch gerade die auch von Viénot unterstützte Suche nach einem Dritten Weg zwischen Liberalismus und Sozialismus wird von Sternhell als Ausdruck der faschistischen Ideologie gewertet. Mit seiner 1983 veröffentlichten Studie »Ni droite ni gauche ${ }^{154}$, in der er seine Thesen zur Entstehung der faschistischen Ideologie darlegte, erregte Sternhell großes Aufsehen in Frankreich. Er kommt in seiner ideengeschichtlich angelegten Analyse zu dem Schluß, daß die faschistische Ideologie gerade dort, wo sie weder an die Macht gelangte noch sich einer überwiegenden Anhängerschaft erfreuen konnte, am

${ }^{152}$ Eine ausfuihrliche Darlegung der faschistischen Ideologie sowie der Kontroversen um Definition und Interpretation des Faschismus kann an dieser Stelle nicht geleistet werden. Es sei verwiesen auf Stanley G. PAYNE, Fascism. Comparison and Definition, Madison 1980; DERS., A History of Fascism 1914-1945, London 1995; Roger GRIFFIN, The Nature of Fascism, London 1991; Karl Dietrich BRACHER, Kritische Betrachtungen zum Faschismusbegriff, in: DERS. (Hg), Zeitgeschichtliche Kontroversen. Um Faschismus, Totalitarismus, Demokratie, München 1976, S. 13-32; Emst NOLTE, Der Faschismus in seiner Epoche. Action francaise, italienischer Faschismus, Nationalsozialismus, München 1963; Wolfgang WIPPERMANN, Europäischer Faschismus im Vergleich (1922-1982), Frankfurt a.M. 1983; DERS., Faschismustheorien. Die Entwicklung der Diskussion von den Anfangen bis heute, Darmstadt ${ }^{7} 1997$ (Erträge der Forschung, 17); HILDEBRAND, Das Dritte Reich, S. 138-149.

${ }^{153}$ Mit der wdroite révolutionnaire« bezeichnete Sternhell die Vertreter eines neuartigen Nationalismus, zu denen er Maurice Barrès, Charles Maurras, Paul Déroulède und Edouard Drumont zählte. Seiner Meinung nach richteten diese eine Revolte gegen den Geist der Französischen Revolution. Gegen den traditionell jakobinischen Nationalismus habe Barrès die Ideologie »de la terre et des morts « gestellt. Der neue Nationalismus verneine den Willen des einzelnen Individuums zugunsten der Bedürfnisse der Gemeinschaft, der er Wahrheit Justiz und Recht unterordne. Er sei stark antirationalistisch und antiintellektuell gefärbt und von den Ideen des Sozialdarwinismus beeinflußt. Vgl. Zeev STERNHELI, La droite révolutionnaire (1885-1914). Les origines françaises du fascisme, Paris 1978.

${ }^{154}$ DERS., Ni droite ni gauche. L'idéologie fasciste en France, Paris 1983. 
frühesten und in ihrer reinsten Form zutage trat, nämlich in Frankreich. Seiner Meinung nach habe die gleichzeitige Krise von Liberalismus und marxistischem Sozialismus zur Entstehung neuer Bewegungen gefuihrt: auf der Rechten ein revolutionärer Nationalismus à la Maurice Barrès, der den Kult der Gewalt, der »terre et des morts « und des Irrationalen pflege, sowie auf der Linken eine Revision des Marxismus, wie sie im revolutionären Syndikalismus von Georges Sorel (Revision von links) oder im Planismus beziehungsweise Neosozialismus von de Man und Déat (Revision von rechts) zum Ausdruck gekommen sei. Dieser revidierte Sozialismus sei antimaterialistisch und antirationalistisch zugleich gewesen, er habe sowohl die Demokratie als auch das Proletariat hinter sich gelassen. In seiner Verbindung mit dem revolutionären Nationalismus sei dann bereits zur Jahrhundertwende eine »synthèse fasciste" entstanden als Revolte gegen Liberalismus, Demokratie, Rationalismus und den philosophischen Materialismus mit dem Ziel, die neu entstandenen städtischen und proletarischen Massen in die nationale Gemeinschaft zu integrie$\operatorname{ren}^{155}$. Vor allem jene Sozialisten, die eine Revision des Marxismus propagierten, während sie gleichzeitig die liberale Demokratie attackierten, trugen in Sternhells Augen in besonderem Maße zur Entstehung der faschistischen Ideologie bei:

Cependant, c'est toujours la révision du marxisme qui constitue la dimension idéologique la plus significative du fascisme. D'ailleurs, à beaucoup d'égards, on pourrait écrire l'histoire du fascisme comme celle d'une incessante tentative de révision du marxisme, d'un effort permanent vers un néo-socialisme. De Sorel à Déat et à Henri de Man dont l'influence sur le socialisme français est considérable, un même phénomène se fait jour constamment: la volonté de dépasser le marxisme ${ }^{156}$.

Sternhell gestand zwar ein, daß die Anzahl erklärter Faschisten in Frankreich gering gewesen sei, doch von ungleich größerem Gewicht sei doch die Prägekraft dieser neuen »faschistischen Synthese « im Gedankengut der jungen Intellektuellen der dreißiger Jahre gewesen, die eine »Revolution des Geistes" gefordert hätten, eine antimarxistische und nicht nur auf das Proletariat zielende Revolution. Viele von ihnen, so Stemhells Schluß, seien demnach faschistisch gewesen, ohne es selbst zu wissen ${ }^{157}$. $\mathrm{Zu}$ diesen vom Faschismus imprägnierten< Intellektuellen zählten die Neosozialisten ebenso wie die Planisten, die Anhänger des Personalismus wie die Jeunes-Turcs. Folgt man den Ausführungen Sternhells, dann muß auch Viénot zu den faschistisch geprägten Intellektuellen gezählt werden, denn er stand, wie bereits dargelegt, gerade den von diesen Kreisen vertretenen Ideen nahe. Von der propagierten geistigen Revolution zieht Sternhell eine direkte Linie zur Révolution nationale von 1940.

I55 Vgl. DERS., Mario SZNAJDER, Maia ASHERI, Naissance de l'idéologie fasciste, Paris 1989, S. 19-24.

${ }^{156}$ DERS., Ni droite ni gauche, S. 34. Vgl. auch DERS., La troisième voie fasciste ou la recherche d'une culture politique alternative, in: MERLIO, Ni gauche ni droite, S. 17-29.

157 Vgl. DERS., Ni droite ni gauche, S. 311. 
Die Verstrickung in die Kollaboration von seiten der Sozialisten Marcel Déat und Hendrik de Man sowie Intellektueller wie Jean Luchaire, Drieu la Rochelle oder Robert Brasillach, die für den »Geist der dreißiger Jahre« stehen, scheint für die Argumentation Sternhells zu sprechen, doch nur auf dem ersten Blick. Bei der Lektüre seiner Thesen entsteht der Eindruck, daß die Beweisführung in umgekehrter Richtung verläuft: die Tatsache, daß die zum Nonkonformismus zählenden Persönlichkeiten wie de Man, Déat, Pierre Andreu oder Jean-Pierre Maxence die Zusammenarbeit mit dem Dritten Reich befürworteten oder im Vichy-Regime Aufgaben übernahmen, liefert für Sternhell den Nachweis dafuir, daß ihr Gedankengut bereits in den zwanziger und dreißiger Jahren als faschistisch betrachtet werden kann. Mit dieser deterministischen Interpretation wird Sternhell dem Phänomen Nonkonformismus jedoch nicht gerecht. Zwar ist darauf hingewiesen worden, daß in der École des Cadres von Uriage, in der Kaderschmiede für künftige Führungskräfte des Vichy-Regimes, Eliten auf der Grundlage einer personalistischen Doktrin ausgebildet wurden ${ }^{158}$. Auf der anderen Seite sind jedoch eine Vielzahl früherer Nonkonformisten oder dieser Bewegung nahestehender Persönlichkeiten später in der Résistance zu finden, wie etwa Alexandre Marc, ein Résistant der ersten Stunde, der die Einladungen nach Uriage ablehnte ${ }^{159}$. Weiterhin wählten Denis de Rougement, Pierre Mendès France und Jacques Kayser den Weg des Widerstandes. Über André Philip, der in de Gaulles France libre zunächst das Kommissariat des Inneren leitete und dann für die Verbindung mit der Assemblée consultative zuständig war, hinterließ die Philosophie des Personalismus zudem deutliche Spuren in den Ideen der Résistance. In den dreißiger Jahren war er ein erklärter Anhänger de Mans gewesen und hauptverantwortlich für die Popularisierung dessen Thesen in Frankreich ${ }^{160}$. Schließlich war der Einfluß de Mans auch auf Viénot entscheidend. Zwar wäre es zu einfach, in dem Zusammentreffen mit dem belgischen Sozialisten den einzigen Grund für Viénots Hinwendung zu Sozialismus und Demokratie zu erblicken, dennoch spielte er eine wichtige Rolle für Viénots Entwicklung nach links. Gerade der von de Man verkörperte Abschied vom Marxismus eröffnete einer Persönlichkeit wie Viénot, von Veranlagung und Herkunft eher intellektuell und geistesaristokratisch orientiert

${ }^{158}$ Die Schule wurde Ende 1942 von Laval geschlossen, da sie als zu subversiv betrachtet wurde. Vgl. HELLMAN, RoY, Le personnalisme, S. $211 \mathrm{f}$.

${ }^{159}$ Vgl. ibid. S. 213. Michel Winock hat darauf hingewiesen, daß die Résistance z. T. auf die antiliberale und antiparlamentarische Kritik rekurrierte. Vgl. Michel WINOCK, Fascisme à la française ou fascisme introuvable?, in: Le Débat 25 (1983) S. 35-44, hier S. 40f., wiederabgedruckt in: DERS., Nationalisme, antisémitisme et fascisme en France, Paris 1990, S. 272 286.

${ }^{160}$ Durch Philip hielt der Personalismus Einzug in das Comité général d'Études sowie in die Verfassungspläne, die die Assemblée consultative der France libre in Algier ausarbeitete. Vgl. Henri MiCHEL, Les courants de pensée de la Résistance, Paris 1962, S. 387f. Zur Verbreitung der Thesen de Mans vgl. André PHIII, Henri de Man et la crise doctrinale du socialisme, Paris 1928. 
als dem Proletariat zugeneigt, den Zugang zum Sozialismus. Charles de Gaulle selbst pflegte seit etwa 1934/35 Kontakte mit dem Ordre nouveau ${ }^{161}$. In dem von ihm 1949 gegründeten Rassemblement du Peuple français (RPF) sollten zudem zwei ehemalige Mitglieder von Ordre nouveau im Führungsstab mitarbeiten, Jean Chauveau (Xavier de Lignac) und Albert Ollivier ${ }^{162}$.

Sternhells Thesen stießen bei französischen Historikern, die seit René Rémonds Untersuchung zur konservativen Rechten in Frankreich ${ }^{163}$ über die Marginalität des Faschismus in ihrem Land einig waren ${ }^{164}$, auf eine Mauer der Ablehnung, nicht zuletzt wegen Sternhells ebenso umfassenden wie unkonkreten Faschismusbegriffs und seiner rein ideengeschichtlich angelegten Analyse, die die politischen, wirtschaftlichen und sozialen Voraussetzungen für die Verbreitung des Faschismus völlig ausblendet ${ }^{165}$. Hilfreicher zur Klärung des Verhältnisses zwischen französischen Intellektuellen und dem Faschismus erscheinen dagegen die Überlegungen von Philippe Burrin, der im Hinblick auf die Verankerung des Faschismus in Frankreich von mehreren konzentrischen Kreisen ausgeht: in der Mitte sei demnach ein faschistischer Kernbereich angesiedelt, zu dem Burrin Bewegungen wie den Francisme, den Parti populaire français (PPF) und den Rassemblement national populaire (RNP) zählt. Daran schließe sich eine "zone de fascisation « an, in der sich die rechtsextremen Ligen und Strömungen wie die nonkonformistische Jeune Droite bewegten. In einer weitläufigen Außenzone schließlich fänden sich

les éléments manifestant une attraction vers le fascisme ou une influence médiate de celui-ci, tous éléments refusant de se définir comme des fascistes: c'est ici qu'il faut situer les hommes et les mouvements portant l'esprit des années 30 , les snon-conformistes` au sens

${ }^{161}$ Vgl. Pascal SIGODA, Charles de Gaulle, la »Révolution conservatrice« et le personnalisme du mouvement "l'Ordre Nouveau «, in: Espoir 46 (1984) S. 43-49, v.a. S. $46 f$.

${ }^{162} \mathrm{Vgl}$. LOUBET DEL BAYLE, Les non-conformistes, S. 420.

${ }^{163}$ Vgl. René RÉMOND, Les droites en France, Paris ${ }^{4} 1982$ (Erstauflage 1954 unter dem Titel: La droite en France).

${ }^{164}$ Vgl. z.B. Raoul GRARDET, der von einem "phénomène d'imprégnation fasciste« mit Blick auf französische Intellektuelle wie Drieu la Rochelle oder Brasillach spricht: Notes sur l'esprit d'un fascisme français 1934-1939, in: La Revue française de Science politique 5 (1955) S. 529-546, Zitat S. 530; Pierre MILZA, Les fascismes, Paris 1991, S. 339-360; BERSTEN, La France des années 30, S. 97f.

${ }^{165}$ Zur Sternhell-Debatte vgl. die Beiträge von Serge BERSTEIN, L'affrontement simulé des années 1930, in: Vingtième siècle. Revue d'histoire 5 (1985) S. 39-53; Jacques JULLARD, Sur un fascisme imaginaire. A propos d'un livre de Zeev Sternhell, in: Annales ESC 39 (1984) S. 849-861; Shlomo SAND, L'idéologie fasciste en France, in: Esprit 8/9 (1983) S. 149-160; Michel WINOCK, Fascisme à la française. Einen guten Überblick über Sternhells Thesen und die in Deutschland kaum zur Kenntnis genommene Debatte bietet der instruktive Aufsatz von Andreas WIRSCHNG, Zeev Sternhell und der französische "Faschismus", in: Mittelweg 36 9(2000/2001) H. 6, S. 41-52. Siehe auch Christine SCHANZE, Faschismus made in France? Die Debatte um "Ni droite, ni gauche" von Zeev Sternhell, in: Helga BORIES-SAWALA (Hg.), Ansichten vom Frankreich der Dreißiger Jahre. Beiträge aus einem interdisziplinären Projekt der Universität Bremen, Bremen 0.J. [2000], S. 55-65 und Robert Soucy, French Fascism: The Second Wave, New Haven, London 1995, S. 1-25. 
large, comme certains jeunes radicaux, les néo-socialistes, le doriotisme première manière, tandis que sur les franges extérieures on pourrait placer les personnalistes des groupes Esprit et l'Ordre nouveau ${ }^{166}$.

In dieser Peripherie finde eine partielle Anziehung durch den Faschismus statt, die unter Umständen den Boden bereiten könne für eine spätere Hinwendung zu ihm. Betrachtet man sich Viénots Entwicklung in den zwanziger Jahren, so läßt er sich innerhalb Burrins Modell in die Außenzone einer teilweisen Attraktion durch bestimmte politische Prinzipien einteilen, die sich auch in der faschistischen Ideologie finden. Zum Faschisten machte ihn dies noch nicht. Er erlag auch nicht wie Drieu la Rochelle und Henry de Montherlant der Gefahr, über seine Begeisterung für die Jugend in den Prozeß eines faschistischen Abgleitens zu geraten. Vor allem für Drieu la Rochelle verkörperte die Jugend die Vitalität und den Dynamismus, die allein die französische Dekadenz zu überwinden vermögen. Bei Montherlant wie bei Drieu verbindet sich das Bild der Jugend allerdings mit einem kämpferisch-heroischen beziehungsweise militärisch-virilen Element, das die Anknüpfung an den Faschismus erleichtert und das bei Viénot völlig fehlt. Drieus Hinwendung zum Faschismus war daher auch wwesentlich unideologisch und von seiner Fixiertheit auf die - natürlich männliche - Jugend bestimmt « gewesen ${ }^{167}$. Viénot befand sich in den zwanziger Jahren in einer Vielzahl von Netzwerken, zum Teil dominiert von konservativen Eliten aus Wirtschaft, Politik und Diplomatie, zum Teil getragen von elitär-geistesaristokratischem, nonkonformistischem, jungkonservativem, reformpädagogischem oder reformsozialistischem Gedankengut. Gleichzeitig pflegte er mit den Kreisen um Pierre Bertaux, André Gide und Paul Desjardins auch engen Kontakt zum linksrepublikanisch-laizistischen Milieu. Er suchte in all diesen Zirkeln Anregungen für seine politische Standortsuche und teilte mit vielen seiner Diskussionspartner die Überzeugung von einer notwendigen Reformierung der parlamentarischen Demokratie in Frankreich. Dabei kam er durchaus auch in Berührung mit dem Faschismus, der die Frage nach dem Dritten Weg in totalitärer Form beantwortete. Viénots Antwort sah letztlich anders aus.

${ }^{166}$ Philippe BURRIN, La dérive fasciste. Doriot, Déat, Bergery 1933-1945, Paris 1986, S. 26.

${ }^{167}$ Edward REICHEL, Nationalismus - Hedonismus - Faschismus. Der Mythos Jugend in der französischen Politik und Literatur von 1890 bis 1945, in: Thomas KOEBNER, Rolf-Peter JANZ, Frank TROMMLER (Hg.), "Mit uns zieht die neue Zeit «. Der Mythos Jugend, Frankfurt a.M. 1985, S. 150-173, hier S. 166. Vgl. auch Marie BALVET, Itinéraire d'un intellectuel vers le fascisme: Drieu la Rochelle, Paris 1984. 
2. Der lange Weg nach links: Viénots politische Entwicklung in den zwanziger Jahren

\section{1. "Je suis de plus en plus anti-démocratique«: Die Suche nach einer angemessenen Regierungsform}

Im Gegensatz zu seiner relativ früh erfolgten außenpolitischen Gedankenbildung war die Festlegung auf einen innenpolitischen Standpunkt bei Viénot lange Zeit retardiert. Zunächst stand sein Verhältnis zur Demokratie unter dem Eindruck außenpolitischer Beobachtungen, ging er doch von einem unheilvollen Einfluß der modernen Massendemokratie auf außenpolitische Entscheidungen aus. Für Viénot stand die aus dem demokratischen System geborene nationalistische Demagogie in direkt ursächlichem Zusammenhang mit der außenpolitischen Dekadenz, die er in der französischen "Politik der Stärke« vorzufinden glaubte: "De Nov. 1918 à Nov. 1923 il y a là pour moi cinq années de pleine décadence française, cinq années de véritable obscurcissement de l'intelligence française. La Démocratie en est d'ailleurs responsable ou plus exactement la démagogie nationaliste ${ }^{168}$ «. Für Viénot waren die außenpolitischen Folgen der Demokratie geradezu verheerend. Nichts sei demokratischer als die immense und skandalöse Ignoranz, die den deutsch-französischen Konflikt bestimme und die zu Subjektivität und Unkenntnis des Gegenübers führe ${ }^{169}$. Die Verehrung für seinen Mentor Lyautey verstärkte diese Skepsis noch. Viénot, der den langsamen bürokratischen Mühlen des demokratischen Systems nichts abgewinnen konnte, sah lieber die schöpferische Kraft einer Einzelpersönlichkeit walten, und hier war ihm Lyautey das bestimmende Vorbild: „En ce temps de forces anonymes et de loi du nombre, l'œuvre de Lyautey vient de nous rappeler ce que peut une volonté de chef, et la capacité créatrice d'une intelligence ${ }^{170}$. Lyautey, der selbst unter Einfluß von Albert de Muns Ralliement-Bewegung ${ }^{171}$ zum Vernunftrepublikaner geworden war, hegte ebenfalls große Vorbehalte gegenüber dem parlamentarischen System, in dem große Visionen kaum verwirklicht werden könnten: „Hélas, le régime parlementaire nous tue plus que jamais. Nos gouvernants ne regardent que vers l'intérieur, vers la Chambre, vers le vote de demain, sont hors d'état de prendre du recul et de garder leurs vues fixées hors et au-delà de nos frontières « ${ }^{172}$. Von seinem Mentor, der sich auch weiterhin zur Monarchie hingezogen fühlte, wurde Viénot demnach wohl kaum zu einer positiven Einstellung gegenüber der Dritten Republik ermun-

\footnotetext{
${ }^{168}$ Viénot an seinen Vater, 7.12.1924: NL Viénot.

${ }^{169}$ Vgl. DERS., Das wahre deutsch-französische Problem.

${ }^{170}$ DERS., Les leçons du Maroc, S. 1907.

171 Vgl. BLOCH, Dritte Französische Republik, S. 96.

${ }^{172}$ Lyautey an d'Ormesson, 9.1.1921, in: André Le RÉVÉREND, Un Lyautey inconnu Correspondance et journal inédits 1874-1934, Paris 1980, S. 301
} 
tert. 1924 forderte Viénot eine Reform des parlamentarischen Systems und ein wresserrement de l'autorité« in Form eines Königs. Dabei war die Rückkehr zur Monarchie als fortschrittliche Gegenmaßnahme gegen die nationalistischen Auswüchse der ungeliebten Massendemokratie gedacht ${ }^{173}$. Es fiel Viénot indes nicht auf, daß der hier formulierte Gedanke nicht wirklich durch Kohärenz bestach, denn gerade die sich für die monarchische Restauration einsetzende Action française stellte in außenpolitischer Hinsicht Viénots größtes Feindbild dar. Die Idee der Wiedereinsetzung eines Königs war jedoch nur kurzlebig und vermutlich auf den Einfluß Lyauteys zurückzuführen. Ein überzeugter Royalist ist Viénot nie gewesen. Ebensowenig Sympathien wie für die Action française empfand Viénot für den Kommunismus. Als er einen politischen Dissens mit Lyautey bereinigen wollte, verlieh er seiner Befürchtung Ausdruck, dieser könne ihn nun für einen »Bolschewisten« halten. Diese Vorstellung war ein regelrechtes Schreckgespenst für Viénot, und er beteuerte nachdrücklich seine Treue zum General: »Parce que je sais, moi, au contraire combien je procède de vous, combien je vous suis fidèle par ma fidélité à votre exemple, à l'esprit même de votre pensée, à tout ce qui est le plus intime de vous, même si parfois je puis m'écarter sur des points matériels qui ne sont rien à côté de cela « ${ }^{174}$.

Als Viénot im Umkreis Lyauteys den Journalisten Wladimir d'Ormesson kennenlernte, erschien er diesem "plutôt nationaliste, ১barrésien<, mais aussi non-conformiste et assez révolutionnaire ${ }^{175}$. Das ausgeprägte Nationalgefühl brachte Viénot aus seinem bürgerlichen Milieu mit, der Nonkonformismus und das Revolutionäre verwiesen bereits zu Beginn der zwanziger Jahre auf die später vollzogene Loslösung vom Herkunftsmilieu, auf Viénots Streben nach politischer Erneuerung und seiner Suche nach einem eigenen politischen Standort. Zunächst dominierte jedoch eine anhaltende innere Unsicherheit in bezug auf das politische System. Diese hatte ihre Ursache in der von Paul Valéry diagnostizierten »Krise des Geistes«, die Viénot wie viele andere Intellektuelle seiner Zeit verspürte. Er bezeichnete sie als »die momentane Schlappe, die der Geist gegenüber den Phänomenen unserer Zeit erlitten hat, diese Art Atemlosigkeit des Gedankens, mit der Wirklichkeit Schritt zu halten und sie zu organisieren ${ }^{176}$. Das Zurückbleiben des politischen Systems hinter den Fakten einer hochtechnisierten und sich schnell weiterentwickelnden Welt lastete Viénot auch der Theorieversessenheit der sreinen Intellektuellen an, zu denen er nicht zählen wollte. Für ihn besaßen die Ideen keinen absoluten Wert:

173 Vgl. Viénot an Lyautey, 29.3.1924: AN, 475 AP 311.

${ }^{174}$ Ders. an dens., 7.4.1924: AN, 475 AP 311.

${ }^{175}$ D'Ormesson, Pierre Viénot, S. 89: NL d'Ormesson.

${ }^{176}$ Pierre VIÉNOT, Schicksal und Vernunft, in: Europdische Revue 1,2 (1925/26) S. 297-301, hier S. 300. Die französische Version des Artikels ist abgedruckt unter dem Titel: Réflexions sur l'idée d'Europe, in: La Revue hebdomadaire, 6.2.1926, S. 56-61 und in: Correspondance de l'Union pour la Vérité 34 (1926) S. 131-136. 
"La `Doctrine ( abstraite et purement intellectuelle, la théorie, deviennent presque nécessairement >le système, toujours en retard sur les faits, incapable de suivre la diversité toujours renouvelée des réalités et des circonstances ${ }^{177}$. Auch das demokratische System der Dritten Republik war seiner Meinung nach nicht fähig, die Nachkriegsprobleme zu lösen. Die Demokratie war in den Augen Viénots eher ein Hindernis beim Prozeß, das politische System mit den materiellen und spirituellen Gegebenheiten der Epoche in Einklang zu bringen. Sie erschien ihm als nicht effizient genug und zudem in ihren Entscheidungen abhängig von Massenstimmungen. 1925 stellte er fest, er sei »de plus en plus anti-démocratique, non pas d'ailleurs en >conservateurı et dans l'idée que l'on doive revenir à ce qui était avant la Démocratie, mais dans la volonté de dépasser celle-ci, ou au minimum de l'organiser « ${ }^{178}$. Bei allen inneren Zweifeln und Ungewißheiten, über zwei Dinge war sich Viénot Mitte der zwanziger Jahre im klaren: Dies war zum einen die Ablehnung der bestehenden Form der Demokratie und zum zweiten sein Selbstentwurf als >Intellektueller der Tatک. Die Verbindung von Gedanke und Tat nach dem Vorbild Lyauteys erschien ihm als der Königsweg der beruflichen Selbstentfaltung. Eng verbunden damit war seine Perzeption der modernen Welt, ein Problem, das ihn während der zwanziger Jahre konstant beschäftigte. »Jeder von uns«, so forderte Viénot, "gleichviel ob individuell oder sozial gesinnt, ob Franzose oder Deutscher, muß seine Gedanken dem Leben anpassen und dazu zuerst sich unserer Zeit voll bewußt werden ${ }^{179}$. Dabei gehe es darum, die Beziehung zwischen sich selbst und der Maschine, zwischen sich und den anderen Menschen und auch zwischen sich und Gott neu zu definieren. Anregungen dafür erhoffte er sich von der Dekade in Pontigny 1926, die dem modernen Staat gewidmet war. Viénot konstatierte: "[...] même chez des esprits de formation entièrement ১démocratiques, l'idée d'une transformation de l'état s'est aujourd'hui imposée. Nous entrons vraiment dans une période spostdémocratique ${ }^{180}$. Wie aber sah diese postdemokratische Phase konkret aus? Noch bis Mitte und sogar bis Ende der zwanziger Jahre kann davon ausgegangen werden, daß Viénot in erster Linie ein Suchender blieb, ohne eine Antwort auf die von ihm selbst gestellten Fragen gefunden zu haben ${ }^{181}$. Dennoch war er sehr wohl dazu in der Lage, seine eigene Rolle innerhalb dieser Umbruchsphase zu definieren:

Dégager le sens profond des faits modernes et agir ensuite avec une claire vue du monde, de l'époque, $[\ldots .$.$] voilà ce qu'on voudrait tenter! Mais peut-être notre monde, dans sa difficulté,$ ne permet-il plus qu'il y ait encore de grands politiques, qui pensent leur action, et dont on

${ }^{177}$ Ders. an Lyautey, 7.4.1924, in: AN, 475 AP 311

${ }^{178}$ Ders. an dens., 8.7.1925, in: AN, 475 AP 311.

179 DERS., Antwort auf drei Fragen II.

${ }^{180}$ Ders. an Lyautey, 13.8.1926: AN, 475 AP 311.

${ }^{181} \mathrm{Vgl}$. z.B. ders. an dens., 4.4.1926: AN, 475 AP 311. 
puisse dire ce mot qu'on a dit de Richelieu et que j'aime tant: ,Il eut l'intention des grandes choses qu'il fit<. Au fond, ce serait ma profonde ambition ${ }^{182}$.

Der ambitionierte und den Vergleich mit Richelieu nicht scheuende Viénot gehörte Mitte der zwanziger Jahre dann auch zu einer Gruppe von 13 Intellektuellen, die innerhalb der Union pour la Vérité ein Reformprojekt mit dem Namen »Enquêtes« aus der Taufe heben wollten. Die Initiatoren dieses Vorhabens waren neben Viénot Aiméry Blacque-Belair, Pierre Drieu la Rochelle, Alfred Fabre-Luce, Ramon Fernandez, Pierre Hamp, Gabriel Marcel, René Massigli, André Maurois, Henry de Montherlant, Jean Schlumberger und Albert Thibaudet. Die Mitglieder dieser Gruppe waren sich im Umkreis der Dekaden von Pontigny begegnet und hatten den Plan gefaßt, ein Diskussionsforum und eine Publikation mit dem Titel Enquêtes herauszubringen, die ab Januar 1926 erscheinen sollte. Von dieser Zeitschrift läßt sich allerdings keine Spur auffinden, und es ist wahrscheinlich, daß das Projekt schließlich doch nicht umgesetzt worden ist. In einer Art Gründungsmanifest beklagen die Teilnehmer die "séparation profonde, et sans cesse aggravée, [...] entre la pensée et la critique d'une part, et, de l'autre, l'action et la vie publique ${ }^{183}$. Sie wollten daher eine Verbindung schaffen zwischen den whommes d'action" und den whommes de pensée«. Enquêtes war als politische Zeitschrift geplant, in der die Gründer ihre abweichenden Meinungen von sich geben, neue Ideen in den öffentlichen Diskurs einbringen und Themen ansprechen sollten, die ihrer Meinung nach von den Parteien vernachlässigt wurden. Paul Desjardins selbst betonte den Einfluß des Krieges auf die Gründungsmitglieder, und zweifellos handelt es sich bei der Projektankündigung um den Versuch, auf die drängenden Fragen und Ungereimtheiten der Nachkriegszeit angemessene zeitgemäße Antworten zu finden. War dies mein frühes Dokument nonkonformistischen Denkens «, wie in der Forschung behauptet ${ }^{184}$ ? Zu den Nonkonformisten im Sinne Loubet del Bayles gehörten diese Intellektuellen nicht. Sie waren eigentlich zu alt für die Generation der Nonkonformisten, wenngleich dieses Merkmal, wie an anderer Stelle bereits ausgeführt, eher ein Anhaltspunkt denn ein verbindliches Ausschlußkriterium ist. Zudem war mit Ausnahme Gabriel Marcels keiner von ihnen im engeren Kreis der späteren Nonkonformisten zu finden ${ }^{185}$. Auch fehlte dem Gründungsmanifest der verbale Radikalismus, die Forderung nach revolutionärer Überwindung der alten Ordnung, die Suche nach einem Dritten Weg bei Ablehnung aller bestehenden Alternativen. Von nonkonformistischem Geist im eigentlichen Sinne kann bei diesem Dokument

${ }^{182}$ Ders. an Schlumberger, 26.3.1924: BLJD, Fonds Schlumberger, Ms 18305.

${ }^{183}$ Paul DESJARDINS, Regain de vie. "Enquêtes" - Leçons et Entretiens, in: Correspondance de l'Union pour la Vérité 34 (1926) S. X-XXI, hier S. XVI.

${ }^{184}$ Hans Manfred Bock, Der Weg Pierre Viénots, S. 113.

${ }^{185}$ Gabriel Marcel war Mitglied des von Alexandre Marc inspirierten Club du Moulin vert, aus dem dann der Ordre nouveau hervorging. Er gehörte auch zu den Unterzeichnern von dessen Gründungsmanifest 1931. Vgl. ECKERT, Konservative Revolution, S. 66f. 
also nicht gesprochen werden. Es kann jedoch als früher Ausdruck des Strebens von Intellektuellen nach umfassender politischer und gesellschaftlicher Modernisierung betrachtet werden. Unter dem Banner der Emeuerung versammelten sich drei Generationen, die sich alle auf das Kriegserlebnis bezogen als Ausgangspunkt ihres Engagements. Schlumberger, Hamp, Marcel, Massigli, Maurois und Thibaudet gehörten der Generation Gides und Valerys an, also der vor dem Weltkrieg sozialisierten Intellektuellen. Drieu la Rochelle, Montherlant und Fernandez zählten hingegen wie Viénot zu den jungen Kriegsteilnehmern, zur "génération du feu«. Schließlich vertrat mit Alfred Fabre-Luce ein Mitglied der Gruppe die von Luchaire so apostrophierte "génération réaliste«. Viénot selbst hatte schon seit längerem Kontakt zu Fabre-Luce. Anfang 1924, als er eine Zeitschrift für außenpolitische Fragen geplant hatte, hatte er auch Gespräche mit Fabre-Luce geführt. Interessanterweise wirkten bei dem EnquêtesProjekt auch jene Männer mit, die Viénot ein Jahr vorher als Konkurrenz zu seiner geplanten außenpolitischen Zeitschrift ausgemacht hatte: Blacque-Belair und Fernandez. Fabre-Luce und Maurois hatte Viénot hingegen für sein eigenes Projekt zu gewinnen versucht. Die Vermutung liegt nahe, daß das EnquêtesProjekt die Weiterentwicklung der ursprünglich getrennt voneinander entstandenen Pläne gewesen ist ${ }^{186}$.

Die Enquêtes-Gruppe versammelte Männer aus verschiedenen politischen Lagern und aus unterschiedlichen Generationen. Was sie vereinte, war der Wille, auf die französische Politik wie auch auf das geistige Leben einzuwirken und in beiden Bereichen für neue Anstöße zu sorgen. In diesem Sinne war die Gruppe »en effet contemporaine ${ }^{187}$. Für Viénot, der sich gleichzeitig auch mit der Gründung des Studienkomitees beschäftigte, stellte Enquêtes einen weiteren Versuch dar, die von ihm favorisierte Einheit von Denken und Handeln zu realisieren. Woran das Projekt letztlich gescheitert ist, läßt sich aufgrund fehlender Quellen nicht nachvollziehen. In der Tat stellt es aber, noch vor den Jeunes-Turcs, vor Révolution constructive und vor den Nonkonformisten der dreißiger Jahre den Versuch dar, gesellschaftliche und politische Reformprojekte öffentlich zu diskutieren.

Die politische Standortsuche Viénots war zum Zeitpunkt der EnquêtesInitiative aber noch längst nicht abgeschlossen. Die Frage, die er sich stellte, war indes klar formuliert: Wie muß ein politisches System beschaffen sein, das die drängenden Fragen der modernen Welt zu lösen vermag? Ab Mitte der zwanziger Jahre beschäftigten ihn diese Gedanken besonders intensiv. Zum Schlüsselbegriff seiner Überlegungen wurde derjenige der Ordnung. Das Problem der Ordnung in einem Land, so gestand er 1926 Lyautey, beschäftige

${ }^{186}$ Vgl. ders. an dens., 12.1.1925 [fälschlich auf 1924 datiert] und ders. an dens., 19.1.1925: NL Viénot.

${ }^{187}$ Paul DESJARDINS, Regain de vie. »Enquêtes « - Leçons et Entretiens, in: Correspondance de l'Union pour la Vérité 34 (1926) S. X-XXI, hier S. XV. 
ihn, und er wüßte gerne, was er selbst eigentlich darüber denke ${ }^{188}$. Gleichzeitig plante er, einen Artikel zu diesem Problem zu schreiben. Was Viénot umtrieb, war die Verzweiflung an einem Gefühl der Einsamkeit, dem er zu entkommen versuchte. Die Befreiung des Individuums aus den Zwängen von Moral und Konvention, wie sie Gide propagierte und wie sie Viénot zu Beginn der zwanziger Jahre enthusiastisch begrüßt hatte, wurde ihm nun zur Belastung: "Cette liberté absolue, cette liberté de tout l'être à tous les instants, cette anarchie absolue me révoltent. Je voudrais construire, enfin construire! enfin un ordre! Mais lequel? Il me semble que notre extrême civilisation a refait de nous des sauvages ${ }^{189}$. Die Verzweiflung und Orientierungslosigkeit, die aus Viénots Worten sprachen, gründeten - wie bei vielen jungen Intellektuellen seiner Zeit - in der nachhaltigen Erschütterung seines Glaubens an althergebrachte Kultur- und Zivilisationsvorstellugen. Am eigenen Leibe hatte er während des Ersten Weltkriegs erlebt, wie dünn der Firnis der Zivilisation im Grunde war. Der Zusammenbruch von Wert- und Ordnungsvorstellungen hinterließ eine innere Leere, die Viénot durch neue, der Epoche angepaßte Ideen auszufüllen versuchte. Sein Streben nach der Errichtung einer äußeren Ordnung ging demnach mit der Sehnsucht nach einer inneren Ordnung einher. Dabei fühlte er sich nur von wenigen Menschen verstanden, so daß das Gefühl der Einsamkeit eine Konstante in Viénots Leben darstellte. Seinem Freund Pierre de Cénival vertraute er an: "L'effrayante solitude de l'homme moderne conscient me devient insupportable ${ }^{190}$. Auch drei Jahre später, im Juli 1929, hatte er noch immer das Gefühl, ein windividu totalement seul [...] au sens intellectuel et spirituek $\aleph^{191}$ zu sein. Eine enge Verbindung mit Andrée Mayrisch, seiner späteren Frau, war für Viénot unter anderem auch deshalb so wünschenswert, weil er in ihr in dieser Hinsicht eine verwandte Seele erblickte, "qui souffre elle aussi de cette absolue solitude où chacun de nous se trouve, et qui cherche, qui cherche ${ }^{192}$. Viénot war sich sicher, die Ideen André Gides nun endgültig hinter sich gelassen zu haben. Zwar erachtete er eine Haltung des Individualismus als noch immer möglich, doch diese bedeutete nunmehr nicht mehr die von Gide proklamierte lustorientierte und sinnenfrohe individuelle Befreiung, sondern im Gegenteil ein Haltung "qui se connaît comme un devoir provisoire et non comme une joie; et tout penché sur l'avenir qui l'absorbera « ${ }^{193}$. Der Zukunft galt Viénots ganze Hoffnung, von der er sich die Überwindung seiner eigenen Unsicherheiten und die Errichtung einer Ordnung erwartete. Dabei sah er es als seine Pflicht an, an diesem Prozeß mitzuwirken.

${ }^{188}$ Viénot an Lyautey, 4.4.1926: AN, 475 AP 311.

${ }^{189}$ Ders. an Schlumberger, 4.4.1926: BLJD, Fonds Schlumberger, Ms 18324.

${ }^{190}$ Ders. an de Cénival, 5.4.1926: NL Viénot.

191 Ders. an d'Ormesson, 3.7.1929: NL d'Ormesson II.

192 Ders. an Schlumberger, 4.4.1929: BLJD, Fonds Schlumberger, Ms 18324.

${ }^{193}$ Ders. an dens., 20.4.1926: BLJD, Fonds Schlumberger, Ms 18327. 
Doch wie sollte diese Zukunft aussehen? Und welche Ordnung wollte Viénot errichten, in der der moderne Mensch sich weniger einsam fühlen würde? Ende 1927 legte er Lyautey seine Gedanken ausführlich dar. Er sei kein Demokrat, so machte er dem General klar, und glaube auch nicht an den universellen Wert und die magische Kraft unsterblicher Prinzipien. Diese gehörten der Vergangenheit an, der er nicht nachtrauere. Die ideale Ordnung sei für ihn vielmehr »la constante adaptation des institutions, des lois, de l'autorité aux transformations incessantes de la réalité, au mouvement des esprits aux créations continues de la vie. Là, c'est le mouvement ${ }^{194}$. Wie eine derartige Anpassung in Permanenz genau aussehen sollte, mit welchen Institutionen sie durchgeführt werden konnte, darüber hatte sich Viénot jedoch keine konkreten Gedanken gemacht. Er selbst fühlte sich uneins mit nahezu allen Doktrinen, allen Regeln und allen strikten Gewißheiten. In politischer Hinsicht bedeutete dies, daß er sich keiner Partei anschließen wollte. Viénot sah sich »ni de droite, ni de gauche $\ll$ und folgerte: $» j e$ suis seul, avec des amis ${ }^{195}$. Er forderte eine neue Doktrin, und sein Bekenntnis zu Lyauteys Werk in Marokko legt den Schluß nahe, daß er damit eine Art `Doktrin der Tatı meinte. Daß Viénot gestalterisch tätig werden und an der Errichtung einer politischen und sozialen Ordnung mitwirken wollte, die er als modern und zeitgemäß empfinden würde, dies erscheint klar. Viel weniger deutlich wird jedoch, wie diese Ordnung im Konkreten wirklich aussehen sollte. $\mathrm{DaB}$ eine Veränderung des aktuellen demokratischen Systems hin zu einer stärkeren Exekutive stattfinden sollte, läßt sich aus seinen Äußerungen schließen. Gleichzeitig sollte die neue Ordnung flexibel genug sein, sich gesellschaftlichen Veränderungen geschmeidig anzupassen. Keine Partei konnte ihm jedoch zu dieser Zeit, im Jahre 1927, ein Modell zeigen, das ihn überzeugt hätte. Zeitweise scheint er seine Hoffnungen auf André Tardieu gerichtet zu haben. Dieser gehörte zu jenen Vertretern der liberalen Rechten, die durch ihre Kritik am Parlamentarismus und ihren Forderungen nach institutionellen Reformen und Stärkung der Exekutive die Tendenzen der Zeit aufgriffen und widerspiegelten. Tardieu galt dabei als einer der Politiker der Rechten, die diese Kritik am weitesten trieben und verstand es mit seinem modernistischen Stil, die Zeitgenossen zu faszinieren ${ }^{196}$. Über die Kontakte zwischen Tardieu und Viénot ist im Detail nichts bekannt, doch erhoffte sich Viénot 1928 anscheinend eine Protektion durch Tardieu, falls dieser nach den nächsten Wahlen Außenminister werden sollte ${ }^{197}$. Diesen Posten übernahm

${ }^{194}$ Ders. an Lyautey, 15.11.1927: AN, 475 AP 311.

195 Ibid.

${ }^{196}$ Zur Situierung Tardieus innerhalb der intellektuellen und politischen Erneuerungsbestrebungen vgl. ausfühlich MONNET, Refaire la République, S. 177-271. Siehe weiterhin LOUBET DEL BAYLE, Les non-conformistes, S. 14; BERSTEIN, La France des années 30, S. 89f;; BLOCH, Dritte Franzősische Republik, S. 362f. Mitte der dreißiger Jahre zog sich Tardieu aus der aktiven Politik zurück und warb verstärkt für seine Reformideen.

197 Dies berichtet BERTAUX, Un normalien à Berlin, S. $184 f$. 
Tardieu dann erst 1932, als Viénot sich zum ersten Mal - dann aber auf seiten der Linken - zur Wahl stelite. Es scheint, daß Viénot in diesen Jahren sowohl für rechte wie auch linke Ideen aufgeschlossen war, sofern sie nur das Signum des Modernen, der Erneuerung, trugen. Dabei war er freilich auch bemüht, persönliche Karrierestrategien mit politischer Gedankenbildung und Zielsetzung in Einklang zu bringen. In den zwanziger Jahren bewegte sich Viénot in einer Reihe verschiedenster Zirkel und Gruppierungen, in denen jene Fragen diskutiert wurden, die ihn beschäftigten. Wie letztlich die Antwort auf seine Fragen aussehen würde, war ihm dabei noch gänzlich unklar. Als er seit 1926 das Berliner Büro des Mayrisch-Komitees leitete, nutzte er die Zeit sowie seine dortigen Kontakte auch, um sich ein Bild über die innenpolitische Situation in Deutschland zu machen, welche er als Vergleichshorizont für Frankreich heranzog.

\subsection{Anregungen aus Deutschland: Die Dynamik der Weimarer Republik}

Im Berlin der zwanziger Jahre war wie an kaum einem anderen Ort eine Vielzahl unterschiedlichster politischer und gesellschaftlicher Strömungen und Bewegungen beheimatet. Die eigentümliche Mischung aus alten Traditionen und neuen Ideen, aus reaktionärem Gedankengut und revolutionärem Elan, die Lancierung neuer Gesellschaftsmodelle von links und von rechts ließ die deutsche Metropole in jenen Jahren wie win einem Fieber des Glanzes von der Erde losgelöst« erscheinen. „Eine ganze Generation von Franzosen«, so sieht es Theodore White, "verfiel [...] dieser Verzauberung “ ${ }^{198}$. Auch Viénot konnte sich dieser Faszination nicht entziehen. Überall dort, wo Ideen neuer Formen der staatlichen oder gesellschaftlichen Ordnung diskutiert wurden, verfolgte Viénot dies mit großem Interesse. Zusammen mit seiner Frau kam er dabei zum einen mit Organisationen im weiteren oder engeren Einzugsbereich jener geistigen Bewegung in Berührung, die von Armin Mohler als Konservative Revolution bezeichnet worden ist ${ }^{199}$. Zum anderen galt das besondere Interesse des Paares der deutschen Jugendbewegung sowie reformpädagogischen Bestrebungen im Umkreis des preußischen Kultusministers Carl Heinrich Becker.

${ }^{198}$ WHTE, Glut in der Asche, S. 127.

199 Armin MOHLER, Die Konservative Revolution in Deutschland 1918-1932. Ein Handbuch, Darmstadt ${ }^{4} 1994$. Der Begriff ist heute nicht unumstritten. Stefan Breuer bezeichnet ihn als weine der erfolgreichsten Schöpfungen der neueren Ideengeschichtsschreibung ". Seiner Meinung nach waren die Vorstellungen der Konservativen Revolutionäre jedoch zu verschieden, um der Bewegung ein eigenes Profil zu verleihen: "Eine wie immer geartete Doktrin, die für alle als konservativ-revolutionär apostrophierten Autoren verbindlich wäre, hat sich [...] nicht ergeben\%. Stefan BREUER, Anatomie der Konservativen Revolution, Darmstadt 1993, S. 1 und S. 180. Rolf Peter Sieferle kommt hingegen zu dem Schluß, daß es win der ideologischen Wirklichkeit der zwanziger und frühen dreißiger Jahre tatsächlich eine ideologische Formation der extremen Rechten gab, deren innere Einheit den Gebrauch eines zusammenfassenden Begriffs gestattet«. Rolf Peter SIEFERLE, Die Konservative Revolution. Fünf biographische Skizzen, Frankfurt a.M. 1995, S. 21. 
Neben den aufgezeigten Berührungspunkten mit dem nonkonformistischen Denken in Frankreich hatte Viénot in den zwanziger Jahren auch Kontakte mit jungrevolutionären Ideen in Deutschland bei den Veranstaltungen des Europäischen Kulturbundes. Dieser Zusammenschluß führender Repräsentanten des europäischen Geisteslebens war von dem 1898 geborenen österreichischen Adeligen Karl Anton Prinz Rohan ins Leben gerufen worden ${ }^{200}$. Nach dem Zusammenbruch der Donaumonarchie war dieser darum bemüht, in Anknüpfung an die kosmopolitische Aristokratie vor 1914, wauf der Ebene hoher Elite [...] die Bildung einer geistig-gesellschaftlichen Oberschicht als Träger europäischen Bewußteins $\aleph^{201}$ zu fördern. $\mathrm{Zu}$ diesem Zweck gründete er 1922 in Wien den Kulturbund, der die Verbindung zwischen den geistigen Eliten der Nationen herstellen und win konservativer Haltung dabei mithelfen [sollte], jene Werte $\mathrm{zu}$ bewahren, ohne die Europas Mechanisierung, Europas Unterwerfung unter die Maschine unausbleiblich $« \operatorname{sei}^{202}$. In den nationalen Komitees des Kulturbundes trafen sich hochrangige Vertreter des geistigen und politischen Lebens, so zum Beispiel in der 1923 gegründeten französischen Gruppe der Friedensnobelpreisträger Baron d'Estournelles de Constant, der Philosoph Paul Desjardins, der Komponist Maurice Ravel, der Mathematiker und ehemalige Marineminister Émile Borel, der Physiker Paul Langevin, der Germanist Henri Lichtenberger sowie die Schriftsteller Roger Martin du Gard und Paul Valéry. Die Gründung der deutschen Gruppe, die nach dem Eintritt Deutschlands in den Völkerbund 1926 erfolgte, war vom Industriellenpaar Georg und Lily von Schnitzler unterstützt worden, und hier fanden sich unter anderem der Archäologe Ludwig Curtius, die Politik- und Sozialwissenschaftler Alfred Weber und Arnold Bergsträsser, die Hindenburg-Nichte Helene von Nostitz, die Künstler Max Beckmann, Max Liebermann und Wilhelm Furtwängler, Harry Graf Kessler sowie Konrad Adenauer und Thomas Mann ${ }^{203}$.

Rohans Streben nach einer europäischen Kulturgemeinschaft entstand vor allem aus der Kriegserfahrung, aus dem Gefühl, nach 1918 ein »bankerottes Europa« vor sich zu sehen, »dessen Reserven erschöpft sind « ${ }^{204}$. Für die junge "Generation der Tat« sei das bürgerlich-demokratische Ideal zusammengebrochen, sie lebe in einer morschen Gesellschaftsordnung, und die Diktatur

${ }^{200}$ Die Familie Rohans stammte ursprünglich aus Frankreich, wanderte nach der Französischen Revolution jedoch ins Habsburgerreich aus. Vgl. die biographischen Daten in: Karl Anton ROHAN, Umbruch der Zeit 1923-1930. Gesammelte Aufsätze, Berlin 1930, S. 15.

${ }^{201}$ DERS., Heimat Europa. Erinnerungen und Erfahrungen, Düsseldorf, Köln 1954, S. 56.

${ }^{202}$ DERS., Europa. Streiflichter, Leipzig 1923, S. 42. Ziel des Kulturbundes war es für Rohan, »die geistige Einheit Europas vorzubereiten, an der Bewußtwerdung dieser Einheit mitzuarbeiten, die Entwicklung und Organisierung eines übernationalen Europäertums zu fördern «. Vgl. DERS., Kulturbund, in: Germania, 26.9.1925.

${ }^{203} \mathrm{Vgl}$. MƯLLER, Deutsch-französische Gesellschaftsbeziehungen, S. 442f.

${ }^{204}$ Karl Anton ROHAN, Die Aufgabe unserer Generation, Köln 1926, S. 8. 
werde zu einer "ganz natürlichen Möglichkeit ${ }^{205}$. Die Kriegserfahrung präge das politische Denken dieser Generation nachhaltig, so resultiere daraus zum Beispiel »die selbstverständliche Einteilung der Menschen in Führer und Geführte ${ }^{206}$. Rohan kritisierte die Demokratie als anonym und projektierte einen europäischen Zusammenschluß, der gegen den Bolschewismus gerichtet sein sollte. Der Aufbau dieser neuen europäischen Ordnung sollte das Hauptziel der jungen "Generation der Sachlichkeit ${ }^{207}$ sein: „Unsere Aufgabe heißt: Gemeinschaft. Nur eine neue, viel tiefere nationale Gemeinschaft kann uns aus der demokratischen Anonymität der Macht herausführen. Nur eine neue übernationale Gemeinschaft führt zu dem von uns erstrebten übernational gegliederten Europa $\aleph^{208}$. Als Vorbild betrachtete Rohan dabei Italien, wo sich im Faschismus »das Lebensgefühl der Jugend ${ }^{209}$ ausdrücke. Das faschistische Italien galt ihm als Modell für die gesamte europäische Jugend, denn dort werde erstmals versucht, Tradition und Zukunftswillen zu verbinden. Der vom Faschismus geschaffene neue Menschentypus sollte in ganz Europa Verbreitung finden, "weil er allein Jugend, Mut und Kraft genug besitzt, um die Aufgaben zu lösen, um die sich die früheren Generationen gedrückt haben ${ }^{210}$. Und Rohan kam zu dem Schluß: "Konservative Revolution nennt man hier dasselbe Lebensgefühl $\aleph^{211}$.

Rohans Broschüre »Europa« gilt nicht nur als das Gründungsmanifest des Kulturbundes, sondern gleichzeitig auch als ein zentraler Text der Konservativen Revolution, in dem die antiliberalen, antirationalistischen und antikommunistischen Gedanken seines Verfassers zum Ausdruck kommen ${ }^{212}$. Die Haltung des Kulturbund-Gründers kann allerdings nicht als verbindlich für die gesamte Mitgliedschaft betrachtet werden. Die Teilnahme von Persönlichkeiten wie dem pazifistischen Wissenschaftler Albert Einstein wäre sonst kaum zu erklären. Wegen seiner nach außen unpolitischen, ganz auf die kulturelle Zusammenarbeit konzentrierten und gleichzeitig geisteselitären Haltung hatte der Euro-

${ }^{205}$ Ibid

${ }^{206}$ DERS., Die Aufgabe unserer Generation (1925), in: DERS., Umbruch der Zeit, S. 24-29, hier S. 27.

${ }^{207}$ Vgl. Ulrich HERBERT, Best. Biographische Studien über Radikalismus, Weltanschauung und Vernunft 1903-1989, Bonn ${ }^{3} 1996$, S. 42.

${ }^{208}$ ROHAN, Die Aufgabe unserer Generation (1925) S. 29.

${ }^{209}$ DERS., Die Aufgabe, S. 19.

${ }^{210}$ DERS., Fascismus und Europa (1926), in: DERS., Umbruch der Zeit, S. 30-31, hier S. 31.

211 DERS., Die Aufgabe, S. 20

${ }^{212}$ Vgl. MỚLLER, Deutsch-französische Gesellschaftsbeziehungen, S. 415. Die Tatsache, daß die Bedeutung Rohans furr die Konservative Revolution in der Historiographie bisher kaum eine Erwähnung fand, führt Müller darauf zurück, daß idie bisherigen Untersuchungen zum Phänomen der skonservativen Revolution ( [...] stark auf preußisch-deutsche und sprotestantische` Autoren eingeschränkt« seien. Ibid. S. 420. In der neueren Forschung wird die von Rohan herausgegebene Europdische Revue jedoch als "Sprachrohr einer katholischen konservativen Revolution « bezeichnet. Vgl. KELLER, Dritte-Weg-Diskurse, S. 107. 
päische Kulturbund starken Zulauf gerade aus konservativen und rechtsliberalen Kreisen des Bildungs- und Besitzbürgertums. Die Organisation besa $\beta$ also einen Doppelcharakter. Während sie sich in ihren Statuten ganz und gar unpolitisch und auf die Kultur konzentriert gab, so war sie geboren und konzipiert aus jungkonservativem Gedankengut heraus und sollte als Instrument genutzt werden, um die Jugend Europas unter diesem Vorzeichen zusammenzuführen.

Die Bekanntschaft zwischen Rohan und Viénot ging auf das Jahr 1922 zurück, als sie in der Pariser Wohnung Lyauteys aufeinander getroffen waren ${ }^{213}$. Als Rohan sich anschickte, ein französisches Komitee seiner Organisation ins Leben zu rufen, war Viénot über dessen Pläne »de création d'une aristocratie intellectuelle européenne ${ }^{214}$ unterrichtet und teilte sie seinem Freund Schlumberger mit. Die Zusammensetzung des Komitees mit dem Kardinal von Paris, Desjardins, der Gräfin d'Harcourt, Valéry und Langevin hielt er für eine "curieuse et heureuse salade ${ }^{215}$, und versuchte, Schlumberger zur Teilnahme zu animieren. Viénot hielt das Projekt Rohans für interessant und glaubte, die stendances un peu trop Keyserlingiennes ${ }^{216}$ könnten durch die französische Beteiligung gemindert werden. Am Dritten Europäischen Kulturbundkongre $B$ in Wien $1926 \mathrm{nahm}$ dann auch Viénot teil und richtete als Leiter des Berliner Büros des Mayrisch-Komitees eine Botschaft an die Anwesenden. Er betonte darin die Rolle der jungen Kriegsteilnehmergeneration, die eine feste und starke europäische Gemeinschaft anstrebe. Diese beruhte in seinen Augen auf den nationalen Werten, die gerade seine Generation mit ihrem Leben verteidigt hatte. An ihr sei es nun, den Krieg zu überwinden und die Grundlagen einer europäischen Solidarität zu schaffen ${ }^{217}$. Dieses Bekenntnis zu einer national wie europäisch gesinnten Generation der ehemaligen Frontkämpfer rief Zustimmung sowohl bei dem italienischen Faschisten Aldo Pontremoli wie auch bei Arnold Bergstrăsser hervor. Bergsträsser betonte die Bedeutung der Nation, die allein dazu geeignet sei, die "gestalthafte Einheit unseres abendländischen Kontinents sich herausbilden $\mathrm{zu}$ lassen $\mathrm{r}^{218}$.

Für den Schriftsteller Hugo von Hofmannsthal stellten die Beiträge des jungen Faschisten Pontremoli, des damals der DDP nahestehenden Bergsträsser sowie Viénots die jugendliche "Apotheose des Kongresses « ${ }^{219}$ dar. Weiterhin sah er in der faschistischen Delegation aus Italien die Verkörperung einer neuen Welt, von deren »Geisteskultur« er beeindruckt gewesen schien ${ }^{20}$. Mit Nachdruck setzte sich Hofmannsthal für Rohan und dessen elitäre Bestrebungen

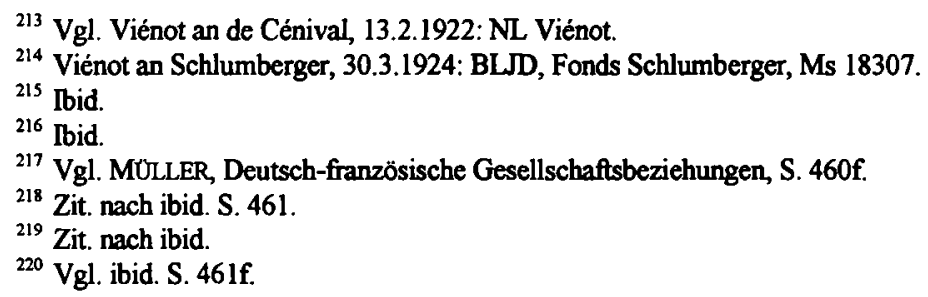


ein. Wie Rohan war auch er fasziniert von dem "neue[n] Lebensgefühl, das der Fascismus geschaffen hat, - heroisch-tragisch, jung-revolutionär und traditionalistisch zugleich, unideologisch-aktivistisch, Noblesse in der Hingabe an ein überindividuelles Ideal $\kappa^{221}$. Hofmannsthal seinerseits bezeichnete die Suche nach der »Ganzheit des Lebens«, nach geistiger Synthese der Nation als »nichts anderes als eine konservative Revolution von einem Umfang, wie die europäische Geschichte ihn nicht kennt « ${ }^{222}$.

Diese von Hofmannsthal favorisierte »konservative Revolution« fand im Kulturbund ihre adäquate Organisation, in der sie »zum gemeineuropäischen Phänomen [wurde], das in nationalstaatlich unterschiedlicher Ausprägung dem Faschismus, dem Nationalsozialismus und der Kollaboration Vorschub geleistet hat ${ }^{223}$. Die Affinitäten Rohans, Alfred Webers und Hofmannsthals zum Faschismus konnten Viénot kaum entgangen sein. Ließ er sich unwissentlich für ihre Zwecke instrumentalisieren, oder war er überzeugt von einer europäischen Verständigung der Kriegsjugend, die über alle ideologischen Grenzen hinaus

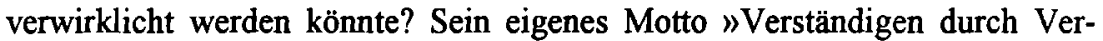
stehen des anderen« fand immerhin, zumindest äußerlich, seine Entsprechung im von Rohan vertretenen Leitsatz: "Verstehen ist die Voraussetzung für Verständigung « ${ }^{224}$. Diese Aufgabe entstand für beide aus der Kriegserfahrung und dem Zusammenbruch der Vorkriegsordnung. Ob sich Viénot aber bewußt war, in welchem zumindest ambivalent anmutenden Kontext diese Ideen hier standen, läßt sich nicht aus den Quellen beantworten. $Z u$ vermuten ist jedoch, daß er in den Veranstaltungen des Kulturbundes ein Forum sah, mit Vertretern der geistigen Elite Europas über aktuelle Zeitfragen, über Krisenbewußtsein und Lösungswege zu diskutieren. Dabei war er an Emeuerungsideen aus dem linken wie aus dem rechten politischen Spektrum gleichermaßen interessiert. Die jungkonservativen und faschistischen Ideen, die von manchen Teilnehmern propagiert wurden, stellten dabei eine von mehreren Möglichkeiten dar, die Krise Europas zu überwinden. Auch sie zählten zu den Anregungen, die Viénot bei seiner Suche nach einer eigenen Antwort aufnahm.

Nach seiner Teilnahme am Kulturbundkongreß in Wien 1926 war Viénot auch bei den Jahrestreffen in Heidelberg und Frankfurt (1927), in Prag (1928) sowie in Krakau (1930) anwesend ${ }^{225}$. Das Treffen in Prag muß dabei für Viénot von besonderem Interesse gewesen sein, behandelte es doch als Thema die "Elemente der modernen Zivilisation« und damit genau die Frage nach dem

${ }^{221}$ ROHAN, Fascismus und Europa, S. 31.

${ }^{222}$ Hugo von HOFMANNSTHAL, Das Schriftum als geistiger Raum der Nation. Rede, gehalten im Auditorium maximum der Universität München am 10. Januar 1927, München 1927, S. 31

${ }^{223}$ MULLER, Deutsch-französische Gesellschaftsbeziehungen, S. 465.

${ }^{224}$ ROHAN, Heimat Europa, S. 57.

${ }^{225}$ Vgl. Viénot an Schlumberger, 19.10.1927: BLJD, Fonds Schlumberger, Ms 18335; ders. an Aline Mayrisch, 11.10.1930: NL Viénot. 
Verhältnis zwischen Kultur und Technik, zwischen Mensch und Maschine, die ihn wie viele Intellektuelle besonders beschäftigte. Die Liste der Redner war hochkarätig besetzt und versprach ein hohes intellektuelles Niveau. So referierten beispielsweise der Architekt Le Corbusier über »Neue Gesinnung in der Baukunst«, der Psychoanalytiker C. G. Jung über »Das Seelenproblem des modernen Menschen $/$ und Arthur Fontaine, der Vorsitzende des Verwaltungsrats im Internationalen Arbeitsamt und Präsident des französischen KulturbundKomitees, über den "Strukturwandel des Staates durch die Technik«. Auch Hendrik de Man war eingeladen, über "Die sozialen Wirkungen der Technik« zu sprechen, war jedoch krankheitsbedingt verhindert. Sein Beitrag wurde in der Europäischen Revue veröffentlicht ${ }^{226}$.

In Anknüpfung an den Vortrag C. G. Jungs versuchte Viénot, den modernen Menschen - und damit das Lebensgefühl der Jugend - zu definieren. Seiner Meinung nach war der moderne Mensch ein Suchender, der Glauben und Hoffnung verloren habe und nun eine neue Gesellschaft, ein neues Sittengesetz, ja eine Metaphysik anstrebe:

Ein neues Lebensgefuihl, das geistiges und seelisches Leben nur mehr in Bewegung, Rhythmus und ständige Emeuerung begreift, erfullt den modernen Menschen. [...] Die einzige Schwierigkeit besteht darin, daß der moderne Mensch nicht in einer modernen, sondern lediglich in einer zeitgenössischen Welt lebt. Dadurch entstehen die Konflikte [...] aus dem Zwiespalt zwischen dem modernen Denken und dem moralischen, sozialen und politischen Zustand der Gegenwart. Keine Epoche hat wohl so ein paradoxes Nebeneinander wie heute gekannt $^{227}$.

Diese offensichtlichen Paradoxien und Ungleichzeitigkeiten waren jedoch in den Augen Viénots vor allem oberflächlicher Natur, denn der moderne Mensch trage die Vergangenheit, die sich ihm scheinbar widersetze, in sich. "Die Unordnung«, so resümierte er, »besteht lediglich in den Dingen der heutigen Welt, während der moderne Mensch nach Nietzsches Gleichnis von dem raus sich selbst rollenden Rads in seiner Bewegung das Gleichgewicht gefunden hat ${ }^{228}$. Die Suche des Menschen - und in diesem Falle wohl vor allem des Intellektuellen - als sinnstiftende Erfahrung, so könnte man die Worte Viénots interpretieren. Die Widersprüche der Epoche liegen demnach im Menschen selbst und lösen sich in ihm auf, während er auf der Suche nach der ihm angemessenen Umwelt den Sinn seines Daseins findet. Diese Sicht auf die zeitgenössische Problematik sagt viel über die Eigendefinition Viénots aus. Er selbst gehörte zu diesem Typus des intellektuellen modernen Menschen, der be-

${ }^{226} \mathrm{Vgl}$. Le CORBUSIER, Neue Gesinnung in der Baukunst, in: Europdische Revrue 4,2 (1928/29) S. 689-700; C. G. JUNG, Das Seelenproblem des modernen Menschen, in: ibid. S. 700-715; Arthur FONTAINE, Strukturwandel des Staates durch die Technik, in: ibid. S. 721-728; Hendrik de MAN, Die sozialen Wirkungen der Technik, in: ibid. S. 594-602.

${ }^{227}$ Elemente der modernen Zivilisation. Der Verband fur kulturelle Zusammenarbeit in Prag, in: ${ }^{228}$ Ibid. Europdische Revue 4,2 (1928/29) S. 716-721, hier S. 719. 
ständig seine Epoche und seine eigene Rolle reflektiert. Viénot sah sich selbst als einer derjenigen, die sden positiven Glaubenssätzen, den objektiven Wahrheiten ein Nein entgegen[setzen], aus dem keine Verzweiflung oder Beunruhigung, sondern eine leidenschaftliche Selbstbehauptung und Lebensbejahung spricht ${ }^{229}$. Das Neue, Moderne, ja das Paradoxe der Epoche zog ihn an, und in seinem Buch »Incertitudes allemandes« verlieh er seiner Faszination für die tumultuarische Weimarer Republik Ausdruck.

Über den Kulturbund und den Heidelberger Kreis um Alfred Weber, Arnold Bergsträsser und Max Clauss kam Viénot auch in Kontakt mit der Europäischen Revue, die Karl Anton Rohan 1925 gegründet hatte und die eine der führenden Europazeitschriften der Zwischenkriegszeit wurde. Max Clauss, der auf Vermittlung Viénots hin in Paris an der École libre des Sciences politiques und an der École normale supérieure ein Austauschsemester verbracht hatte, übernahm 1926 die Redaktion der Zeitschrift, die nach seinen Worten, »der Formierung einer jungen Reserve in Europa, vor allem der Sammlung und Weiterbildung ihrer Elite ${ }^{230}$ dienen wollte. Zur Redaktions- und Autorenmannschaft der Europäischen Revue gehörten neben Max Clauss auch Arnold Bergsträsser und Alfred Weber sowie der Jurist Carl Schmitt. Die Zeitschrift gab sich ein modernes und westlich-mondänes Erscheinungsbild, das auf junge Konservative wie auch auf einige Liberale anziehend wirkte. Vom Redakteur Max Clauss ist die Pointe überliefert, daß in seinen Augen »erklärte Zivilisationsfeinde« wie Ernst Jünger oder der Jurist Hans Grimm die inhaltlich denkbare Mitarbeit an der Europäischen Revue so angewidert abgelehnt hätten, »als wenn sie in einer Nacktrevue mit Josephine Baker hätten auftreten sollen ${ }^{231}$. Obwohl die Zeitschrift in den Augen Müllers von Anfang an als Organ der Konservativen Revolution geplant gewesen sei, so versammelte sie Autoren, deren politisches Spektrum weit über Rohans jungkonservative Neigungen hinausging und die Europäische Revue zur bedeutendsten deutschsprachigen Europazeitschrift der Zwischenkriegszeit werden ließen. Zu ihnen zählten unter anderem Henri Lichtenberger, Ernst Robert Curtius, Wladimir d'Ormesson, C. G. Jung, Émile Mayrisch, D. H. Lawrence, Ortega y Gasset, André Malraux, Hendrik de Man, Émile Vandervelde und Paul Valéry sowie die Mitglieder der Enquêtes-Gruppe Pierre de Lanux, Alfred Fabre-Luce, Henry de Montherlant, Ramon Fernandez und Drieu la Rochelle. Die zumindest in ihrer Anfangsphase durch Meinungspluralismus geprägte Europäische Revue spiegelte ein gesamteuropäisches Problem- und Krisenbewußtsein wider und bot den Autoren ein Diskussionsforum zur Erörterung der unterschiedlichsten ordnungspolitischen und weltanschaulichen Vorstellungen. Vertreter des französischen Linksrepubli-

${ }^{229}$ Ibid.

${ }^{230}$ Zit. nach MOLLER, Der Publizist Max Clauss, S. 389.

${ }^{231}$ Zit. nach DEMS., Deutsch-französische Gesellschaftsbeziehungen, S. 446. 
kanismus kamen in ihr ebenso zu Wort wie Repräsentanten der Konservativen Revolution oder des italienischen Faschismus ${ }^{232}$.

Seit 1926 erschien in der Europäischen Revue die Rubrik »Das junge Europa«, die "von einer sehr breit gefaßten, ideologisch fast nicht fixierten Grundeinstellung des Bewußtseins der Weltkriegsgeneration her [...] die großen politischen Probleme ${ }^{233}$ behandeln wollte. Rohan verwies auf den intendierten "politischen Realismus«, der aus dem Bewußtsein hervorgehe, daß »die herkömmlichen Polaritäten zwischen rechts und links unwiederbringlich der alten Welt angehören, deren gigantischen Zusammenbruch wir heute erleben ${ }^{234}$. Auch hier wurde also ein Projekt lanciert, welches - eigentlich ganz im Sinne Viénots - die überkommenen Parteigrenzen zu überwinden suchte ${ }^{235}$. Es ist daher auffällig, daß Viénot trotz seiner guten Kontakte zum Kulturbund und seiner Freundschaft vor allem zu Max Clauss nur einen einzigen Artikel in der Europäischen Revue veröffentlichte, der 1926 unter dem etwas pathetischen Titel »Schicksal und Vernunftu erschien. Viénot untersuchte darin die verschiedenen Bedeutungen des Begriffs »Europa« in Frankreich und in Deutschland, die sich seiner Meinung nach regelrecht entgegenstünden. Während in Frankreich Europa mit dem Völkerbund gleichgesetzt werde, lehne Deutschland diese Vorstellung ab:

Dieses Europa deutscher Geistesart bietet dem Menschen, dem es als eine Tatsache geschenkt und von dem es nicht gewollt ist, einen gänzlich verschiedenen Seinskreis von jenem Europa, das französischer Geist erträumt. Anstatt ein ‘Bund, eine ‘Gesellschaft‘ zu sein, ist es eine >Gemeinschaft, in deren Schoß der Mensch sein Schicksal kennen, aber nicht bestimmen kann, in der er Teil eines Körpers ist und nicht eines der rastlos tätigen Glieder einer moralischen Wesenheit ${ }^{236}$.

In Viénots Augen standen sich zwei Geistesrichtungen gegenüber: auf der einen Seite der Rationalismus der Franzosen, auf der anderen Seite der Pantheismus der Deutschen, auf der einen Seite Vernunft, auf der anderen Schicksal. Diese national-antithetische Sichtweise sollte ihre Auflösung finden in einer Synthese, das heißt ins Praktische gewendet, einer deutsch-französischen Zusammenarbeit. Dieses Bekenntnis zu einer national begründeten und auf Komplementarität ausgerichteten Verständigung war genau die Konzeption, die er mit dem Deutsch-Französischen Studienkomitee umzusetzen suchte. Gleichzeitig sah er aber auch Verbindungen zwischen der deutschen und der französischen Jugend:

${ }^{232} \mathrm{Vgl}$. Bock, Das "Junge Europa《, S. 315ff.

${ }^{233}$ Karl Anton ROHAN, Das erste Jahr des "Jungen Europau, in: Europaische Revue 2,2 (1926/27) S. 383-384, hier S. 383.

234 Ibid.

${ }^{235}$ Rohan bekräftigte: "Es handelt sich im Jungen Europar wirklich nicht darum, das Rechts und Links der alten Welt zum Gespensterkampf aus dem Grabe zu holen, oder, um es realistischer auszudrücken, durch Injektionen am Leben zu erhalten, sondern unsere Pflicht ist es einzig und allein, allen lebens- und zukunftsfeindlichen Ideologien entgegen unsere lebendige realistische Haltung durchzusetzen«. Ibid. S. 384.

${ }^{236}$ VÉNNOT, Schicksal und Vernunft, S. 298. 
Die Generation [der Franzosen] endlich, die im Kriege heranwuchs, steht unbewußt deutscher Geistesrichtung durch ihr Pflichtbewußtsein, ihr Ertragen der Härten des Lebens, durch ihr Entsagen gegenüber dem Individualismus der letzten Generation, vielleicht sogar durch ihren verminderten Freiheitsdrang nahe ${ }^{237}$.

Gerade diese Generation der deutschen Jugend interessierte Viénot besonders, denn von ihr erwartete er wichtige neue Impulse für den politischen Gärungsprozeß in Deutschland. Seit seinem Heidelberg-Aufenthalt 1924 war er mit dem gleichaltrigen Amold Bergsträsser, dem Schüler des Soziologen Alfred Weber, befreundet. Uber ihn kam er in Kontakt mit der bündischen Jugendbewegung und mit den von ihren Anhängern gelesenen Schriftstellem ${ }^{238}$. So versorgte Viénot seine Freunde Gide und Schlumberger mit den Schriften Hans Blühers, der in seiner Darstellung der Wandervogel-Bewegung die Lehre vom Männerbund propagierte ${ }^{239}$. Gleichzeitig verlieh er seiner offenen Bewunderung für den Dichter Stefan George Ausdruck:

Stephan George est à mes yeux le plus grand poète vivant et son influence morale malheureusement de plus en plus travestie et rétrécie par ses disciples - est encore considérable. Il n'est pas exagéré de dire, je crois, que l'élite intellectuelle de la jeunesse all[eman]de la subit dans la plus large mesure ${ }^{240}$.

Die Bekanntschaft mit den Schriften des von der bündischen Jugend verehrten Stefan George könnte auch durch Ernst Robert Curtius erfolgt sein, denn dieser hatte sich während seiner Studienzeit zeitweilig im Umkreis des neoromantischästhetizistischen George-Zirkels bewegt und war nachhaltig von diesem geprägt

${ }^{237}$ Ibid. S. 300.

${ }^{238}$ Die bündische Jugendbewegung war nach dem Ersten Weltkrieg aus einer Verbindung der Ideale von Wandervogelbewegung und Pfadfindertum entstanden und verstand sich als ein auf Führung und Gefolgschaft beruhender Zusammenschluß. Vgl. Werner KINDT (Hg.), Die deutsche Jugendbewegung 1920 bis 1933. Die bündische Zeit, Düsseldorf, Köln 1974; Walter Z. LAQUEUR, Die deutsche Jugendbewegung. Eine historische Studie, Köln 1962; Thomas ROHKRAMER, Eine andere Moderne? Zivilisationskritik, Natur und Technik in Deutschland 1880-1933, Paderbom u.a. 1999, S. 141-156.

${ }^{239}$ Hans BLUHER, Wandervogel. Geschichte einer Jugendbewegung, 3 Bde., Berlin 1912. Vgl. Viénot an an Schlumberger, 10.10.1923: BLJD, Fonds Schlumberger, Ms 18303; ders. an Gide, 16.10.1023: BLJD, Fonds Gide, $\gamma$ 844.2. Aus den Briefen geht nicht explizit der Titel des Blüher-Werkes hervor. Vermutlich handelt es sich aber um das in der Jugendbewegung vieldiskutierte Hauptwerk Blühers: Die Rolle der Erotik in der männlichen Gesellschaft. Eine Theorie der menschlichen Staatsbildung nach Wesen und Wert, 2 Bde., München 1917/1919. Zu Blüher vgl. Hans-Thomas HAKL, Blüher Hans, in: Caspar von SCHRENCKNOTZING (Hg.), Lexikon des Konservatismus, Graz, Stuttgart 1996, S. 70-72.

${ }^{240}$ Viénot an Bloch, 23.10.1931: BN, Papiers Bloch, XLVII, Lettres adressées à Jean-Richard Bloch. Während seines Heidelberg-Aufenthalts hatte Viénot auch Kontakt zu Friedrich Gundolf, der dem George-Kreis angehörte. Vgl. Viénot an seine Mutter, 15.12.1924: NL Viénot. Stefan Breuer rechnet das Werk Georges dem »Ästhetischen Fundamentalismus « zu. Vgl. Stefan BREUER, Ästhetischer Fundamentalismus. Stefan George und der deutsche Antimodernismus, Darmstadt 1995. Vgl. auch Michael WINKLER, Der Jugendbegriff im GeorgeKreis, in: KOEBNER, Der Mythos Jugend, S. 479-499. 
worden $^{241}$. Auch Alfred Weber zeigte seinerseits Sympathien für George. Die von Weber proklamierte "Notwendigkeit einer national-integrativen Prägekraft des /Geistigen « $^{242}$ traf sich wiederum mit den Vorstellungen Curtius' über die Rolle der Geisteswissenschaften. Es war darum kein Zufall, daß Curtius und der Weber-Schüler Bergsträsser 1930 zusammen ihr zweibändiges Frankreichbuch veröffentlichten ${ }^{243}$, welches geprägt war von einer »kontrastivantithetischen Wahrnehmung, die die gesamte Darstellung des Gemeinschaftswerks von Curtius und Bergsträsser über Frankreich bestimmte und darüber hinaus zum Signum des deutschen Frankreichbildes der Zwischenkriegszeit wurde ${ }^{244}$. Der Heidelberger Kreis, in dem Viénot sich 1924 aufhielt, und zu dem auch Max Clauss gehörte, beeinflußte Viénots Bild der deutschen Jugend. Zwar dürfte Viénot, der gegen Ende der zwanziger Jahre seine auf nationalen Grundlagen beruhende Verständigungskonzeption revidierte, kaum der nationalpsychologischen Deutung in Curtius' und Bergsträssers Frankreichbuch zugestimmt haben, zumal er Curtius 1931 eher dem »ewigen« als dem »modernen $\ll$ Deutschland zurechnete ${ }^{245}$. Dennoch teilte er ihren Glauben an die deutsche Jugend als moderne politische Kraft.

Um den Austausch der deutschen und der französischen Jugend zu fördern, nutzte Viénot auch seine Beziehungen zu Lyautey als Vorsitzenden der französischen Pfadfinder. Dieser sollte aufgrund seiner Position dazu beitragen, eine Studienreise deutscher Jugendverbände nach Frankreich zu erleichtern ${ }^{246}$. Ein Mitglied dieser Studentengruppe war Ernst Wilhelm Eschmann aus der Deutschen Freischarbewegung. Er war von Alfred Weber mit einer Arbeit über den italienischen Faschismus promoviert worden und gehörte ab 1929 zur Redaktion der Zeitschrift Die Tat. Viénot schilderte Lyautey die Jugendbewegung als eine der interessantesten Erscheinungen der "Allemagne nouvelle ${ }^{247}$, als eine intellektuelle Bewegung, die mehr sei als reines Pfadfindertum. Die

${ }^{241}$ Vgl. Bock, Die Politik des "Unpolitischen«, S. 17f. Bock hebt den Einfluß des GeorgeKreises auf Curtius hervor, denn das sich dort abzeichnende »Interaktionsmuster einer durch Kooptation sich ergänzenden Kulturelite mit gesellschaftlichem Führungsanspruch blieb für Curtius weit über seine Zugehörigkeit zum George-Kreis hinaus prägend«. Ibid. S. 19.

Curtius zeigte sich auch angetan über Blühers »Rolle der Erotik in der männlichen Gesellschaft «: "Das ist der Atem der Jugend und des Märzwindes, der befeuerte Pulsschlag aus dem der Reigen, der Hymnus, das heroische Leben geboren wird. Es ist so schön, daß Blüher alle liberalen und fortschrittlichen Ideologien verpönt«. Zit. nach ibid. S. 31 f.

${ }^{242}$ Horst SCHMTT, Existentielle Wissenschaft und Synopse. Zum Wissenschafts- und Methodenbegriff des ijungen A Arnold Bergsträsser (1923-1936), in: PVS 30 (1989) S. 466-481, hier S. 469.

${ }^{243}$ CURTIUS, Die französische Kultur; BERGSTRĀSSER, Staat und Wirtschaft Frankreichs.

${ }^{244}$ BOCK, Die Politik des »Unpolitischen«, S. 31.

${ }^{245} \mathrm{Vgl}$. VIÉNOT, Incertitudes allemandes, S. 97.

${ }^{246}$ Vgl. Viénot an Lyautey, 23.2.1928: AN, 475 AP 311; Lyautey an Viénot, 28.2.1928: NL Viénot. Vgl. auch RAY, Annäherung an Frankreich, S. 37.

${ }^{247}$ Viénot an Lyautey, 23.2.1928: AN, 475 AP 311. 
Jugend, die für ihn einen »esprit nouveau« verkörperte, sei vor allem auf der Suche nach neuen Werten:

Ces garçons remettent en question la plupart de la génération qui les a procédés. Ils cherchent une sposition d'esprit‘ neuve, une hiérarchie sociale autre que la hiérarchie de l'argent, travaillant, si j'ose dire, à une shumanisation des relations sociales et, pour employer leur propre expression, à la création d'un inouveau type d'homme ('der neue Mensch') plus ivrair, plus simple et aussi moralement mieux adapté à la vie moderne que le type conventionnel d'il y a trente ans ${ }^{248}$.

Die Affinität Viénots zur Jugendbewegung dürfte auch von ganz anderer Seite Unterstützung gefunden haben. Andrée Mayrisch, mit der Viénot seit Mitte der zwanziger Jahre zunehmend enger befreundet war, gehörte in ihrer Jugend selbst der Pfadfinderbewegung "Les campeuses bronzées de Dudelange« an und behielt auch in späteren Jahren ein starkes Interesse an Bildungs- und Erziehungsfragen ${ }^{249}$. Die beiden standen in ihren Berliner Jahren in engem Kontakt mit den Kreisen um den preußischen Kultusminister Carl Heinrich Becker, die sozial- und bildungsreformerische Projekte lancierten. Becker, der wie Viénot große Hoffnungen auf die erneuernde Kraft der Jugendbewegung setzte, propagierte das Ideal eines "neuen Menschen«, der in pädagogischen Hochschulen ausgebildet werden sollte. Der »neue Mensch « war laut Becker, "völlig unpolitisch, aber ein Gemeinschaftsmensch, in dem nicht nur die Jugendbewegung weiterlebt, sondern auch das Kriegserlebnis, in dem die Sehnsucht nach neuer geistiger und seelischer Bindung lebendig ist, in dem eine starke Religiosität pulsiert, der junge Mensch sozialer Gesinnung ${ }^{250}$. In diesem Diskussionszusammenhang traf Viénot mit Persönlichkeiten wie Eugen Rosenstock, der »treibende[n] Kraft der Erwachsenenbildung in den zwanziger Jahren ${ }^{251}$, Helmuth James Graf Moltke und Adolf Reichwein zusammen, die sich mit Ideen über die »neue Erziehung" der Reformpädagogik und Jugendbewegung sowie über den »neuen Menschen« in einer modernen sozialen und demokratischen Ordnung auseinandersetzten ${ }^{252}$. Rosenstock, Moltke sowie Carl Dietrich von Trotha organisierten 1928 bis 1930 im schlesischen Löwen-

${ }^{248}$ Ibid.

${ }^{249}$ Als sie in Berlin ihre Promotion vorbereitete, interessierte sich Andrée Mayrisch auch für die Wandervögel, mit denen sie zusammentraf und die sie sehr positiv beurteilte. Andrée Mayrisch an ihre Mutter, 9.11.1925; NL Viénot. Vgl. auch MỨLLER, Andrée Mayrisch und Pierre Viénot, S. 134.

${ }^{250}$ Zit. nach MULLER, Weltpolitische Bildung, S. 389.

${ }^{251}$ Ger van ROON, Neuordnung im Widerstand. Der Kreisauer Kreis innerhalb der deutschen Widerstandsbewegung, München 1967, S. 26.

${ }^{252} \mathrm{Vgl} \mathrm{hierzu} \mathrm{allg.} \mathrm{Ulrich} \mathrm{JUNG,} \mathrm{Eugen} \mathrm{Rosenstocks} \mathrm{Beitrag} \mathrm{zur} \mathrm{deutschen} \mathrm{Erwachsenenbil-}$ dung der Weimarer Zeit, Frankfurt a.M. 1970; Ulrich HERRMANN (Hg.), »Neue Erziehung" - "Neue Menschen «. Anstitze zur Erziehungs- und Bildungsreform in Deutschland zwischen Kaiserreich und Diktatur, Weinheim, Basel 1987 (Geschichte des Erziehungs- und Bildungswesens in Deutschland, 5). 
berg »Arbeitslager«, wo sich Studenten, Arbeiter und Bauern begegneten ${ }^{253}$. Der geistige Austausch von Menschen mit verschiedenen Erfahrungshintergründen, ideologischen Prägungen und sozialen Hintergründen wurde dort mit körperlicher Arbeit in Einklang gebracht. Die jungen Teilnehmer sollten innerhalb der Gemeinschaft lernen, sich in ihrer Verschiedenheit zu akzeptieren und Verantwortung zu übernehmen. Viénot war zweifellos von den pädagogischen Experimenten in Beckers Umfeld unterrichtet. Zusammen mit dem Bildungsreformer wollte er 1927 selbst eine woffensive dans les universités de Prusse orientale ${ }^{254}$ veranstalten, die jedoch nicht näher ausgeführt und anscheinend auch nicht verwirklicht wurde. Andrée Mayrisch war unterdessen besonders mit der Familie Reichwein befreundet. Mit Pierre Viénot teilte sie dessen Hoffnung auf die Jugend in Deutschland, die trotz der auch in ihren Reihen verbreiteten nationalistischen Tendenzen noch bis zu Beginn der dreißiger Jahre anhielt.

So nahmen an dem deutsch-französischen Jugendtreffen des Sohlbergkrei$\operatorname{ses}^{255}$ in Rethel vom 2. bis 9. August 1931 auch Viénot, der kurze Zeit vorher

${ }^{253}$ Aus den Teilnehmern der schlesischen Arbeitslager reknutierte sich später eine Reihe von Mitgliedern des Kreisauer Kreises, u.a. Carl Dietrich von Trotha, Horst von Einsiedel, Adolf Reichwein, Hans Peters, Peter Graf Yorck von Wartenburg, Otto Heinrich von der Gablentz, Theodor Steltzer und Fritz Christiansen-Weniger. Vgl. Eugen ROSENSTOCK, Carl Dietrich von TROTHA (Hg.), Das Arbeitslager. Berichte aus Schlesien von Arbeitern, Bauern, Studenten, Jena 1931; Christian ILLIAN, Freiheit in konkreter Verantwortung. Der Kreisauer Kreis und die schlesischen Arbeitslager für Arbeiter, Bauern und Studenten, Zu Helmuth James von Moltkes Konzept der »kleinen Gemeinschaften«, in: Dirk BOCKERMANN u.a. (Hg.), Freiheit gestalten. Zum Demokratieverständnis des deutschen Protestantismus, Kommentierte Quellentexte 1789-1989, Festschrift für Günter Brakelmann zum 65. Geburtstag, Göttingen 1996, S. 334-348; van ROON, Neuordnung im Widerstand, S. 26-34; KELLER, Dritte-Weg-Diskurse, S. 110. Keller weist auf den Einfluß personalistischer Ideen auf den deutschen Widerstand hin, vor allem durch die Rezeption des christlich-neoscholastischen Denkens von Jacques Maritain. Vgl. ibid. S. 111.

254 Viénot an seine Mutter, 18.3.1927: NL Viénot.

${ }^{255}$ Der Sohlbergkreis war im Sommer 1930 von Otto Abetz, dem Vorsitzenden der Arbeitsgemeinschaft Karlsruher Jugendbünde, und vom Journalisten Jean Luchaire als informelles und überpolitisches Forum für den deutsch-französischen Dialog der Jugend gegnündet worden. 1934 wurde Abetz Frankreichreferent der NS-Reichsjugendfuihnung, bevor ihn Ribbentrop für seine Dienststelle rekrutierte. Von 1940-1944 war er als deutscher Botschafter in Frankreich tätig. Vgl. Otto ABETZ, Das offene Problem. Ein Rückblick auf zwei Jahrzehnte deutscher Frankreichpolitik, Köln 1951, S. 26-40; Dieter TEMANN, Deutsch-französische Jugendbeziehungen der Zwischenkriegszeit, Bonn 1989 (Pariser Historische Studien, 28), S. 114-119; DERS., Nachwuchseliten für die Verständigung? Ein Aspekt deutsch-französischer Kulturbeziehungen in der Zwischenkriegszeit, in: Rainer HUDEMANN, Georges-Henri SOUTOU (Hg.), Eliten in Deutschland und Frankreich im 19. und 20. Jahrhundert. Strukturen und Beziehungen, Bd. 1, München 1994, S. 101-109; Rita ThalmanN, Du Cercle de Sohlberg au Comité France-Allemagne: une évolution ambiguë de la coopération francoallemande, in: BOCK, MEYER-KALKUS, TREBISCH, Entre Locamo et Vichy, Bd. 1, S. 6786. Zum Treffen in Rethel siche RAY, Annäherung an Frankreich, S. 57-65; UNTEUTSCH, Vom Sohlbergkreis zur Gruppe Collaboration, S. 59-63. 
seine »Incertitudes allemandes« veröffentlicht hatte, und sein Freund Max Clauss teil. Daneben waren auf französischer Seite unter anderem Bertrand de Jouvenel und Pierre Brossolette von Notre Temps sowie Robert Aron, Arnaud Dandieu, Philippe Lamour und Alexandre Marc ${ }^{256}$ vom Ordre nouveau anwesend. Die Euphorie des ersten Treffens ein Jahr zuvor ${ }^{257}$ war einer Desillusionierung gewichen angesichts der weit auseinanderliegenden Positionen von Deutschen und Franzosen hinsichtlich der Rüstungsfrage, der Reparationen oder der deutsch-österreichischen Zollunionspläne vom März 1931. Vor allem die deutschen Teilnehmer legten eine offen nationalistische und revisionistische Haltung an den Tag, so daß Jean Luchaire ihnen schwere Vorwürfe machte insofern als

les jeunes congressistes français se sont séparés nettement des vieilles générations, leur ont adressé de dures critiques et ont franchement abordé les vues d'avenir. Au contraire, chez les Allemands, aucune critique des agissements des forces au pouvoir, un ensemble frappant pour approuver les revendications les plus nationalistes ${ }^{258}$.

Viénot bemühte sich um eine vermittelnde Stellungnahme. Er zeigte Verständnis für die Enttäuschung der Deutschen angesichts einer französischen Politik, die dem deutschen Wunsch nach Liquidierung des Reparationsproblems nicht nachkommen wollte. Auf der anderen Seite warf er Frankreich vor, sich zu lange ein falsches Bild von Deutschland gemacht und von ihm eine Anpassung an die eigene Denkweise erwartet zu haben. Viénot forderte dazu auf, ein gemeinsames »terrain d'entente ${ }^{259}$ für die Zukunft zu suchen, statt weiterhin in gegenseitiger Unkenntnis zu verharren. Die lauten und zum Teil aggressiven, sich auf den Volkstumsgedanken berufenden deutschen Töne - so äußerte Erich Benz, der künftige Leiter des deutsch-französischen Schüleraustauschdienstes, der Franzose besitze »kein nennenswertes Rasseempfinden, wie er ja auch dem Eindringen fremden, farbigen Blutes, im Süden des Landes beispielsweise, kaum einen Widerstand entgegensetzt ${ }^{260}$ - lösten jedoch auch bei Viénot Erschrecken aus, und er warnte sque l'Allemagne doit prendre garde de ne pas revenir à un idéal qui l'asservirait ${ }^{261}$. In den Augen Dieter Tiemanns zählten Viénot und die Pariser Intellektuellen aus den nonkonformistischen Zirkeln zu den »hyperkritischen Teilnehmer[n] des Kongresses« und sorgten "gemeinsam mit einigen Deutschen, die sich auf ihre germanozentrischen Positionen versteift hatten, für ein scharfes Profil des deutsch-französischen Ge-

${ }^{256}$ Alexandre Marc unterhielt engen Kontakt zu Otto Abetz. Anders als dessen Partner Jean Luchaire lehnte Marc jedoch die Organisation eines pazifistischen Kongresses ab. Vgl. RoY, Alexandre Marc, S. 211 und S. $214 f$.

${ }^{257}$ Vgl. dazu die Sondernummer in: Notre Temps, 10.8.1930.

${ }^{258}$ Notre Temps, 16-23.8.1931, Sp. 649f.

${ }^{259}$ Ibid. Sp. 633f.

${ }^{260}$ Erich BENZ, Deutsch-französisches Jugendtreffen in Frankreich. Der Kongreß von Rethel, 2.-9. August 1931: DFR 4 (1931) S. 782-785, hier S. 783.

${ }^{261}$ Notre Temps, 16-23.8.1931, Sp. 648. 
gensatzes $\aleph^{262}$. Die zunehmende Hinwendung zu betont nationalen Standpunkten wie sie Viénot bereits im Studienkomitee erlebt hatte, sah er nun selbst bis in jene Teile der Jugend vordringen, die sich europäisch gaben. Viénot machte für diese Entwicklung jedoch Frankreich mitverantwortlich. $\mathrm{Zu}$ lange habe es von Deutschland eine Konversion zum französischen Denken gefordert und auf diese eine deutsch-französische Annäherung begründen wollen. Nun dürften sich die Franzosen nicht darüber wundem, daß als Reaktion darauf die deutsche Jugend die europäische Verständigung auf einer nationalen Konzeption des Deutschtums vollziehen wolle. Viénot sah es jedoch als sein Recht, wenn nicht seine Pflicht an, gegen die eine wie die andere Entwicklung zu protestieren: »Mais nous qui avons protesté contre la première tendance, nous avons le droit de protester contre la seconde et je ne m'en suis pas privé « ${ }^{23}$.

Was so unterschiedliche geistige und politische Tendenzen wie den Europäischen Kulturbund, die bündische Jugendbewegung, die reformpädagogischen Ansätze um Becker und den reformerischen Sozialismus eines Adolf Reichwein über alle Trennlinien hinweg verbanden, das war das Bestreben, etwas Neues zu schaffen. Die Zielrichtung dieser Bestrebungen und die eingesetzten Mittel mochten grundsätzlich verschieden sein, doch ihnen allen haftete etwas Modernes an, der Wunsch nach Revision des Bestehenden. Diese Absichten waren charakteristisch für die Epoche, sie drückten gewissermaßen den Zeitgeist aus. In der Person Viénots schienen sich die diversen, sich teilweise widersprechenden und letztlich doch alle auf die Überwindung des Bestehenden zulaufenden Tendenzen gleichsam zusammenzuziehen. Die Beobachtung und Beteiligung an diesen Bewegungen entsprach einem tiefen inneren Bedürfnis Viénots, an der Erneuerung teilzuhaben. Die Suche nach seinem eigenen Standort sowie nach einem adäquaten, modernen System für Frankreich machten die deutschen Experimente, kamen sie nun von rechts oder links, umso faszinierender. Konnten sie Anregungen geben für die künftige Gestalt der Dritten Republik? Das verwirrende und chaotische geistige Deutschland der Weimarer Republik wurde für Viénot nicht nur als politischintellektuelles Beispiel einer ihre Ordnung suchenden Nation gesehen, es wurde darüber hinaus auch zur Projektionsfläche seiner eigenen Ungewißheiten: die »Incertitudes allemandes« verbanden sich mit seinen wincertitudes personnelles« zu einer Hoffnung auf ein neues Zivilisationsmodell in Deutschland, welches für Frankreich zum Beispiel werden könnte. Diese Vorbildfunktion des deutschen Suchens bezeichnete Viénot später im Rückblick als einen wichtigen Grund seiner Hingezogenheit zum Nachbarland:

Alle Probleme der modernen Welt und des modernen Menschen sind dort gestellt worden. [...] Alle, die in dieser Zeit am inneren Leben Deutschlands teilnahmen, fühlten sich diesem Streben tief verbunden. Sie waren sich bewusst, dass ihre eigene Existenz mit auf dem Spiele

${ }^{262}$ TIEMANN, Deutsch-französische Jugendbeziehungen, S. 122.

${ }^{263}$ Viénot an d'Ormesson, 10.8.1931: NL d'Ormesson II. 
stand. Das geistige Ringen in Deutschland nahm europăische, nahm Weltmasstäbe [sic] an. Dieses Deutschland war zu einem Menschheitswert geworden. Man hatte Grund zu der Annahme, dass es - wie andere Länder zu anderen Zeiten neue Formen der Zivilisation und des Gemeinschaftslebens geschaffen haben - sich der Welt erschliessend, sich selber finden werde ${ }^{264}$.

Die Suche eines Landes voller Ungewißheiten, im Inneren verworren und tumultuarisch, übte nicht trotz, sondern gerade wegen dieser Beschaffenheit eine Faszination auf Viénot aus. Der innere Tumult und Aufruhr, die Infragestellung tradierter Wertvorstellungen entsprach der Orientierungslosigkeit des ehemaligen Weltkriegsteilnehmers, der auf der Suche war nach einer politischen und geistigen Heimat.

\subsection{Die Revision politischer Ansichten}

Die zwanziger Jahre stellten für Pierre Viénot eine Orientierungsphase dar, sowohl in politischer wie auch in persönlicher Hinsicht. Während seine politischen Reflexionen um den Gedanken der politischen Ordnung in Frankreich und um ein angemessenes Verhältnis zu Deutschland kreisten, so machte er auch eine private Evolution durch, die ihn weg führte von seinem Ursprungsmilieu. Bereits zu Beginn der zwanziger Jahre hatten die Erfahrungen in Marokko, danach seine Anlehnung an André Gide und seine Bekanntschaft mit der Mayrisch-Familie die Begrenzungen seines bürgerlich-konservativen Herkunftsmilieus aufgebrochen. Diese Phase der Abnabelung setzte sich im Laufe des Jahrzehnts fort. Dabei versuchte Viénot einen Spagat zwischen einem Leben, dessen Werte, Inhalte und Ziele er aus eigenen Erkenntnissen und Bedürfnissen formulierte und seiner Verbundenheit zur Familie, für die Religiosität und Tradition eine zentrale Rolle spielten. Daß dieser Brückenschlag mit zunehmender Emanzipierung von seinem Herkunftsmilieu immer schwieriger wurde, mag zu Viénots »incertitudes personnelles« beigetragen haben. So versicherte er 1926 seiner Mutter, er sei »profondément >familial « ${ }^{265}$, mußte jedoch bald danach auch gestehen, daß er ein seltsamer Sohn sei »qui rentre assez mal dans les catégories dans lesquelles on est habitué à classer les gens `dans nos milieux « ${ }^{266}$. Sein 30 . Geburtstag regte Viénot ebenfalls zu Reflexionen über seine Entwicklung an, und er stellte fest, daß er derjenige der vier Viénot-Brüder sei, der stets das abenteuerlichste, individuellste und am wenigsten mit dem traditionellen Modell übereinstimmende Leben geführt habe $^{267}$. Zeitweise führte dieser Individualismus auch zu Konflikten mit seinen Eltern, und bisweilen schien ihm sein Lebensstil für diese nicht vermittelbar.

${ }^{264}$ Pierre VIÉNOT, Um Frankreich zu retten - und Deutschland mit ihm, in: Die Zukunft. Ein neues Deutschland: Ein neues Europa!, 28.4.1939.

${ }^{265}$ Viénot an seine Mutter, 13.8.1926: NL Viénot.

${ }^{266}$ Ders. an dies., 26.4.1927: NL Viénot.

${ }^{267}$ Ders. an dies., 5.8.1927: NL Viénot. 
"Mais ma vie presque tout entière échappe à ta compétence...«, fuhr er seine Mutter im Jahr 1928 ein wenig harsch an, set tu n'y peux rien! Tu ne connais personne des gens que je vois... Tu ne peux t'intéresser aux choses que je fais... Alors? Avec la meilleure bonne volonté je n'ai pas grand'chose à te raconter ${ }^{268}$. Die zeitweilige Kommunikationsstörung mit der Familie gipfelte in einem regelrechten Eklat, als sich Viénot und Andrée Mayrisch, beide ungläubig, im Juli 1929 für eine zivile Trauung ohne kirchlichen Segen entschieden. André Viénot machte seinem jüngsten Bruder daraufhin eine "scène épique, lui disant qu'il trahit sa lignée, son milieu; qu'il est un révolté, un malfaiteur; qu'il se met au ban de sa classe... ${ }^{269}$. Die Dissonanzen zwischen den Brüdern kehrten in den folgenden Jahren immer wieder, führten aber nie zum Bruch. Die Familie akzeptierte die Entscheidungen des Sohnes, wenngleich sie sie wohl kaum hatte nachvollziehen können. Als Viénot 1940 vor einem Militärgericht des Vichy-Regimes stand, übte sich die Familie in Solidarität. Es war der Bruder André, der Viénots Verteidigung übernahm.

Nicht nur in persönlicher Hinsicht nabelte sich Viénot von den Vorstellungen seines Geburtsmilieus ab. Auch in bezug auf seine politischen Ansichten veränderte sich gegen Ende der zwanziger Jahre sein Koordinatensystem in entscheidender Weise. 1930 war Viénot aus dem von ihm mitbegründeten DeutschFranzösischen Studienkomitee ausgeschieden in der Einsicht, daß von den dort vertretenen konservativen Eliten die erhoffte außenpolitische Innovation nicht geleistet worden war. Ende der zwanziger Jahre rissen in der Folge der Verschlechterung der politischen Beziehungen die nationalen Interessenkonflikte zwischen der deutschen und der französischen Sektion wieder auf, und Viénot revidierte sein ursprüngliches, auf nationalen Grundlagen formuliertes Verständigungskonzept. Hatte er Mitte der zwanziger Jahre einem wie immer gearteten "ssuper-état européen « eine klare Absage erteilt und sich für den Ausbau gemeinschaftlicher nationaler Interessengrundlagen in politischer, wirtschaftlicher und kultureller Hinsicht ausgesprochen ${ }^{270}$, so löste er sich zum Dekadenwechsel von dieser Position. Eine national-kulturelitäre Haltung à la Curtius, der er sich lange Zeit verbunden gefühlt hatte, konnte für ihn nicht länger der Ausgangspunkt für weitere Verständigungsbemühungen sein. Diese Umorientierung manifestierte sich in der Auseinandersetzung mit den Thesen Friedrich Sieburgs zum deutsch-französischen Problem, die der Pariser Korrespondent der Frankfurter Zeitung 1931 in der Neuen Rundschau veröffentlicht hatte ${ }^{271}$. Sieburg konstatierte, daß »die dünnen Fäden zwischen Deutschland und Frank-

${ }^{268}$ Ders. an dies., 22.9.1928: NL Viènot.

${ }^{269}$ D'Ormesson, Pierre Viénot, S. 95: NL d'Ormesson II.

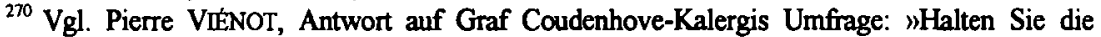
Schaffung der Vereinigten Staaten von Europa für notwendig? Halten sie das Zustandekommen der Vereinigten Staaten von Europa für möglich?«, in: Paneuropa 2 (1925/26) H. 6/7, S. 52-54.

${ }^{271} \mathrm{Vgl}$. zu der Kontroverse BocK, Friedrich Sieburg et Pierre Viénot. 
reich fast zerrissen scheinen « und bescheinigte der deutschen Jugend eine ablehnende Haltung gegenüber Frankreich ${ }^{272}$. Er plädierte für eine Verständigung mit Frankreich, deren Konzept jedoch die antithetisch-nationalpsychologische Deutung des Autors offenbarte. Deutschland und Frankreich sah Sieburg als vom Schicksal bestimmte Gegenspieler. »Euch das Glück, uns das Schicksal, Euch die Vollkommenheit, uns die Größe, Euch den Frieden, uns den Aufruhr «, mit diesen und anderen Gegenüberstellungen versuchte Sieburg salles Wesen, ja das Universum zwischen den beiden größten Völkern der Welt« zu teilen ${ }^{273}$. Die in dieser Opposition auftretenden Spannungen könnten seiner Meinung nach nicht durch Europa gelöst werden, denn dies war ihm eine zu unkonkrete und letztlich nicht geeignete Größe zur Bereinigung des deutsch-französischen Verhältnisses. "Das Problem《, so resümierte Sieburg, »ist nur aus einer ınotion nationale ‘ heraus oder überhaupt nicht zu lösen $\aleph^{274}$.

Genau dieses Annäherungskonzept auf der Basis einer nationalen Politik kritisierte Viénot in seiner Replik auf Sieburg, denn seiner Meinung nach führte es in eine Sackgasse. Die von Sieburg konstruierten Gegensatzpaare erschienen Viénot sinnlos, und er sah die Gefahr, "zu den schlimmsten Gepflogenheiten des Schrifttums der Kriegsjahre ${ }^{275}$ zurückzukehren. Die nationale Methode besaß in seinen Augen keinen wirklichen Erkenntniswert, denn das Bemühen um gegenseitiges Verstehen als Voraussetzung der Verständigung führe aus einem nationalen Blickwinkel immer nur zur Suche nach dem Fremden beim Gegenüber. Dieser Eindruck vom anderen entspreche aber nicht der Wirklichkeit: „Die nationale Einstellung zeigt uns ein Bild des anderen Volkes, das in Wirklichkeit unser eigenes Bild ist, aber umgedreht und gegensätzlich, sozusagen unser photographisches Negativ ${ }^{276}$. Durch sinnlose Verallgemeinerungen würde dann ein Konflikt völlig unvereinbarer Nationalcharaktere konstruiert, der sich auf eine Objektivität berufe, die im Grunde nichts anderes sei als »die Unfähigkeit, aus sich selbst herauszugehen«, also eine ausgesprochene Subjektivität ${ }^{277}$.

Viénot gestand, selbst jahrelang so gedacht zu haben, doch nun erscheine ihm diese Methode aussichtslos, denn auf einer vermeintlichen Gegnerschaft könne keine Verständigung aufgebaut werden. Das deutsch-französische Problem müsse vielmehr, so forderte es Viénot, in den größeren Kontext eines Kulturproblems eingeordnet werden, nämlich dem Problem des Individuums in der modernen Gesellschaft:

${ }^{272}$ Friedrich SIEBURG, Deutschland und Frankreich, in: Die Neue Rundschau 42,2 (1931) S. 303-315, hier S. $303 f$.

273 Ibid. S. 313.

${ }^{274}$ SEBURG, Deutschland und Frankreich, S. 307

${ }^{275}$ VIÉNOT, Frankreich und Deutschland, S. 722.

276 Ibid. S. 724.

${ }^{277}$ Ibid. S. 725. 
Eine deutsch-französische Verständigung kann nur dann entstehen, wenn den deutschfranzösischen Beziehungen ein Bemühen um die Lösung jenes größeren Problems zugnunde gelegt wird und wenn beide Länder jener europäischen Kultur ihre Treue bezeugen, deren Wesen ewiges Vorwärtsdrängen ist und die nicht in ihrer Vergangenheit gerettet werden kann - möge diese Vergangenheit bürgerlich oder snational c heißen -, sondern nur in ihrer Zukunft. Der Konflikt kann nur gelöst werden durch die gemeinsame Arbeit an einer neuen Ordnung, die uns, Frankreich und Deutschland, mit all unseren Verschiedenheiten in sich einschließt, aber die über uns hinauswächst und in der unser Gegensatz sich auflöst ${ }^{278}$.

Der gegenseitige Verzicht auf die nationale Auseinandersetzung sei dabei der erste und unabdingbare Schritt für eine internationale und vor allem deutschfranzösische Verständigung. Der von Viénot verwendete Begriff der wneuen Ordnung« ist sicherlich nicht zufällig gewählt und verweist auf dessen Streben nach gesellschaftlicher und politischer Emeuerung. Während jedoch in den zwanziger Jahren der Begriff des wordre« immer dazu herangezogen wurde, die innere Beschaffenheit eines politischen Systems zu bezeichnen, wird er hier zum ersten Mal in internationaler Hinsicht benutzt. Diente bis dahin die Situation der Weimarer Republik als Folie, vor der die Entwicklung der Dritten Republik beurteilt wurde, so ging Viénots neuer Vorschlag nun weiter. Das neuartige Zivilisationsmodell, über das Viénot lange nachgedacht hatte und das er sich für Frankreich herbeiwünschte, zielte über dessen Grenzen hinaus und vereinte beide Länder, Deutschland und Frankreich, zu einem gemeinschaftlichen Ganzen. Obwohl Viénot selbst wohl keine konkrete Idee einer supranationalen Struktur im Kopf hatte, so weisen seine Gedanken auf eine solche hin. Allerdings, das war klar, konnten derartige Pläne erst in der Zukunft realisiert werden. Die Verwirklichung außenpolitischer Verständigung im Sinne dieser neuen internationalen Ordnung fand ihre Bedingung in der Lösung der Kulturkrise, die seit Ende des Ersten Weltkrieges die Gemüter der Intellektuellen beschäftigte. An dieser Stelle zeigt sich, wie eng das Problem der Krise mit dem der Verständigung im Denken von Intellektuellen wie Viénot verknüpft war. Für Viénot bedeutete dies konkret eine Revision seiner außenpolitischen Maximen. Stand er den Locarno-Verträgen 1925 wohlwollend, aber doch skeptisch gegenüber, so entwickelte er sich zu Beginn der dreiBiger Jahre zu einem überzeugten Befürworter des Briandismus. Während sich die Außenpolitik Frankreichs und Deutschlands in einem Prozeß der Renationalisierung befand, wandte sich Viénot dem Völkerbund zu und wurde einer seiner nachdrücklichsten Verteidiger. Mehr oder weniger im Gegensatz zu den Tendenzen der Zeit, zumindest in außenpolitischer Hinsicht, trat Viénot von nun an für die Methoden multilateraler Diplomatie ein ${ }^{279}$.

$\mathrm{DaB}$ Viénot sich seit Beginn der dreißiger Jahre mit den Zielen und Methoden der Linken identifizierte, lag zum einen an seiner Enttäuschung über das auBenpolitische Scheitern der nationalen Methode, wie sie im Studienkomitee

${ }^{278}$ Ibid. S. 734.

279 Vgl. dazu Kap. V.2. 
versucht worden war. Zum zweiten war der Grund jedoch in Viénots zunehmender Überzeugung zu sehen, daß die gesellschaftliche und politische Modernisierung, die er seit Jahren anstrebte, nur auf Seiten der Linken zu verwirklichen sei. "Il est attiré par le socialisme«, so beschreibt es Wladimir d'Ormesson, "parce qu'il se sent avant tout smoderner et qu'il voit dans le socialisme les formes nécessaires de la société contemporaine ${ }^{280}$. Das Bekenntnis zur Linken bedeutete jedoch zunächst in erster Linie ein Bekenntnis zum Briandismus. Viénots Beitritt zur SFIO erfolgte erst 1937. Nachdem er sich für eine politische Karriere in den Reihen der Linken entschlossen hatte, zog er seinen alten Mentor Lyautey ins Vertrauen und erläuterte ihm die Beweggründe für seine politische Entwicklung. Es sei gut möglich, so der ehemalige Schützling, daß er sich den Sozialisten anschließe. Auf jeden Fall werde er sich aber in ihrer unmittelbaren Nähe situieren. Viénot sah sich genötigt, diesen Schritt vor dem General zu rechtfertigen und legte ihm seine Beweggründe und gleichzeitig sein politisches Glaubensbekenntnis dar:

[...] parce que je crois à l'ordre et que je ne vois que désordre dans le monde social, politique et moral qui est le nôtre aujourd'hui; parce que je crois à l'action personnelle et que notre hiérarchie actuelle, toute entière fondée sur l'argent, me paraît tueuse de toute initiative désintéressée, de tout courage, de toute santé morale; [...] parce que j'ai horreur des nationalismes; parce que la bêtise de droite est, consciemment ou inconsciemment, intéressée et, par là même, plus impardonnable que celle de gauche; parce que j'ai le dégoût de la lutte de classes lorsqu'elle est le fait des plus forts contre les plus faibles, tandis que je puis l'excuser quand elle est la défense ignorante du plus faible contre le plus fort; parce que j'aime terriblement ce qui est vivant et que, si je vois bien de la vie à droite, c'est sur une voie qui me parait sans issue; parce que je n'ai pas de goût que pour l'avenir... ${ }^{281}$.

Viénot räumte ein, daß es eine politische Rechte geben müsse, Menschen, die bremsen, bewahren und vielleicht sogar verhindern. Er wolle jedoch lieber zu den anderen gehören, ließ er Lyautey wissen. Um dem General klarzumachen, daß er seine Ideen nicht verraten habe, berief sich Viénot auf die Werte, denen sich Lyautey verbunden fühlte und die auch für ihn richtungsweisend seien. Dies seien, so Viénot, Verantwortungsgefühl, Mut, Würde und Respekt. Gerade um diese Werte in die Zukunft hinüberzuretten, müsse man sich nach links orientieren.

Entgegen seiner Ankündigung schloß sich Viénot jedoch zunächst nicht den Sozialisten an. Einmal mehr machte sich seine Skepsis gegenüber bestehenden Parteien bemerkbar. Zwar hatte sich jetzt sein Motto des "ni droite ni gauche" zugunsten der Linken verändert, jedoch bedeutete dies nicht eine Identifikation mit einer festgefügten parteipolitischen Organisation. Wenn er auch 1928 für den radikalsozialistischen Kandidaten seines Heimatwahlkreises gestimmt

${ }^{280}$ D'Ormesson, Pierre Viénot, S. 89f: NL d'Ormesson II.

${ }^{281}$ Viénot an Lyautey, 18.4.1930: AN, 375 AP 311. 
hatte ${ }^{282}$ und briandistische Positionen unterstützte, blieb er doch als Politiker in erster Linie ein Individualist und wollte sich selbst auch gar nicht anders sehen:

C'est qu'en effet je serais réduit à mes seules forces, négligeant - ou mieux encore, refusant - l'appui d'un parti, où je vois une trop grande gêne pour l'avenir. Vous le voyez, je reste un déplorable Einzelgänger... Mais c'est très amusant, très anregend, et bien qu'Andrée en soit choquée, c'est ma vraie voie... ${ }^{283}$.

Viẻnots ausgeprägter Individualismus war eines der letzten Überbleibsel seiner bürgerlichen Herkunft und Erziehung, die er nicht abstreifen konnte. Auch wenn er sich zur politischen Linken bekannte, sich später sogar der SFIO anschloß, so blieb er stets der Einzelgänger, für den er sich hielt. Seine Identifikation mit der Linken hatte nichts mit einem Bekenntnis zu einer wie immer gearteten sozialistischen Revolutionstheorie zu tun oder mit einer Sehnsucht nach der Befreiung der Arbeitermassen durch die Segnungen einer sozialistischen Gesellschaftsform. "En ce qui concerne la réforme de l'Économie«, so ließ er vernehmen, »je ne crois pas pour ma part à la possibilité de l'instauration directe et totale du socialisme ${ }^{284}$. Neben der politischen und gesellschaftlichen Modernität, die er anstrebte und für die ihm die Linke größere Gewähr zu bieten schien, fand er dort zudem Werte vertreten, die mehr humanistischen als marxistischen Ursprungs waren und die er aus seiner bürgerlichen Tradition mitbrachte. Werte, die nicht zuletzt von einer Person wie dem Sozialistenchef Léon Blum verkörpert wurden, der auf Viénot einen starken Einfluß ausübte ${ }^{285}$. Léon Blum war wie Viénot erst als Spätberufener zum Sozialismus gekommen. Aus gutbürgerlichem Elternhaus stammend, hatte er sich bald einen Namen als hochbegabter Jurist im Staatsrat sowie als Literaturkritiker in der Revue blanche gemacht. Sein politisches Engagement nahm in der DreyfusAffäre seinen Ausgangspunkt, wobei Jean Jaurès sein bestimmendes Vorbild war. Blum suchte im Sozialismus eine höhere Form des Humanismus, und aus der Masse der französischen Parlamentarier ragte er durch seinen intellektuellen Zuschnitt, sein Charisma und seinen moralischen Anspruch heraus. All diese Eigenschaften waren dazu angetan, Viénot zu gefallen. Zwischen den beiden Männern herrschte offensichtlich eine große persönliche Affinität. Nach Auskunft d'Ormessons waren sie regelrecht geschaffen füreinander, denn 》Viénot, comme Blum, est avant tout un intellectuel. En outre, Viénot est naturellement attiré par les natures aristocrates. Or, Blum, comme la plupart des Juifs, est un aristocrate ${ }^{286}$. Sicherlich bedeutete die Bekanntschaft mit Blum nicht Viénots Damaskuserlebnis in bezug auf den Sozialismus, wie es

${ }^{282}$ Vgl. ders. an d'Ormesson, 18.4.1928: NL d'Ormesson.

${ }^{283}$ Ders. an Becker, 26.5.1930: GStA PK, NL Becker, 2616.

${ }^{284}$ Pierre VIÉNOT, Enquête sur le rajeunissement de la France, S. 561.

${ }^{285}$ Der genaue Zeitpunkt, wann Viénot und Blum sich kennengelernt haben, läßt sich nicht bestimmen. Vermutlich liegt er zwischen der Veröffentlichung von Viénots "Incertitudes allemandes« und seinem Einzug ins Parlament 1932.

${ }^{286}$ D'Ormesson, Pierre Viénot, S. 96: NL d'Ormesson II. 
d'Ormesson vermutet, doch die politische Identitätsfindung in den Reihen der Linken war nunmehr endgültig abgeschlossen. Für Viénot lagen die Beweggründe für sein Bekenntnis zur Linken, später zum Sozialismus, in seinem Bekenntnis zu jenen Werten, die er durch so verschiedene Persönlichkeiten wie Lyautey und Léon Blum gleichermaßen verkörpert sah. Innenpolitische Modernität, Pflicht- und Verantwortungsgefühl für das Staatswesen, soziale Gerechtigkeit sowie außenpolitische Zusammenarbeit und Verständigung waren die Koordinaten, innerhalb derer er sich engagierte und die er zu Beginn der dreißiger Jahre nur im linken Lager sah. Daran konnten auch alarmierende Briefe von Viénots altem Mentor Lyautey nichts ändern, der seiner Überzeugung Ausdruck verlieh, Frankreich werde just an jenen Doktrinen zugrunde gehen, an die Viénot glaube ${ }^{287}$.

${ }^{287}$ Lyautey an Viénot, 27.5.1934: NL Viénot. 